\title{
The benefit of warm perfusion to reduce reperfusion injury and predict graft function in renal transplantation
}

Citation for published version (APA):

Stubenitsky, B. M. (2000). The benefit of warm perfusion to reduce reperfusion injury and predict graft function in renal transplantation. [Doctoral Thesis, Maastricht University]. Universiteit Maastricht. https://doi.org/10.26481/dis.20001222bs

Document status and date:

Published: 01/01/2000

DOI:

10.26481/dis.20001222bs

Document Version:

Publisher's PDF, also known as Version of record

Please check the document version of this publication:

- A submitted manuscript is the version of the article upon submission and before peer-review. There can be important differences between the submitted version and the official published version of record.

People interested in the research are advised to contact the author for the final version of the publication, or visit the DOI to the publisher's website.

- The final author version and the galley proof are versions of the publication after peer review.

- The final published version features the final layout of the paper including the volume, issue and page numbers.

Link to publication

\footnotetext{
General rights rights.

- You may freely distribute the URL identifying the publication in the public portal. please follow below link for the End User Agreement:

www.umlib.nl/taverne-license

Take down policy

If you believe that this document breaches copyright please contact us at:

repository@maastrichtuniversity.nl

providing details and we will investigate your claim.
}

Copyright and moral rights for the publications made accessible in the public portal are retained by the authors and/or other copyright owners and it is a condition of accessing publications that users recognise and abide by the legal requirements associated with these

- Users may download and print one copy of any publication from the public portal for the purpose of private study or research.

- You may not further distribute the material or use it for any profit-making activity or commercial gain

If the publication is distributed under the terms of Article $25 \mathrm{fa}$ of the Dutch Copyright Act, indicated by the "Taverne" license above, 
The benefit of Warm Perfusion to reduce reperfusion injury and predict graft function in Renal Transplantation 
(1) BM Stubenitsky, Maastricht 2000 ISBN 9090143238

Omslag illustratie: Charles A. Lindbergh and Alexis Carrel with the first apparatus for the culture of whole organs (1930s).

Vormgeving en druk: Datawyse bv Maastricht 


\section{The benefit of Warm Perfusion to reduce reperfusion injury and predict graft function in Renal Transplantation}

\section{Proefschrift}

ter verkrijging van de graad van doctor aan de Universiteit Maastricht, op gezag van de Rector Magnificus

Prof. dr. A.C. Nieuwenhuijzen Kruseman, volgens het besluit van het College van Decanen, in het openbaar te verdedigen op vrijdag 22 december 2000 om 12.00 uur door

Bart M Stubenitsky

Geboren te Washington D.C. op 28 maart 1971 


\section{Promotor}

Prof. dr. G. Kootstra

Co-promotor

Dr. M.H. Booster

Beoordelingscommissie

Prof. dr. J.P. van Hooff (voorzitter)

Prof. dr. T.M. van Gulik (Academisch Medisch Centrum, Amsterdam)

Dr. J.G. Maessen

Prof. dr. J.G.R. De Mey

Prof. dr. M.L. Nicholson (Leicester General Hospital, United Kingdom)

Acknowledgements

The work presented in this thesis was supported by a grant from the Dutch Kidney Foundation (NSN grant C97.1677).

Breonics, Inc. is gratefully acknowledged for their contribution to the work presented and their financial support for the publication of this thesis. 


\section{Contents}

CHAPTER 1

Introduction

CHAPTER 2

Kidney preservation in the next millennium

CHAPTER 3

Exsanguinous Metabolic Support technology

CHAPTER 4

Impact of cold ischemia on ex vivo renal function

I deleterious effect of prolonged cold ischemia on ex vivo renal function

II negative effect of cold ischemia on initial renal function

CHAPTER 5

Ex vivo viability testing of kidneys after postmortem warm ischemia

CHAPTER 6

Exsanguinous Metabolic Support perfusion- a new strategy to reduce injury seen after reperfusion of the kidney

CHAPTER 7

Pretransplant prognostic testing of damaged kidneys during ex vivo warm perfusion

CHAPTER 8

Conclusions

Summary

Samenvatting

CHAPTER 9

Acknowledgements

Curriculum vitae 
$n^{2}$

$+2$

$x^{2}$

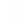

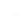

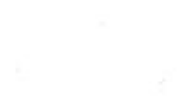




\section{CHAPTER 1}

\section{Introduction}

Most people are aware that dialysis will keep patients with end-stage renal failure alive. The significant morbidity and mortality associated with dialysis is however not widely recognized (1). The kidney is an amazing organ, functioning both as an endocrine gland as well as a filtering unit, which up to date cannot be adequately replaced by any artificial device. Very few patients on dialysis are able to lead normal, productive lives.

The excellent rehabilitation rates experienced after kidney transplantation have, therefore, made organ transplantation the therapy of choice. Rarely has a medical discipline generated and sustained such public attention. The concept of transplantation, in its various forms, has been discussed throughout history (2). Over the past decades the field of kidney transplantation has evolved into a well-established therapy for irreversible failure of renal function. Since Carrel (3) first used the concept of transplantation to develop his innovative surgical techniques for suturing blood vessels, which eventually lead to the first successful renal allograft transplantation in 1954 by Joseph Murray (4), more than 500.000 kidney transplants have been performed worldwide. Because the costs of maintaining patients with a functioning graft are only approximately one third of those for patients on dialysis and because the overall quality of life is much better, renal transplantation has become the therapy of choice for patients with end-stage renal disease (5-7). Two major developments represent the cornerstones of this success: the development of organ preservation and the development of immunosuppression.

\section{ORGAN PRESERVATION}

Hypothermia has represented the foundation of organ preservation. The benefits of hypothermia were recognized early, when in 1937 Bickford et al. noted that hypothermia prolonged the duration of tissue survival (8). There are two primary techniques for organ preservation using hypothermia that were introduced in the 1960 's and have been used clinically with virtually no change since that time. 
The first was successfully introduced by Belzer et al., applying the principle of continuous hypothermic perfusion (machine perfusion; MP) for kidney preservation (9). MP involves the use of a machine to pump a cold perfusate through the organ at low pressure, simulating metabolism by supplying oxygen and nutrients and removing metabolic end products. The optimal perfusion pressure and flow rate providing adequate tissue distribution of the perfusate were carefully examined $(10,11)$. The result was a lower than physiologic perfusion pressure and flow, because higher pressures mechanically damaged the endothelium of the organs vasculature $(12,13)$. In addition, the perfusate had to contain a colloid for the prevention of interstitial and cellular edema caused by the hydrostatic pressure generated by the pump. Further enhancements entailed adding substrates to suppress cell swelling and regulating $\mathrm{pH}$. In the early years of organ preservation using MP, cryoprecipitated plasma was used as a colloid in which the lipoprotein aggregates were removed by freezing, thawing, and filtration. The complex manufacturing technique, the potential disease transmission, and the inter-batch variability inherent in biological products, brought Belzer's group to develop a fully synthetic perfusion solution (Belzer's perfusate). Among the components used the most important are: $5 \%$ hydroxylethylstarch (HES) as a source colloid to prevent interstitial edema, gluconate to prevent cell edema, glutathione as an antioxidant, and adenosine and phosphate to allow for maintenance of intracellular high-energy phosphate molecules. They reported successful 5-day and 7-day machine preservation using Belzer's perfusate $(14,15)$.

\section{Static Storage}

In the late 1960's Collins et al. provided the basis for hypothermic static storage (cold storage; CS) with a crystalloid preservation solution containing elevated concentrations of potassium and phosphate (16). Preservation by CS involves flushing the organ with the perfusate to cool and remove blood from the vasculature, followed by storage in the preservation solution on ice. For the kidney, successful CS has been obtained with several different types of solutions (16-20). The efficacy of all cold storage solutions is primarily based on suppressing cell swelling and preventing cellular acidosis. Of the various formulations of hypothermic solutions University of Wisconsin (UW) solution has been shown to be most effective for long-term cold storage (21). In the UW solution developed for static storage the impermeants lactobionic acid and raffinose are though to prevent cell swelling. Allopurinol is added to reduce reperfusion injury during rewarming by preventing the xanthine oxidase cascade leading to generation of free radicals. Adenosine is added to stimulate ATP regeneration during reperfusion. Glutathione is included to suppress lipid peroxidation, and hydroxyl starch is used for colloid osmotic pressure and to facilitate the flushout of the 
organ. At present, the preservation limit for kidneys not subjected to ischemia prior to procurement ranges from 48 to 72 hours (20).

As storage times over 48 hours are rarely necessary and MP proved to be a more complex and costly procedure, CS has gained worldwide favor for clinical kidney preservation. This interpretation has been reinforced by several studies that showed no difference in one-year graft survival between the two methods of preservation (22-24).

\section{IMMUNOSUPPRESSION}

Graft loss due to acute rejection represented the major problem facing organ transplantation half a century ago. The introduction of the immunosuppressive agent Cyclosporine in the 1970's, improved both graft and patient survival rates considerably. Over the past 30 years, the 1-year graft survival of renal transplants increased from about $40 \%$ to greater than $80 \%(25)$. Despite the progress in the short-term survival, improvements in long-term outcomes remain one of the challenges for the future. Chronic allograft nephropathy is the most prevalent cause of retransplantations, accounting for approximately $30 \%$ of patients awaiting renal transplantation (26). While immunosuppressive drugs are used in doses sufficient to prevent acute rejection, chronic allograft dysfunction still develops and represents the major cause of graft loss after one year following renal transplantation (27). Although the precise mechanisms responsible for the specific pathological changes remain unclear, it is generally recognized that parameters other than purely immunologic play a role in the pathogenesis of chronic allograft nephropathy $(26,28)$. Ameliorating chronic dysfunction without increasing side effects, such as opportunistic infections, malignancy, or nephrotoxicity, represents the major obstacle facing clinical transplantation in this century. Ultimately, the induction of human tolerance to the alloantigens of a graft while maintaining the immune repertoire in the absence of maintenance immunosuppression could theoretically provide for indefinite graft survival. Achieving such a state could also avoid the complications associated with the immunosuppressive therapy. Tolerance continues to be the 'Holy Grail' of many transplant scientists and clinicians.

\section{THE ORGAN SHORTAGE}

In addition to the problem of chronic allograft dysfunction facing clinical transplantation, future progress in the field of transplantation is limited by a demand for transplants beyond the availability of donor organs. It has been calculated that the need for kidneys quadruples the actual supply. Unfortunately, future prospects are even worse. The discrepancy between demand and supply will most 
likely expand as the incidence of endstage renal disease is increasing along with a growing elderly population. Obviously, more effort is needed in effectuating potential donors through education to the public.

Boosting the low rates of cadaveric donations which in Europe vary from 27 per million inhabitants in Spain to 5 in Greece (29) would work towards this goal. Countries that have presumed consent laws that do not require next of kin to be notified or give their consent generally have higher donation rates than countries requiring informed consent. The use of kidneys harvested from living related donation and living altruistic donation certainly contribute to the supply, but there is a broad consensus that these will not be sufficient to alleviate the shortage of organs.

\section{Alternatives ways of meeting demand}

Artificial organs or human cells and tissues derived from human embryonic stem cells could provide other alternatives for the future. However, to date they still remain more distant possibilities taken the complexity of the kidney and the practical and ethical difficulties of culturing human embryonic stem cells (29). Xenotransplantation, if it ever proves feasible and safe, appears to offer a panacea. Aside from the ethical issues, the potential risk of spreading animal diseases to the human population causing man-made pandemics is the biggest concern and barrier to clinical studies (29). Prospects that the transplant of animal organs, tissues and cells into humans will become a practical proposition in the near future seem unlikely. If rejection still represents the major cause of graft loss in human renal transplants (27), it seems optimistic to assume that the formidable barriers of cross-species rejection will be overcome in the near future.

\section{Non-heartbeating donors}

To substantially increase the supply of transplantable organs with sources that are readily available, efficient use of all potential cadaveric donors is needed. Most kidneys that are currently procured come from heartbeating $(\mathrm{HB})$ donors. These are donors who succumb to cerebral injury and are maintained on life-support systems. Heartbeating donors represent only a small fraction of all deceased patients, and thus represent a limited donor pool (30).

An important way to improve the current use of potential donors is to relax the criteria for donor selection, which means expanding the procurement base into the non-heartbeating (NHB) donor population. A common clinical feature in these donors is that they have sustained irreversible cardiac arrest before organs are procured. The moment the heart of a donor stops beating, the cessation of blood flow results in ischemia. The onset of ischemia initiates a phase of metabolic depression leading to cell death. Harvesting of the ischemically damaged kidney is preceded by rapid cooling, by means of in situ perfusion (ISP) or total body cooling 
(TBC), thereby reducing the tissue's metabolic demands for nutrients and oxygen and lengthening the period during which the anoxic organ retains viability. ISP involves cooling and flushout of blood through a double balloon-triple-lumen catheter, which is inserted via the femoral artery into the aorta (31-33). The catheter has been designed to block the aorta at its bifurcation and at the level of the diaphragm by means of two balloons. Selective perfusion of the aorta above the point where the renal arteries originate is hereby obtained. Immediately after perfusion has started, a venectomy is performed to facilitate venous outflow. A catheter connected to a sterile bag is used for collection of out flowing blood and preservation solution.

TBC involves using blood to perfuse the whole body via the femoral vessels. Blood is oxygenated and cooled by means of extracorporal circulation, and given back into the donor. Perfusion is achieved by means of a roller pump, a temperature exchanger, and a bubble oxygenator $(34,35)$. Once adequate cooling of the organ has been established, nephrectomy can be performed.

To date the use of NHB programs has, in some centers, lead to a $40 \%$ increase in kidneys for transplantation (36). Studies have calculated a potential availability of NHB kidneys of 2 to 4.5 times the number of kidneys from HB donor. Such an increase of available grafts would help to ease the growing demand of organs considerably (37). Although the NHB donor source seems to be an immediate answer to the growing demand for kidneys, two obstacles delay its widespread clinical usage. First, the severity of the reperfusion injury in these kidneys. Secondly, the uncertainty of the negative impact of the warm ischemic damage on posttransplant function.

\section{REPERFUSION INJURY}

Unfortunately, the compounding damage of warm ischemia (WI) followed by cold preservation appears to be a major barrier in effectively using NHB donor kidneys as a source for renal transplantation. Hypothermic preservation in itself is not benign. It results in edema, alterations in permeability, and tubular damage. The principle difference between warm and cold temperatures is the rate at which the cell injury and death occur. Organs damaged by warm ischemia cannot tolerate further damage mediated by hypothermia $(38,39)$, since the accumulated inhibition of metabolism, by both WI and Cold Ischemia, negatively influences the severity of the reperfusion injury $(40)$. It is well appreciated that reperfusion from a metabolically inactive state results in a microvascular response that exhibits many of the same characteristics as acute inflammation, including endothelial cell injury, fluid accumulation and inflammatory cell infiltration (41). In order to enhance the use of NHB donor kidneys, the detrimental effects of reperfusion should be minimized. The severity of the reperfusion injury could be reduced by restoration of renal metabolism prior to actual reperfusion with 
blood. However, it seems very unlikely that the hypothermic preservation methods currently used could sustain this active process.

\section{VIABILITY TESTING}

It is fascinating to recall the experience of the person who first recognized that death of a body does not coincide with death of an organ (42). That specific observation actually represents the foundation for the organ transplantation as we know it. The individual response to ischemia that occurs during the death process, illustrates the difficulties one may encounter in defining the degree of damage. It seems apparent that some cellular mechanisms function adequately whereas others express inevitable, irreversible damage. The transition from viable to nonviable appears to be a time dependent process. It is known that, due to variation in the resistance to ischemia, the duration of the insult does not always correlate with graft function posttransplantation. Of course, transplantation of a nonviable kidney is ethically unacceptable. Until the damaging effects of ischemia can be evaluated prior to transplantation, the donor pool cannot be efficiently expanded with organs from NHB donors.

Lack of the ongoing metabolism that is an inherent feature of the current hypothermic preservation methods makes it difficult to discriminate viable from nonviable kidneys.

\section{THESIS STATEMENT}

The present thesis is comprised of experimental studies using ex vivo warm perfusion technology to: (1) explore the possibilities of reducing the damage to the kidney seen upon reperfusion from the cold (2) to determine the potential of developing prognostic testing to evaluate the functional status of kidneys prior to implantation. The experimental work was performed using both a bovine calf slaughterhouse model and a canine autotransplantation model. 


\section{REFERENCES}

1. Sikorski R, Peters R. Test tube kidneys. Science 1999; 284: 1952.

2. Kuss R, Bourget P. An Illustrated History of Organ Transplantation: The Great Adventure of the Century; Laboratoires Sandoz, Rueil-Malmaison, France 1992. 1992.

3. Carrel A, Guthrie CE. The transplantation of veins and organs. Am Med J 1905; 10: 1101.

4. Murray JE, Tilney NL, Wilson RE. Renal transplantation: a twenty-five year experience. Ann Surg 1976; 184 (5): 565.

5. Laupacis A, Keown P, Pus N, et al. A study of the quality if life and cost-utility of renal transplantation. Kidney Int 1996; 50: 235.

6. Eggers PW. Effect of transplantation on the Medicare end-stage renal disease program. N Engl J Med 1988; 318 (4): 223.

7. Russell JD, Beecroft ML, Luwin D, Churchill DN. The quality of life in renal renal transplantationa prospective study. Transplantation 1992; 54 (4): 656.

8. Bickford RJ, Winton FR. The influence of temperature on the isolated dog kidney. J Physiol, Lond 1937; 89: 198.

9. Belzer FO, Ashby BS, Dunphy JE. 24-hour and 72-hour preservation of canine kidneys. Lancet 1967; 2 (7515): 536.

10. Gattone VH, Filo RS, Evans HP, Leapman SB, Smith EJ, Luft FC. Time course of glomerular endothelial injury related to pulsatile perfusion preservation. Transplantation 1985; 39 (4): 396.

11. Grundman R, Raab M, Meusel E, Kirchhoff A, Pichlmaier H. Analysis of the internal perfusion pressure and flow rate of the renal vascular resistance and oxygen conservation in the hypothermically perfused kidney. Surgery 1975; 77 (3): 451.

12. Griffiths G], Kormano M, Morris T. Relationship of perfusion pressure to the microcirculation of the preserved canine kidney. Invest Radiol 1977; 12: 338.

13. Cerra FB, Raza S, Andres GA, Siegel JH. The endothelial damage of pulsatile renal preservation and its relationship to perfusion pressure and colloid osmotic pressure. Surgery 1977; 81 (5): 534.

14. Mc Anulty JK, Ploeg RJ, Southard JH, Belzer FO. Successful five-day perfusion preservation of the canine kidney. Transplantation 1989; 47 (1): 37.

15. McAnulty JF, Vreugdenhil PK, Southard JH, Belzer FO. Improved survival of kidneys preserved for seven days with a phospholipase inhibitor. Transpl Proc 1991; 23 (1): 691.

16. Collins GM, Bravo-Shugarman M, Terasaki PI. Kidney preservation for transportation: Initial perfusion and 30 hours' ice storage. Lancet 1969; 2 (7632): 1219.

17. Ross H, Marshall VC, Escott ML. 72-hr canine kidney preservation without continuous perfusion. Transplantation 1976; 21 (6): 498.

18. Lam FT, Ubhi CS, Mavor AID, Lodge JPA, Giles GR. Clinical evaluation of PBS140 solution for cadaveric renal preservation. Transplantation 1989; 48 (6): 1067.

19. Groenewoud AF, Thorogood J. Current status of the Eurotransplant randomized multicenter study comparing kidney graft preservation with Histidine-Tryptophan-Ketogluterate, University of Wisconsin, and Eurocollins. Transplant Proc 1993; 25 (1): 1582.

20. Ploeg RJ, Goossens D, McAnulty JF, Southard JH, Belzer FO. Successful 72-hour cold storage of dog kidneys with UW solution. Transplantation 1988; 46 (2): 191.

21. Lindell SL, Gandolph D, Southard JH, Belzer FO. Comparison of PBS, HTK, and UW solutions for kidney preservation. Transplant Proc 1991; 23 (5): 2399.

22. Toledo Pereyra LH. Pulsatile perfusion is still indicated for kidney preservation [letter]. Transplantation 1982; 34 (2): 110.

23. Vaughn WK, Mendez Picon G, Humphries AL, Spees EK. Method of preservation is not a determinant of graft outcome in kidneys transplanted by Southeastern Organ Procurement Foundation Institutions. Transplantation 1981; 32 (6): 490. 
24. Spees EK, Vaughn WK, Mendez-Picon G, Humphries AL. Preservation methods do not affect cadaver renal allograft outcome: the SEOPF prospective study 1977-1982. Transplant Proc $1984 ; 32: 490$.

25. Terasaki PI, Yuge J, Cecka JM, Gjertson DW, Takemoto S, Cho Y. Thirty-year trends in clinical kidney transplantation. Clin Transpl 1993: 553.

26. Womer KL, Vella JP, Sayegh MH. Chronic allograft dysfunction: mechanism and new approaches to therapy. Seminars in Nephrology 2000; 20 (2): 126.

27. Weber M, Deng S, Olthoff K, et al. Organ transplantation in the twenty-first century. Urol Clin North Am 1998; 25 (1): 51.

28. Paul LC. Chronic allograft nephropathy: An update. Kidney Int 1999; 56: 783.

29. Butler D, Wadman M, Lehrman S, Schiermeier Q. Briefing xenotransplantation: Last change to stop and think on risks of xenotransplants. Nature 1998; 391: 320.

30. Brasile L, Clarke J, Haisch C. Issues and problems in organ preservation in the U.S. Artif Cells Blood Substit Immobil Biotechnol 1994; 22 (2): 327.

31. Anaise $D$, Smith $R$, Ishimaru $M$, et al. An approach to organ salvage from non-heartbeating cadaver donors under existing legal and ethical requirements for transplantation. Transplantation 1990; 49 (2): 290.

32. Heineman E, Daemen JHC, Kootstra G. Non-heartbeating donors: methods and techniques. Transplant Proc 1995; 27 (5): 2895.

33. Booster MH, Wijnen RMH, Vroemen JPAM, Hooff van JP, Kootstra G. In situ preservation of kidneys from non-heart-beating donors; a proposal for a standardized protocol. Transplantation 1993; 56: 513.

34. Koyama I, Hoshino T, Nagashima N, Adachi H, Omoto R. A new approach to kidney procurement from non-heart-beating donors: core cooling on cardiopulmonary bypass. Transplant Proc 1989; 21 (1): 1203.

35. Gomez M, Alvarez J, Arias \}, et al. Cardiopulmonary bypass and profound hypothermia as a means for obtaining kidney grafts from irreversible cadiac arrest donors: cooling technique. Transplant Proc 1993; 25 (1): 1501.

36. Daemen JHC, de Wit RI, Bronkhorst MWGA, Yin M, Heineman E, Kootstra G. Non-heart-beating donor program contributes $40 \%$ of kidneys for transplantation. Transplant Proc 1996; 28 (1): 105 ,

37. Daemen JW, Oomen AP, Kelders WP, Kootstra G. The potential pool of non-heart-beating kidney donors. Clin Transplant 1997; 11 (2): 149.

38. Hardie IR, Balderson GA. Early and long-term function of cadaveric kidneys preserved by ice storagec after flushing with Collins' solution. In: Pegg DE, Jacobsen IA, Halasz NA (eds). Organ preservation: basic and applied aspects. Lancester: MTP. 1982: 313.

39. Grundmann R, Bischoff A, Albrod A, Pichlimaier H. Canine kidney perfusion after after various warm ischemia periods. In: Pegg DE, Jacobseen IA (eds). Organ preservation II. New York: Churchill Livingstone. In: Morris PJ, Tilney NL: (eds). Progress in transplantation (vol. 2). New York: Churchill Livingstone 1979: 33.

40. Gao W, Takei Y, Marzi I, et al. Carolina rinse solution-anew strategy to increase survival time after orthotopic liver transplantation in the rat. Transplantation 1991; 52: 417.

41. Granger DN, Korthuis RJ. Physiologic mechanisms of postischemic tissue injury. Annu Rev Physiol 1995; 57: 311.

42. Maessen JG. Evaluation of ischemic injury in donor kidneys - an experimental study. Thesis. Wibro dissertatiedrukkerij, Helmond. 1988. 
CHAPTER 2

\section{Kidney preservation in the next millenium}

BM Stubenitsky, MH Booster, AP Nederstigt, JK Kievit, RWA Jacobs, G Kootstra

Transplant International 1999; 12: 83 


\begin{abstract}
For the past decades, severe hypothermia has represented the foundation of organ preservation in clinical transplantation. Beneficial as hypothermia has proven to be in preserving grafts from heartbeating donors, hypothermia does not seem to provide the window necessary for the prospective evaluation of organ function. With the increasing use of non-heartbeating donors it is logical to propose that if organs are to be evaluated prospectively, it will be necessary to preserve at warmer temperatures. Since both glomerular and tubular functions are inhibited at temperatures below $18^{\circ} \mathrm{C}$, such a goal will necessitate organ preservation at a temperature greater than $20^{\circ} \mathrm{C}$. The principle of preservation at warmer temperatures is not new, but with future developments and approaches, successful realization appears within reach. In this overview, a brief history of previous attempts at warm preservation, in the context of the current status of kidney preservation, is presented. Future developments and approaches, with the potential for prospective testing of the function and enhanced resistance to ischemic damage, will be discussed.
\end{abstract}


The evolution of transplantation has made kidney allografting the preferred treatment for patients with end stage renal failure. Transplantation provides improved quality of life and is more cost effective when compared to dialysis (1). Currently, one-year graft survival rates for cadaver-donor transplants are above $80 \%$ and one-year patient survival $95 \%$ (2). Offsetting this success is the increasing discrepancy between the availability of, and demand for, transplantable kidneys. Within the Eurotransplant region, procurement rates remained stable during 1996 and 1997 , whereas the number of potential recipients on the waiting list increased by $4 \%$ (3), resulting in approximately 3.000 procedures compared to 11.000 patients awaiting transplantation (4).

A major contributing factor to the organ shortage is the detrimental effect of ischemia. Upon harvesting, the loss of the vascular circulation causes ischemia with the concordant depletion of oxygen and nutrients to the kidney. The ischemia, with the resulting loss of metabolic activity, initiates a cascade of cellular damage. This injury cascade leads to the breakdown of high energy compounds necessary for cellular metabolism, a generalized loss of cellular integrity, and activation of degenerative enzymes. The result is the loss of all structural and functional components of the cell. While it has been proposed that the kidney can tolerate as much as two hours of warm ischemia before the damage becomes so severe that it is irreversible and reperfusion with blood will not restore a life-sustaining function, transplanting an allograft with warm ischemic exposure of this magnitude is never considered clinically. Once a kidney is removed, preservation techniques must preserve the organ sufficiently to insure the organ functions when transplanted and preserve it over a long enough period to allow time for tissue typing, matching, and transportation.

Since the 1950's hypothermia is known to result in a marked protection against ischemic damage (5-8). The effectiveness of hypothermia can be explained by its influence on suppressing the organ's metabolic rate approximately 12 fold by cooling to $4^{\circ}$ to $8^{\circ} \mathrm{C}$. It was subsequently realized that inhibition of cell swelling and acidosis by a preservation solution in combination with hypothermia could further extend the preservation period, the so-called solution effect. There are two methods of hypothermic preservation in use today: cold static storage (CS) and continuous, cold machine preservation (MP). CS was developed using a crystalloid, intracellular-like solution. Much of the early work in CS was developed by Collins et al. (9). Belzer et al. successfully applied the principle of MP for kidney preservation (10). MP involves the use of a machine to pump a cold perfusate through the organ at low pressure, simulating metabolism by supplying oxygen and nutrients and removing metabolic end products. The mostly widely used perfusate for MP, developed by Belzer's group, contains $5 \%$ hydroxylethylstarch (HES) as a colloid to prevent interstitial edema, gluconate to 
prevent cell edema, glutathione and adenosine and phosphate to allow for maintenance of intracellular high-energy phosphate pools.

For more than 30 years there has been an ongoing debate within the transplantation community as to which method is superior, but with the one year graft survival of heartbeating $(\mathrm{HB})$ donor kidneys being comparable between the two methods of preservation, the less labor intensive CS gained popularity (11-13). Recently, however, there has been a resurgence of interest in the use of MP for kidney preservation because of it's ability to reduce the occurrence of a delay in normal graft function, called delayed graft function (DGF), from $25 \%$ to $10 \%$ as compared to CS (14). DFG requires a need for dialysis and longer hospitalization, and appears to lead to a poorer long term graft outcome (14-18).

It is very apparent that when one considers graft outcomes with kidneys from young heartbeating $(\mathrm{HB})$ donors, cold preservation by either method has been remarkably successful and has provided the foundation for the growth experienced in clinical transplantation. However, in recent years, use of nonheartbeating $(\mathrm{NHB})$ donor kidneys, where a prior insult of warm ischemia precedes the period of cold preservation, has been implemented in attempts to attenuate the growing gap between the demand and supply of kidneys for transplantation $(19,20)$. For these ischemically damaged kidneys, MP also seems to be more preferable than CS (21). In a clinical experiment, in which one kidney of a NHB donor was cold stored and the other kidney was machine perfused, earlier graft function was observed in the latter (22-24). Nevertheless, with the use of NHB donor kidneys, a dramatic increase in DGF and primary non-function (PNF) has been encountered as compared to HB donor kidneys (23, 25-33). Cold preservation has therefore proven to be less effective in cases of $\mathrm{NHB}$ donors as compared to $\mathrm{HB}$ donors.

\section{THE NEED FOR PROSPECTIVE EVALUATION AND IMPROVED PRESERVATION OF NHB DONOR KIDNEYS}

It has been postulated that a more pharmacological approach to organ preservation might lead to an improvement in the initial graft function (34). MP offers the possibility of both pharmacological intervention and testing because the organ is continuously being perfused. Perfusion allows for the administration of agents, sampling of the perfusate, and monitoring of the perfusion dynamics during preservation.

Until now, pharmacological agents have played a minimal role in clinical organ preservation, despite intensive research targeted on the reduction of ischemic damage. This is largely due to the fact that the pharmacologic agents must already be present at the time of the ischemic insult and, therefore, are not relevant to a clinical situation. Southard (35) postulated that the agents often are inactive or insoluble at the hypothermic temperatures used in preservation, and 
that poor permeability inhibits adequate access to the sites where they are most required. In addition, a combination of drugs may be needed to counteract the various stages of injuries at different sites, since cell death is the consequence of a cascade of cellular injury.

Viability testing in clinical transplantation has gained renewed interest with the resurgence of the NHB donor. The extent of warm ischemic damage in these donors is often difficult to determine on clinical data alone. Historically, ex vivo evaluation of the viability status has focused on perfusion pressure and the corresponding perfusate flow for an interpretative vascular resistance. Differences in the values of glomerular filtration rate (GFR) and perfusate flow rate per time were used to distinguish between prior warm ischemic injured and non-injured kidneys. Lewis et al. (36) reported that deterioration in the ex vivo GFR and flow rate occurred sooner in warm ischemically damaged kidneys and later in non-damaged kidneys. This observation is not surprising when one considers that prior warm ischemic damage compounded by cold ischemic exposure, would be expected to result in compromised function sooner than in kidneys with a single insult caused by metabolic inhibition from hypothermia.

In contrast to the attempts of using vascular perfusion characteristics as marker of viability, Kootstra et al. have taken the inverse approach of evaluating the leakage of the intracellular enzyme alpha glutathione S-transferase ( $\alpha$-GST) into the extracellular space and, subsequently, the perfusate $(37,38)$. The inhibition of metabolism caused by hypothermia results in the loss of cell surface polarity and normal cellular barrier function. Therefore it seems logical that intracellular components leak into the extracellular spaces during organ preservation. The extent of alteration in permeability was found to correlate with the degree of prior warm ischemic exposure. However, $\alpha$-GST has been reported to be confined to the proximal tubule. Tubular epithelium is known to have remarkable capacity to regenerate following ischemic insult. While the $\alpha$-GST marker is convenient for evaluating tubule damage, more informative viability markers that can differentiate between reversible and irreversible damage will be important for prospective organ evaluation.

Other approaches have been developed to aid in the determination of the ischemic damage. These include energy charge, electrolyte concentrations, and functional studies. Yet, despite these efforts, there is currently no objective method or assay to evaluate the potential function of a renal allograft, making transplantation the only definitive test of graft viability (39). An impediment to developing viability testing is the hypothermia during preservation. Hypothermia inhibits metabolism by over $95 \%$ and decreases oxygen consumption exponentially $(40,41)$, making evaluation of renal function virtually impossible. Organ preservation by means of hypothermia slows the ongoing extracorporeal ischemic/hypoxic damage rather than preventing or reversing such damage. Therefore, the result of the hypothermic mediated inhibition of metabolism during preservation is the rate change in the processes leading to cell death (42). 
Kootstra's group demonstrated that intermittent perfusion with normothermic blood in a canine transplant model extended the cold preservation times significantly, resulting in more viable kidneys at reimplantation as compared to cold preservation alone. It was postulated that the beneficial effect of this intermittent perfusion in the course of cold preservation could be attributed to a washout of metabolic waste products, and a restoration of exhausted enzyme systems and energy sources (43-45)

The difficulties experienced with viability testing can also be attributed to the complex and multiple injury mechanisms prior to, and resulting from, the preservation period, as well as the subsequent injury to which the kidney is exposed upon reperfusion. The deleterious effects of sudden restoration of oxygenation and blood flow to the cold, anoxic organ, leading to subsequent damage, makes it difficult to predict function prospectively.

The development of new and more physiologic preservation technology could potentially lead to improved preservation and the development of viability assays for NHB donor kidneys. If such a theoretic technology could support adequate metabolism and corresponding function during the preservation period, then it might be feasible to develop viability testing that could distinguish between viable and non-viable organs. A more physiologic preservation technology will need to focus on:

1. Facilitation of a polypharmacologic approach during preservation to ameliorate ischemic injury;

2. Creating an environment in which the development of prospective testing during machine perfusion can be achieved;

3. Developing technology that can reverse ischemic damage during preservation rather than attempting to slow down the biochemical processes that lead to cell death;

4. Better understanding of the mechanisms involved in preservation-reperfusion injury.

Since hypothermia does not seem to provide the milieu for achieving these goals, the most promising and expedient principle appears to be organ preservation at warmer temperatures.

\section{KIDNEY PRESERVATION AT WARMER TEMPERATURES}

The idea of preserving an isolated portion of the body in order to examine its functions is not new. In 1812, physiologist Le Gallois wrote: 'If one could substitute for the heart a kind of injection...of arterial blood, either natural or artificially made,... one would succeed easily in maintaining alive indefinitely any part of the body whatsoever' (46). For more than 150 years, researchers have attempted to achieve this goal. In reviewing this body of work, it becomes apparent that the previous attempts at mimicking a physiologic preservation failed for two major 
reasons. First, the failure to maintain the integrity and normal barrier functions of the vasculature leads to a rapid deterioration in vascular flow and a concurrent development of edema. Second, the inability to support adequate delivery of nutrients and oxygen lead to a deteriorating metabolic state. In light of these two major failures, the historical experience in preserving organ ex vivo at near physiologic temperatures is described below.

\section{Vascular integrity during warm temperature perfusion}

In 1849 , normothermic isolated kidney perfusion, using defribrinated blood, was initiated by Loebell (47). In 1903 Brodie (48) designed a perfusion system for isolated organs by oxygenating the blood with air. Unfortunately flow rates in the kidney were rarely sufficient. In 1914, Bainbridge and Evans managed to increase the renal blood flow and improve function during isolated perfusion by incorporating an animal lung into the circuit, postulating that the vasoconstrictive materials present or formed in the defibrinated blood were removed by the lung. Nevertheless, the survival of such a preparation was limited to approximately 6 hours (49). In 1925, active urine secretion was achieved during a 5 hour period (50). However, these early attempts to study the isolated kidney by means of a heart-lung kidney preparation had little success in keeping the organ alive, and its function remained depressed compared to physiologic values.

Winton and co-workers (1940) extensively studied the kidney's physiology during isolated perfusion. Using a pump-lung-kidney preparation and an arterial pressure of approximately $100 \mathrm{mmHg}$, they examined inulin and creatinine clearance and the influence of the perfusion temperature (51). Although the observed values were, for the most part, abnormally low, with kidneys only surviving for a few hours in good condition, they described a decrease in renal blood flow and creatinine clearance with cooling. Changes were found in the composition of urine that were comparable to that of serum transudate when reducing the temperature from $37^{\circ} \mathrm{C}$ to $3-13^{\circ} \mathrm{C}(40)$. The observation of a decrease in renal blood flow with hypothermia was later confirmed by Levy, who attributed it to increased viscosity and vasoconstriction (41). Kupfer et al. performed detailed studies of the pump-lung-kidney preparation, describing the impairment of glomerular filtration rate, para-aminohippuric acid clearance, creatinine urine/plasma ratio, and the rate of sodium excretion. The average survival of the preparation was 6 hours (52).

Experiments by Nizet and Cuypers et al. revealed a severe deterioration in vascular circulation when blood was stored for 40 minutes, or if the blood was handled traumatically. They described a neutralizing effect of the vasoactive phenomenon by the lung, liver and kidney itself $(53,54)$. By reducing the mechanical damage to the blood, using newly procured blood, and a reduction of the volume used, they claimed to have achieved near normal kidney function in an ex-vivo perfusion system (55). 
The studies performed in the 1950 's by Cough et al. $(56,57)$ focused on sustaining viability in excised kidneys at $25^{\circ} \mathrm{C}$ for extended times without the use of a lung. They succeeded in maintaining urine production for up to 7 hours by using blood-pump-oxygenator preparations. Subsequent attempts at reimplantation of these kidneys failed. Telander (58) successfully transplanted baboon and sheep kidneys following normothermic kidney perfusion with fresh heparinized blood for periods ranging from 5 to 7 hours. The perfusate consisted of heparinized blood, and a balanced salt solution (1:1) containing vitamins, the essential amino acids, and low molecular weight dextran. Posttransplant function, evaluated after contralateral nephrectomy performed within 21 days of the reimplantation, proved to be relatively normal. They additionally perfused kidneys for at least 24 hours without reimplantation, suggesting the feasibility of prolonged warm perfusion by diluting the perfusate with balanced salt solution and adding low molecular weight dextran. Thus, although some obstacles were solved, physiological studies using the isolated kidney perfusions with blood had their limitations, including brevity of the steady-state period, low glomerular filtration rates, abnormal tubular functions, alterations in intrarenal blood flow distribution, and limited duration of survival $(59,60)$.

In the 1960's several investigator established the correlation between platelets, blood cell aggregates and degradation products during blood perfusion and the difficulties experienced with rising perfusion pressure, tissue edema, and impaired or no function upon reimplantation of the organ (61-64). To avoid these difficulties, plasma was selected as a perfusate. The first attempts involved using plasma diluted in a 1:3 ratio with an electrolyte solution. The diluted plasma resulted in minimal edema and pressure rise. However the organs proved to be non-viable after transplantation. When undiluted plasma was used, a recurrence of the rising perfusion pressure, severe edema, and tissue destruction was seen. When frozen sections of the kidney were taken during perfusion, multiple small emboli were seen in the arterioles, in addition to fat droplets in the tubules and intratubular cells (65). The rising perfusion pressure was attributed to obstruction of the vessels by lipid components released into the perfusate by denaturation. The occurrence of fat emboli during warm perfusion appeared to be less when a membrane oxygenator was used instead of a film oxygenator. It was postulated that the low density lipoproteins aggregated into larger particles due to damage. Belzer's group found a beneficial effect of denaturing the lipoproteins by freezing and quick thawing prior to usage (cryoprecipitated plasma). This process removed about $30-35 \%$ of the lipid components, believed to be mainly low density lipoproteins that exhibited less stability than high density lipoproteins. No fat emboli could be found after this filtration (65). 


\section{Oxidative metabolism during warm preservation}

In subsequent years several investigators attempted to preserve kidneys at $25^{\circ} \mathrm{C}$ by means of a perfusion apparatus and an acellular perfusate modeled after that described by Belzer et al. This perfusate consisted of the homologous pooled plasma, cryoprecipitated and filtered, to which was added hydrocortisone, sodium penicillin, insulin, magnesium sulfate, dextrose-water solution, and mannitol. The additives in the perfusate were chosen on an empirical basis. Magnesium and insulin were added to mimic hibernation, as described by Suomalainen (66). Penicillin was used against possible infections, and the steroids as membrane stabilizers (67). The dextrose and mannitol were used to maintain osmotic pressure. The arterial pressure was maintained at $60-95 \mathrm{mmHg}$, the $\mathrm{pH}$ in the range 7.3-7.5, and the $\mathrm{PaO}_{2}$ above $400 \mathrm{mmHg}$. Clearance values were relatively low being approximately $20 \%$ of the normal values for in vivo kidneys (68-70). All researchers described a decrease in tubular function occurring between 2 and 4 hours of preservation when using an acellular perfusate. Supporting these findings were Malinin et al.'s observations (71) showing a $57 \%$ reduction of intact glomeruli after 4 hour perfusion at $25^{\circ} \mathrm{C}$, compared to a $21 \%$ reduction in the organs perfused at $5^{\circ} \mathrm{C}$. At $25^{\circ} \mathrm{C}$ the ongoing renal oxidative metabolism during preservation varies from 50 to $75 \%$ of the physiological oxygen consumption. These findings suggest that the oxygen required by the organ during preservation at elevated temperatures can not adequately be provided by the oxygen dissolved in an acellular perfusate (41), thus leading to anoxic damage after 2-4 hours of perfusion. Since warm perfusion appeared feasible only for short periods of time, it was mainly used experimentally as an intermittent warm perfusion, attempting viability testing of the organ, during hypothermic preservation.

In terms of whether warm temperature perfusion could provide the basis for developing viability testing, the work of Pegg et al. (72) suggested that renal metabolism and function during warm perfusion was sufficient to enable comparisons between test groups in terms of tubular secretion and reabsorption. Following 24 hours of hypothermic preservation, they attempted to estimate renal function by in vitro normothermic perfusion. Using a bloodless perfusate, kidneys were perfused at $37^{\circ} \mathrm{C}$ for 2 hours. All kidneys demonstrated impaired renal function during perfusion, such as increased permeability resulting in proteinuria. None of the kidneys were reimplanted and outcomes were not determined. In spite of this, differences in function could be determined, and these results support the concept that viability testing could be developed if the perfusion temperature was sufficient to support ongoing cellular metabolism.

A sufficient oxygen supply with an acellular perfusate can be achieved by adding an oxygen carrier, such as a hemoglobin preparation or a perfluorochemical, to the preservation solution. Early trials with solutions containing hemoglobin proved to be unsuccessful, mainly due to the development of kidney 
damage similar to pigment nephropathy seen after massive hemolysis or rhabdomyolysis $(73,74)$. With the development of highly purified stroma free hemoglobin (SFH), less toxic side effects were observed, leading to the assumption that the contamination with erythrocyte stroma was responsible for the previously observed toxicity $(75-81)$. Nevertheless, several investigators described a continuous decrease in flow when perfusing kidneys with a SFH solution, with histology revealing hemoglobin deposits in the glomeruli (82) and tubules (83). Other investigators confirmed these adverse effects on the kidney function using ultrapure SFH, which was not observed with polymerized hemoglobin's (84-87). Confirmation of the low-grade toxicity to the kidney by using different purified and polymerized or cross-linked hemoglobin derivatives was obtained in several studies. Minimal reductions in the clearance and reabsorptive functions of the kidney were observed $(88-90)$ along with moderate structural alterations (88, 90-93), all of which were reversible. This led to the conclusion that the hemoglobin molecule itself had a toxic effect by passing through the glomerular filter. Support for this interpretation was provided by the findings of Tam and Wong (86), showing that polymerization of hemoglobin into very large macromolecules prevented passage through the glomerular filter. In a study performed by Willinger et al. (94), ultrapure polymerized bovine hemoglobin was used to evaluate the structural and functional integrity of isolated perfused rat kidneys. They demonstrated a beneficial effect of the polymerized hemoglobin on kidney function, morphology, and oxygenation in comparison to control kidneys perfused with a hydroxylethyl starch solution. Therefore, polymerized hemoglobin appeared to be a promising oxyphoretic additive for the perfusion of rat kidneys.

Horiuchi et al. described 12 hour normothermic canine kidney perfusion with a pyridoxalated hemoglobin-polyoxyethylene (PHP) solution in combination with UW-solution (95). PHP is a conjugate of human hemoglobin with alphacarboxymethyl and omega-carboxymethoxyethylene, used because of its longer half-life time and higher oxygen transporting capacity (96). Although PHP provided for a stable flow and pressure, histology revealed 30 to $40 \%$ tubular damage. None of the kidneys were reimplanted.

Advances in perfluorochemical (PFC) emulsion technology provided for another class of oxygen carriers. PFCs differ from hemoglobin preparations in that they are totally synthetic compounds on a liquid hydrocarbon base. In contrast to hemoglobin, oxygen is not chemically bound to the PFC carrier. PFCs take up and release oxygen following Henry's linear law, based on the partial pressure of the gas, rather than Barcroft's sigmoid curve described for hemoglobin (97). Unlike hemoglobin, acidosis, alkalosis, 2,3-diphosphoglycerate, and temperature seem to have no or litle effect on the oxygen delivery of PFCs. PFC molecules do not mix with water, and it is therefore necessary to emulsify them for intravascular usage. Early emulsions were quite ineffective, but problems with the stability of the emulsion were solved by improving the adhesion of the surfactant film to the fluorocarbon droplet $(98)$. These second-generation PFC emulsions 
possessed a much greater PFC concentration, a lower toxicity profile, and the potential for providing physiological concentrations of oxygen.

Early studies involving the perfusion of kidneys with PFC were reported by Beisang et al. in 1970 (99). In 1975 Nakaya et al. perfused rabbit kidneys at room temperature for 9 hours with a PFC emulsion (100). Overall, oxygen delivery and renal metabolism were better maintained with PFC supplementation when compared to the results with a perfusate consisting of electrolytes alone. However, none of these kidneys were reimplanted. Other studies during the 1970 's confirmed the possibility of perfusion with a PFC solution, although histologic abnormalities where seen after approximately 5 hours of perfusion (101). In the 1980's Dun and colleagues managed to perfuse kidneys with a PFC emulsion for 18 hours, but the development of edema and corresponding increase in vascular resistance lead to the loss of organ viability (102). Kawamura et al. (103) managed to perfuse damaged and undamaged rabbit kidneys at $25^{\circ} \mathrm{C}$ with a perfusate formulation similar to human extracellular fluid supplemented with a PFC (3\% v/v). A perfusion pressure of $80 \mathrm{mmHg}$ proved to be most suitable for studying the differences in physiologic dynamics between the ischemically damaged and undamaged kidneys. No kidneys were transplanted after the 12 hours of perfusion.

Recently, successful ex vivo canine kidney preservation at temperatures of $25-32^{\circ} \mathrm{C}$ for 6 to 18 hours has been described by Brasile (104). This warm preservation method is based on a perfusate developed from a modified tissue culture medium and a PFC emulsion (perflubron) as an oxygen carrier. In the experiments described by Brasile et al., the canine kidneys perfused at $25^{\circ} \mathrm{C}$ and $32^{\circ} \mathrm{C}$ respectively, demonstrated stable flow dynamics, diuresis, glucose, and oxygen consumption. The urine produced was free of protein and glucose, and histologic evaluation of the kidney showed intact glomeruli and tubuli, with no evidence of edema. Six kidneys were successfully transplanted following 6 hours perfusion at $25^{\circ} \mathrm{C}$. This warm perfusion is proposed to enable functional evaluation of kidneys prior to transplantation, to resuscitate kidneys following warm ischemic damage equivalent to NHB donor kidneys, and to prevent reperfusion injury (105-108).

\section{PRESERVATION INTO THE NEXT MILLENIUM}

It is logical to consider that an in vitro measurement during warm temperature perfusion which mirrors the physiologic functions of kidneys in vivo would provide the best mechanism to develop testing that could distinguish between viable and non-viable organs prospectively. Such testing will most likely require multiple assays that form a score which predicts PNF better than one analysis alone. The viability testing could be coupled with the traditional cold preservation. A cold preserved organ could be transitioned to warm perfusion and the restored metabolism used to evaluate function prior to transplantation. 
There are two areas in organ transplantation where advancements in preservation-reperfusion phenomenon will be important. The first is the elimination of the damaging effects of cold preservation. The second is the amelioration of injurious events during reperfusion. The manifestation of the injury sustained during warm ischemia and hypothermic preservation are now only observed upon reperfusion of the organ. Reperfusion injury is, in part, the direct result of the increase in temperature and re-exposure to a high oxygen tension following hypothermic preservation. The development of near-normothermic preservation technology may present the opportunity to prevent much of this reperfusion injury. Additionally, warm temperature preservation could provide a mechanism to repair warm ischemic damage by utilizing pharmacological agents to enhance cellular metabolism.

Obviously many obstacles will need to be overcome before warm perfusion preservation can become a reality. Issues pertaining to potential contamination, how warm perfusion would interface with traditional hypothermic preservation, mechanisms to support metabolism, and what would be needed to maintain the organs under such conditions for extended periods of time are just a few of the areas which will need to be addressed.

Provided these substantial obstacles can be overcome, there is evidence from several groups of researchers suggesting that warm temperature organ preservation would be beneficial in providing a reproducible viability assay and, perhaps, in diminishing DGF in NHB donor kidneys. 


\section{REFERENCES}

1. Eggers PW. Effect of transplantation on the Medicare end-stage renal disease program. NEngl ] Med 1988; 318 (4): 223.

2. Terasaki PI, Yuge J, Cecka JM, Gjertson DW, Takemoto S, Cho Y. Thirty-year trends in clinical kidney transplantation. Clin Transpl 1993: 553.

3. Cohen B. Introduction. Eurotransplant Newsletter 1998; 145: 1.

4. Meester de J. Kidney: donation, waiting lists and transplants. In: Cohen B, Persijn G, De Meester J (eds) Eurotransplant International Foundation. Annual Report 1996. Koninklijke Bibliotheek, The Hague 1996: 27.

5. Schloerb PR, Waldorf RD, Welsh JS. The protective effect of kidney hypothermia on total renal ischemia. Surg Forum 1957; 8: 633.

6. Bogardus GM, Schlosser RJ. The influence of body temperature upon ischemic renal damage. Surgery $1956 ; 39$ (6): 970.

7. Semb C. Partial resection of the kidney: anatomical, physiologic and clinical aspects. Ann R Coll Surg London 1957; 19: 137.

8. Keller R, Swinney J, Taylor RM, Uldell PR. The problem of renal preservation. Br J Urol 1966; 38 (6): 653.

9. Collins GM, Bravo-Shugarman M, Terasaki PI. Kidney preservation for transportation: Initial perfusion and 30 hours' ice storage. Lancet 1969; 2 (7632): 1219.

10. Belzer FO, Ashby BS, Dunphy JE. 24-hour and 72-hour preservation of canine kidneys. Lancet 1967; 2 (7515): 536.

11. Toledo Pereyra LH. Pulsatile perfusion is still indicated for kidney preservation [letter]. Transplantation 1982; 34 (2): 110.

12. Vaughn WK, Mendez Picon G, Humphries AL, Spees EK. Method of preservation is not a determinant of graft outcome in kidneys transplanted by Southeastern Organ Procurement Foundation Institutions. Transplantation 1981; 32 (6): 490.

13. Spees EK, Vaughn WK, Mendez-Picon G, Humphries AL. Preservation methods do not affect cadaver renal allograft outcome: the SEOPF prospective study 1977-1982. Transplant Proc 1984; 32: 490.

14. Cecka JM, Terasaki PI. The UNOS scientific renal transplant registry. United Network for Organ Sharing. Clin Transpl 1995: 1.

15. Sanfilippo F, Vaughn WK, Spees EK, Lucas BA. The detrimental effects of delayed graft function in cadaver donor renal transplantation. Transplantation 1984; 38 (6): 643.

16. Rosenthal JT, Danovitch GM, Wilkinson A, Ettenger RB. The high cost of delayed graft function in cadaveric renal transplantation. Transplantation 1991; 51 (5): 1115.

17. Ferguson RM, Henry ML, Sommer BG, Sachs L, Orosz CG. A single center experience with cyclosporine in renal transplantation: Ohio State University 1983 to 1987. Clin transpl. 1987 1987: 195.

18. Koyama H, Cecka JM, Terasaki PI. A comparison of cadaver donor kidney storage methods: pump perfusion and cold storage solutions. Clin Transpl 1993; 7: 199.

19. Daemen JW, Oomen AP, Kelders WP, Kootstra G. The potential pool of non-heart-beating kidney donors. Clin Transplant 1997; 11 (2): 149.

20. Cho YW, Terasaki PI, Cecka JM, Gjertson DW. Transplantation of kidneys from donors whose hearts have stopped beating. N Engl J Med 1998; 338 (4): 221.

21. Booster MH, Wijnen RM, Yin M, et al. Enhanced resistance to the effects of normothermic ischemia in kidneys using pulsatile machine perfusion. Transplant Proc 1993; 25 (6): 3006.

22. Kozaki M, Matsuno N, Tamaki T, et al. Procurement of kidney grafts from non-heart-beating donors. Transplant Proc 1991; 23 (5): 2575. 
23. Matsuno N, Sakurai E, Tamaki I, Uchiyama M, Kozaki K, Kozaki M. The effect of machine perfusion preservation versus cold storage on the function of kidneys from non-heart-beating donors. Transplantation 1994; 57 (2): 293.

24. Matsuno N, Sakurai E, Uchiyama M, Kozaki K, Miyamoto K, Kozaki M. Usefulness of machine perfusion preservation for non-heart-beating donors in kidney transplantation. Transplant Proc 1996; 28 (3): 1551.

25. Wijnen RMH, Booster MH, Stubenitsky BM, de Boer J, Heineman E, Kootstra G. Outcome of transplantation of non-heart-beating donor kidneys. Lancet 1995; 345 (8957): 1067.

26. Hoshinaga K, Fujita T, Naide $Y$, et al. Early prognosis of 263 renal allografts harvested from non-heart-beating cadavers using in situ cooling technique. Transplant Proc 1995; 27 (1): 703.

27. Casavilla A, Ramirez C, Shapiro R, et al. Experience with liver and kidney allografts from non-heart-beating donors. Transplant Proc 1995; 27 (5): 2898.

28. Gonzalez C, Castelao AM, Torras J, et al. Long-term follow-up of transplanted non-heart-beating donor kidneys. Transplant Proc 1995; 27 (5): 2948.

29. Schlumpf R, Weber M, Weinreich T, Klotz H, Zollinger A, Candinas D. Transplantation of kidneys from non-heart-beating donors:An update. Transplant Proc 1995; 27 (5): 2942.

30. Dunlop P, Varty K, Veitch PS, Nicholson ML, Bell PRF. Non-heart-beating donors: The Leicester experience. Transplant Proc 1995; 27 (5): 2940.

31. D'Allessandro AM, Hoffman RM, Belzer FO. Non-heart-beating donors: One response to the organ shortage. Transplant Rev 1995; 9: 168.

32. Orloff MS, Reed Al, Erturk E, et al. Nonheartbeating cadaveric organ donation. Ann Surg 1994; 220 (4): 578.

33. Kievit JK, Oomen APA, de Vries B, Heineman E, Kootstra G. Update on results of NonHeart-Beating donor kidney transplantation. Transplant Proc 1997; 29: 2989.

34. Anaise D. Pharmacological agents in organ preservation. In: Collins GM, Dubernard JM, Land W and Persijn GG (eds) Procurement, Preservation and Allocation of Vascularized Organs. Kluwer, Dordrecht 1997: 145.

35. Southard $\mathrm{JH}$. Improving early graft function: role of preservation. Transplant Proc 1997; 29: 3510.

36. Inman S, Osgood R, Plott W, Richardson B, Lewis R. Identification of kidneys subjected to pre-retrieval warm ischemic injury during hypothermic perfusion preservation. Transpl Proc 1998; 30: 2309.

37. Kievit JK, Oomen AP, Janssen MA, van Kreel BK, Heineman E, Kootstra G. Viability assessment of non-heart-beating donor kidneys by alpha glutathione S-transferase in the machine perfusate. Transplant Proc 1997; 29 (1-2): 1381.

38. Kievit JK, Nederstigt AP, Oomen AP, Janssen MA, Schoot L, Kootstra G. Release of alpha-glutathione S-transferase (alpha GST) and pi-glutathione S-transferase (pi GST) from ischemic damaged kidneys into the machine perfusate-relevance to viability assessment. Transplant Proc 1997; 29 (8): 3591.

39. Kootstra G. The asystolic, or non-heartbeating, donor. Transplantation 1997; 63 (7): 917.

40. Bickford RJ, Winton FR. The influence of temperature on the isolated dog kidney. JPhysiol, Lond 1937; 89: 198.

41. Levy MN. Oxygen consumption and blood flow in the hypothermic, perfused kidney. Am J Physiol 1959; 197: 11.

42. Southard JH. Biochemistry and cell physiology of organ preservation. In: Collins GM, Dubernard JM, Land W and Persijn GG (eds) Procurement, Preservation and Allocation of Vascularized Organs. Kluwer, Dordrecht 1997: 103.

43. Maessen JG, van der Vusse G], Vork M, Kootstra G. Intermediate normothermic perfusion during cold storage of ischemically injured kidneys. Transplant Proc 1989;21 (1 Pt 2): 1252.

44. Wijk van der J, Slooff MJ, Rijkmans BG, Kootstra G. Successful 96- and 144-hour experimental kidney preservation: a combination of standard machine preservation and newly developed normothermic ex vivo perfusion. Cryobiology 1980; 17 (5): 473. 
45. Wijk van der J, Rijkmans BG, Kootstra G. Six day kidney preservation in a canine model. Influence of a one to four hour ex-vivo perfusion interval. Transplantation 1982; 35 (5): 408.

46. Le Gallois CJJ. Expériences sur le principe de la vie. Dissertation. Paris 1812.

47. Loebell CE. De conditionibus quibus secretiones in glandulis perficiuntur. Dissertation. Marburg 1849.

48. Brodie TG. Perfusion of surviving organs. J Physiol 1903; 29: 266.

49. Bainbridge FE, Evans CL. The heart, lung, kidney preparation. J Physiol 1914; 48: 278.

50. Starling EH, Verney EB. The secretion of urine as studied on the isolated kidney. Proc Roy Soc (B) 1925; $97: 321$.

51. Shannon JA, Winton FR. The renal excretion of inulin and creatinine by the anaestetized dog and by the pump-lung-kidney preparation. J Physiol 1940; 98: 97.

52. Kupfer S, Thompson DD, Pitts RF. The isolated kidney and its response to diuretic agents. Am J Physiol 1951; 167: 703.

53. Nizet A, Cuypers Y, Massillon L, Lambert S. Mise en évidence de facteurs réduisant le débrit sanguin rénal et libéré par les hématies. Arch Int Phsiol Biochem 1957; 65: 568.

54. Cuypers Y, Körver G, Nizet A. Neutrlisation per différents organes de l'action vasoconstrictice du sang hépariné et conservé. Arch Int Physiol Biochem 1961; 69: 213.

55. Nizet A, Cuypers $Y$, Deetjen P, Kramer K. Functional capacity of the isolated perfused dog kidney. Pflügers Archiv 1967; 296: 179.

56. Cassie GF, Couch NP, Dammin G], Murray JE. Normothermic perfusion and replantation of the excised dog kidney. Surg Gyn Obst 1959; 109: 721.

57. Couch NP, Cassie GF, Murray JE. Survival of the excised dog kidney perfused in a pump oxygenator system. Surgery 1958; 44 (4): 666.

58. Telander RL. Prolonged normothermic perfusions of the isolated primate and sheep kidney. Surg Gyn Obst 1964; 118: 347.

59. Nizet A. The isolated perfused kidney: possibilities, limitations and results. Ed. review. Kidney Int 1975; 7: 1.

60. Gagnon JA, Grove DW, Flamenbaum W. Blood flow distribution and tissue solute content of the isolated-perfused kidney. Pflügers Archiv 1974; 347 (4): 261.

61. Long DM, Sanchez L, Varco RL, Lillehei CW. Use of low molecular weight dextran and serum albumin as expanders in extracorporeal circulation. Surgery 1961; 50: 12.

62. Belzer FO, Park HY, Vetto RM. Factors influencing renal blood flow during isolated warm perfusion. Surg Forum 1964; 15: 222.

63. Born GVR, Cross MJ. Effect of inorganic ions and of plasma proteins on the aggregation of blood platlets by adenosine diphosphate. J Physiol 1964; 170: 397.

64. Swank RL, Fellman JH, Hissen WW. Aggregation of blood cells by 5-Hydroxytryptamine (Serotonin). Circ Res 1963; 13: 392.

65. Belzer FO, Ashby BS, Huang JS, Dunphy JE. Etiology of rising perfusion pressure in isolated organ perfusion. Ann Surg 1968; 168 (3): 382.

66. Suomalainen $P$. The magnesium and calcium metabolism of hibernating hedgehogs and the production of artificial hibernation. Suom Kemistilethi 1938; 11: 29.

67. Lotke PA. Lysosome stabilizing agents for hypothermic kidney preservation. Nature 1966; 212 (6): 512.

68. Benjamin JL, Sell KW. Assessment of renal function during isolated in vitro perfusion. Transpl Proc 1971; 3 (1): 616.

69. Benjamin JL, Sell KW. Effects of temperature on kidneys preserved by hypothermic perfusion. Transplantation 1972; 14 (4): 501.

70. Sell KW, Small A, Benjamin JL. Renal function in the hypothermic perfused state. Transplant Proc 1972; 4 (4): 617.

71. Malinin GI, Benjamin JL, Sell KW. Histochemistry of renal lesions induced by pulsatile hypothermic perfusion. Lab Invest 1974; 31 (5): 543. 
72. Fuller BJ, Pegg DE. The assesment of renal preservation by normothermic bloodless perfusion. cryobiology 1976; 13: 177.

73. Amberson WR. Blood substitutes. Biol Rev 1937; 12: 48.

74. Amberson WR, Jennings IJ, Rhode CN. Clinical experience with hemoglobin saline solution. J Appl Physiol 1942; 1: 469.

75. Rabiner SF, Rosenfeld S. Role of intravascular hemolysis and the reticuloendothelial system in the production of a hypercoagulable state. I Lab Clin Med 1963; 62: 1005.

76. Rabiner SF, Helbert JR, Lopas H, Friedman LH. Evaluation of a stroma-free hemoglobin solution for use as a plasma expander. I Exp Med 1967; 126 (6): 1127.

77. Rabiner $\mathrm{S}$, Friedman $\mathrm{LH}$. The role of intravascular hemolysis and the reticuloendothelial system in the production of a hypercoagulable state. $\mathrm{Br}$ J Haematol 1968; 14 (2): 105.

78. Birndorf $\mathrm{NI}$, Lopas $\mathrm{H}$. Effect of red cell stroma-free hemoglobin solution on renal function in monkeys. J Appl Physiol 1970; 29 (5): 573.

79. Relihan M, Litwin MS. Effects of stroma-free hemoglobin solution on clearance rate and renal function. Surgery 1972; 71 (3): 395.

80. Friedman $\mathrm{HI}$, Devenuto F. Morphological effects of transfusions with hemoglobin solutions. Crit Care Med 1982; 10 (4): 288.

81. Vogel WM, Lieberthal W, Apstein CS, Levinsky N, Valeri CR. Effects of stroma free hemoglobin solutions on isolated perfused rabbit hearts ans isolated perfused rat kidneys. Biomater Artif Cells Artif Organs 1988; 16 (1-3): 277.

82. Schier JF, Rudowski WJ, Daszynski J, Goralski SA, Helczynski L. Influence of stroma-free hemoglobin solution on renal function in dogs. Z Exper Chir 1979; 12 (3): 138.

83. Benesch RE, Benesch R, Renthal RD, Maeda N. Affinity labeling of the polyphosphate binding site of hemoglobin. Biochemistry 1972; 11 (19): 3576.

84. Haupt AS, Ochs R, Schubert GE. Renal lesions in ischaemic kidneys infused with haemoglobin: an electron microscopic study. Urol Res 1982; 10 (1): 1.

85. Lee R, Atsumi N, Jacobs EE, Jr., Austen WG, Vlahakes GJ. Ultrapure, stroma-free, polymerized bovine hemoglobin solution: evaluation of renal toxicity. J Surg Res 1989; 47 (5): 407.

86. Tam SC, Wong 'T. Impairment of renal function by stroma-free hemoglobin in rats. J Lab Clin Med 1988; 111 (2): 189.

87. Savitsky JP, Doczi J, Black J, Arnold JD. A clinical safety trial of stroma-free hemoglobin. Clin Pharmacol Ther 1978; 23 (1): 73.

88. Feola M, Simoni J, Canizaro PC, Tran R, Raschbaum G, Behal FJ. Toxicity of polymerized hemoglobin solutions. Surg Gynecol Obstet 1988; 166 (3): 211.

89. Feola M, Simoni J, Tran R, Canizaro PC. Nephrotoxicity of hemoglobin solutions. Biomater Artif Cells Atrif Organs 1990; 18 (2): 233.

90. Takahashi T, Iwasaki K, Malchesky PS, et al. Effects of single dose infusion of pyridoxalated hemoglobin polyoxyethylene conjugate solution on canine renal function. Artif Organs 1991; $15(6): 462$.

91. Smith CD, Schuschereba ST, Hess JR, McKinney LA, Bunch D, Bowman PD. Liver and kidney injury after administration of hemoglobin crosslinked with bis-(3,5-dibromosalicyl)-fumarate. Biomater Artif Cells Artif Organs 1990; 18 (2): 251.

92. Matsushita M, Yabuki A, Chen JF, et al. Renal effects of a pyridoxalated hemoglobin polyoxyethylene conjugate solution as a blood substitute in exchange transfusions. ASAIO Trans 1988; 34 (3): 280.

93. Lenz G, Junger $H$, Schneider M, Kothe $N$, Lissner R, Prince AM. Elimination of pyrioxalated polyhemoglobin after partial exchange transfusion in chimpanzees. Biomater Artif Cells Immobilization Biotechnol 1991; 19 (4): 699.

94. Willinger CC, Schramek H, Pfaller K, Joannidis M, Deetjen P, Pfaller W. Ultrapure polymerized bovine hemoglobin improves structural and functional integrity of the isolated perfused rat kidney. Renal Physiol Biochem 1995; 18 (6): 288. 
95. Horiuchi T, Ohta Y, Hashimoto K, et al. Machine perfusion of isolated kidneys at $37^{\circ} \mathrm{C}$ using pyridoxalated hemoglobin-polyoxyethylene (PHP) solution, UW solution and its combination. Biomater Artif Cells Immobilization Biotechnol 1992; 20 (2-4): 549.

96. Iwashita Y. Relationship between chemical properties and biological properties of pyridoxalated hemoglobin-polyoxyethylene. Biomater Atrif Cells Immobilization Biotechnol 1992; 20 (2-4): 299.

97. Riess JG. Fluorocarbon-based in vivo oxygen transport and delivery systems. Vox Sang 1991; 61 (4): 225.

98. Voiglio El, Zarif L, Gorry FC, et al. Aerobic preservation of organs using a new perflubron/ lecithin emulsion stabilized by molecular dowels. J Surg Res 1995; 63 (2): 439.

99. Beisang AA, Feemster J, Dietzman RH, et al. Damage assay of kidneys frozen by intraarterial perfusion with a fluorocarbon. Fed Proc 1970; 29 (5): 1782.

100. Nakaya S, Sekita M, Ohyanagi H, et al. In "Symposium on perfluorchemical artificial blood, Kyoto 1975". Osaka: Igakushobo, pp 187-201 1975.

101. Hall CA. Perfluorocarbon emulsion in the perfusion of canine organs. Fed Proc 1975; 34 (6): 1513.

102. Dunn RN, Merkel FK, Roseman D, Haklin M, English K. Is normothermic preservation an alternative to hypothermic preservation? In: Pegg DE, Jacobsen IA and Halasz NA (eds) Organ Preservation: Basic and applied aspects. MTP Press, Lancaster 1982: 273.

103. Kawamura A, Meguro M, Takahashi A, et al. Artificial conditioner for stored organs. Int I Artif Organs 1994; 17 (1): 53.

104. Brasile L, Clarke J, Green E, Haisch C. The feasibility of organ preservation at warmer temperatures. Transplant Proc 1996; 28 (1): 349.

105. Brasile L, Green E, Haisch C. Warm ex vivo perfusion prevents reperfusion injury in warm ischemically damaged kidneys. Transplant Proc 1997; 29: 3422.

106. Brasile L, Green E, Haisch C. Ex vivo resuscitation of kidneys following postmortem warm ischemia. Transplant Proc 1997; 29: 3518.

107. Haisch C, Thomas F, Green E, Brasile L. Evaluating renal allograft function prospectively. Transplant Proc 1996; 28 (1): 363.

108. Haisch C, Green E, Brasile L. Predictors of graft outcome in warm ischemically damaged organs. Transplant Proc 1997; 29: 3424. 

CHAPTER 3

Exsanguinous Metabolic Support technology 
Exsanguinous Metabolic Support (EMS) technology is a patented proprietary warm perfusion technology developed by Breonics, Inc. (301 Nott Street, Schenectady, NY 12305) that can maintain an organ in a metabolically active condition while isolated from the rest of the physiologic system. EMS functions by supporting two major ongoing and critical processes: the support of continued cellular metabolism and the maintenance of the integrity of the vasculature in order to provide continued barrier functions. The technology consists of a solution and a perfusion system.

By definition, one must substitute for the systemic functions during the time that an organ is isolated from the physiologic system. Therefore the warm perfusion technology must provide the required nutrients necessary to maintain metabolic functions for all of the cellular components within an organ. Similarly, for continued metabolism in an isolated organ, a near physiologic temperature must be maintained. The failure to provide the necessary nutrients to sustain an adequate basal metabolism leads to compromised cellular functions and ultimately cell damage. Nutrient delivery includes: (a) all the needed raw materials for synthesis, substrates for energy and ongoing metabolism, vitamins and trace elements primarily for catalytic functions and bulk inorganic ions for both catalytic and physiologic functions; (b) physiologic parameters such as temperature, $\mathrm{pH}$, oxygen tension, oncotic pressure and perfusion pressures must be kept within a defined range. During EMS perfusion, the vascular endothelial integrity is maintained in order to preserve its normal barrier functions to macromolecules and for continued electrostatic repulsion.

An appropriate perspective for understanding the EMS technology is that it is a combination of the knowledge accumulated in the fields of cell biology, tissue culture and biochemistry and represents the maintenance of an intact organ in tissue culture-like conditions. Nevertheless, EMS is distinct from traditional tissue culture in its ability to preserve intact complex tissue without any form of dispersion. The warm perfusion technology allows for an organ to metabolize and function as if it were part of an intact physiologic system. While the tenants and principles of traditional tissue culture technology have been applied to the development of the warm perfusion technology, EMS goes beyond traditional tissue culture by supplying the physical parameters and processes necessary to maintain an intact organ.

\section{THE EMS SOLUTION}

The basal solution consists of a highly enriched tissue culture-like solution which contains essential and non-essential amino acids, carbohydrates, metabolites, inorganic ions, serum proteins, lipids, hormones, vitamins, reducing agents, a 
buffering system, trophic factors, vasodilators, radical scavengers, and adenine compound substrates adjusted to a $\mathrm{pH}$ of 7.4 (table 1).

Components of the solution that are distinct from traditional tissue culture media formulations and provide unique functions during the warm perfusion are described in the following section:

- An adequate supply of oxygen cannot be dissolved by an aqueous solution. A major reason why previous studies attempting a warm temperature preservation failed was because of the inability to supply enough oxygen. The use of red blood cells has been problematic because of the mechanical damage that occurs to the circulating red cells over time. EMS uses either a perfluorochemical emulsion or a chemically modified hemoglobin as the source of an oxygen carrier. Perfluorochemicals are not specific oxygen carriers, but rather function as a sponge for any gas. Although they can provide an adequate supply of oxygen to the renal cells during EMS perfusion, perfluorochemicals preferentially take up $\mathrm{CO}_{2}$ at a rate that is eight times that of oxygen. Chemically modified hemoglobin's that do not cause nephrotoxicity can be successfully used to deliver an adequate supply of oxygen to an intact organ. Therefore, an oxygen carrier is an integral component of the solution.

- Aside from providing colloid osmotic pressure, by far the most important function of albumin is its carrier functions. In the same manner that an oxygen carrier delivers oxygen and removes carbon dioxide, albumin delivers nutrients to the cells within the nephron and removes the by-products of the ongoing metabolism. Studies with albumin have demonstrated a simple binding equilibrium, where the higher the albumin concentration, the more binding sites there are available. Therefore, a too low concentration of albumin results in competition for shared transport mechanisms among the various ingredients. This makes albumin an integral component of the EMS solution.

- A growth factor can be described as a stimulating substance that is not a nutrient, in that it is not an intracellular metabolic substrate or cofactor. The definition we have employed for the incorporation of growth factor is that it is a small protein that induces increased cell synthesis of nucleic acids and proteins, or case of cell damage or death, leads to recovered cellular mass. Growth factor evaluation was pursued with the EMS technology because it is recognized that growth factors stimulate the transport of small molecules causing an increased rate of transport through the plasma membrane. By far the most beneficial effect observed is the prevention of the development of interstitial edema. The growth factor used is of the heparin-binding class of acidic-FGF and is an integral component of the EMS solution. 
TABLE 1. Composition of the EMS solution.

\begin{tabular}{|c|c|c|c|}
\hline DL-Alanine & $.12 \mathrm{~g} / \mathrm{L}$ & Menadione (Na Bisulfate) & $.00003 \mathrm{~g} / \mathrm{L}$ \\
\hline L-Arginine $\mathrm{HCl}$ & $.14 \mathrm{~g} / \mathrm{L}$ & Myo-Inositol & $.0001 \mathrm{~g} / \mathrm{L}$ \\
\hline DL-Aspartic Acid & $.12 \mathrm{~g} / \mathrm{L}$ & Niacinamide & $.00005 \mathrm{~g} / \mathrm{L}$ \\
\hline L-Cysteine $\mathrm{HCl} \mathrm{H}_{2} \mathrm{O}$ & $.00022 \mathrm{~g} / \mathrm{L}$ & Nicotinic Acid & $.00005 \mathrm{~g} / \mathrm{L}$ \\
\hline L-Cystine $2 \mathrm{HCl}$ & $.52 \mathrm{~g} / \mathrm{L}$ & Para-Aminobenzoic Acid & $.0001 \mathrm{~g} / \mathrm{L}$ \\
\hline DL-Glutamic Acid & $.2672 \mathrm{~g} / \mathrm{L}$ & D-Pantothenic Acid Ca & $.00002 \mathrm{~g} / \mathrm{L}$ \\
\hline intblL-Glutamine & $.20 \mathrm{~g} / \mathrm{L}$ & Polyoxyethylenesorbitan Monoolate & $.04 \mathrm{~g} / \mathrm{L}$ \\
\hline Glycine & $.10 \mathrm{~g} / \mathrm{L}$ & Pyridoxal $\mathrm{HCl}$ & $.00005 \mathrm{~g} / \mathrm{L}$ \\
\hline L-Histidine $\mathrm{HCl} \mathrm{H}_{2} \mathrm{O}$ & $.04376 \mathrm{~g} / \mathrm{L}$ & Pyridoxine $\mathrm{HCl}$ & $.00005 \mathrm{~g} / \mathrm{L}$ \\
\hline L-Hydroxyproline & $.02 \mathrm{~g} / \mathrm{L}$ & Retinol Acetate & $.00028 \mathrm{~g} / \mathrm{L}$ \\
\hline DL-Isoleucine & $.08 \mathrm{~g} / \mathrm{L}$ & Riboflavin & $.00002 \mathrm{~g} / \mathrm{L}$ \\
\hline DL-Leucine & $.24 \mathrm{~g} / \mathrm{L}$ & Ribose & $.001 \mathrm{~g} / \mathrm{L}$ \\
\hline L-Lysine $\mathrm{HCl}$ & $.14 \mathrm{~g} / \mathrm{L}$ & Thiamine $\mathrm{HCL}$ & $.00002 \mathrm{~g} / \mathrm{L}$ \\
\hline DL-Methionine & $.06 \mathrm{~g} / \mathrm{L}$ & Thymine & $.0006 \mathrm{~g} / \mathrm{L}$ \\
\hline DL-Phenylalanine & $.10 \mathrm{~g} / \mathrm{L}$ & Uracil & $.0006 \mathrm{~g} / \mathrm{L}$ \\
\hline L-Proline & $.08 \mathrm{~g} / \mathrm{L}$ & Xanthine $\mathrm{HCl}$ & $.00069 \mathrm{~g} / \mathrm{L}$ \\
\hline DL-Serine & $.10 \mathrm{~g} / \mathrm{L}$ & Calcium Chloride $2 \mathrm{H}_{2} \mathrm{O}$ & $.265 \mathrm{~g} / \mathrm{L}$ \\
\hline DL-Theonine & $.12 \mathrm{~g} / \mathrm{L}$ & Ferric Nitrate $9 \mathrm{H}_{2} \mathrm{O}$ & $.00144 \mathrm{~g} / \mathrm{L}$ \\
\hline DL-Tryptophan & $.04 \mathrm{~g} / \mathrm{L}$ & Magnesium Sulfate (anhydrous) & $1.2 \mathrm{~g} / \mathrm{L}$ \\
\hline L-Tyrosine $2 \mathrm{Na}$ & $.11532 \mathrm{~g} / \mathrm{L}$ & Potasium Chloride & $.40 \mathrm{~g} / \mathrm{L}$ \\
\hline DL-Valine & $.10 \mathrm{~g} / \mathrm{L}$ & Sodium Acetate (anhydrous) & $.10 \mathrm{~g} / \mathrm{L}$ \\
\hline Adenine Hemisulfate & $.02 \mathrm{~g} / \mathrm{L}$ & Sodium Chloride & $6.8 \mathrm{~g} / \mathrm{L}$ \\
\hline Adenosine Triphosphate $2 \mathrm{Na} 2 \mathrm{Na}$ & $.002 \mathrm{~g} / \mathrm{L}$ & Sodium Phosphate Monobasic (anh) & $.224 \mathrm{~g} / \mathrm{L}$ \\
\hline Adenylic Acid & $.0004 \mathrm{~g} / \mathrm{L}$ & D-Glucose & $2.0 \mathrm{~g} / \mathrm{L}$ \\
\hline Alpha Tocopherol Phosphate 2Na & $.00002 \mathrm{~g} / \mathrm{L}$ & Insulin & $.01 \mathrm{~g} / \mathrm{L}$ \\
\hline Ascorbic Acid & $.001 \mathrm{~g} / \mathrm{L}$ & Bovine Serum Albumin & $30 \mathrm{~g} / \mathrm{L}$ \\
\hline D-Biotin & $.00002 \mathrm{~g} / \mathrm{L}$ & Sodium Bicarbonate & $4.4 \mathrm{~g} / \mathrm{L}$ \\
\hline Calciferol & $.0002 \mathrm{~g} / \mathrm{L}$ & Pyruvate & $.22 \mathrm{~g} / \mathrm{L}$ \\
\hline Cholesterol & $.0024 \mathrm{~g} / \mathrm{L}$ & Transferin & $.10 \mathrm{~g} / \mathrm{L}$ \\
\hline in0 Choline Chloride & $.001 \mathrm{~g} / \mathrm{L}$ & Serum & $10 \mathrm{ml}$ \\
\hline Deoxyribose & $.001 \mathrm{~g} / \mathrm{L}$ & B-cyclodextrin & $.50 \mathrm{~g} / \mathrm{L}$ \\
\hline Folic Acid & $.00002 \mathrm{~g} / \mathrm{L}$ & Chordroitin sulfate $B$ & $.004 \mathrm{~g} / \mathrm{L}$ \\
\hline Glutathione (reduced) & $.0001 \mathrm{~g} / \mathrm{L}$ & Acidic fibroblast growth factor & $.02 \mathrm{~g} / \mathrm{L}$ \\
\hline Guanine $\mathrm{HCL}$ & $.0006 \mathrm{~g} / \mathrm{L}$ & heparin & $.18 \mathrm{~g} / \mathrm{L}$ \\
\hline Hypoxanthine & $.0006 \mathrm{~g} / \mathrm{L}$ & & \\
\hline
\end{tabular}


The EMS solution is complex and not in an equilibrium state. Rather during warm perfusion, the cells within the nephron must be able to catalyze energy-yielding reactions among the various components of the intact organ culture system. While the tendency in dealing with such a complex solution is to group the individual ingredients into the generic categories, this represents a serious oversimplification. Unlike the situation with hypothermic solutions, where cellular metabolism is largely inhibited and transport mechanisms are shut down, and therefore, the components remain mostly unaltered; warm perfusion is dynamic. A better approach to understanding the interactions is to group the ingredients into function rather than chemical classes. A review of table 2 highlights the multifactoral role of some EMS ingredients in that these components serve multiple functions.

TABLE 2. Functional categories.

\begin{tabular}{llll}
\hline Metabolic factors & Trophic factors & Antioxidants & Carrier function \\
\hline Glucose & Glucose & Amino Acids & Oxygen carrier \\
Pyruvate & Pyruvate & Serum albumin & Serum albumin \\
ATP & Insulin & Cyclodextrin & \\
Cholesterol & Growth factor & vitamins & \\
Amino acids & Amino acids & & \\
Bicarbonate & Mucopolysaccaride & & \\
Inositol & Magnesium & & \\
lons & & & \\
\hline Vasodilators & Large vessel specific & Microvessel specific & \\
\hline Arginine & Cyclodextrin & Mucopolysaccaride & \\
Growth factor & Heparin & Magnesium & \\
& Growth factor & Growth factor & \\
\hline
\end{tabular}

\section{THE EMS PERFUSION SYSTEM}

\section{Temperature}

Metabolism is directly correlated to the temperature at which tissue is maintained ex vivo. In determining the optimal perfusion temperature, considerations focused on several key factors. At temperatures below $22^{\circ} \mathrm{C}$ a cessation of glomerular filtration occurs and below $18^{\circ} \mathrm{C}$ tubular activity is inhibited. Most enzyme 
systems functioning at normothermia experience an approximately two-fold decrease for every ten-degree decrease in temperature. Likewise, the demand for oxygen is decreased as the temperature is declined. These considerations highlighted the need for a minimal threshold perfusion temperature of $25^{\circ} \mathrm{C}$. At the upper end of the temperature scale, $37^{\circ} \mathrm{C}$ is the usual temperature at which cells in tissue culture are maintained. However, maintaining an intact organ containing approximately three trillion cells at $37^{\circ} \mathrm{C}$ represented huge obstacles in terms of supporting the metabolic rate and eliminating the accumulation of metabolic by-products.

After evaluating canine kidneys perfused ex vivo at varying temperatures with subsequent reimplantation, it was determined that warm perfusion could adequately support organ metabolism at temperatures ranging from $25-34^{\circ} \mathrm{C}$. This temperature range supported oxidative metabolism, as determined by the oxygen consumed by the kidney, at rates ranging from approximately $50 \%$ to approximately $75 \%$ of physiologic levels. In current studies warm perfusion is conducted at a temperature range of $30-32^{\circ} \mathrm{C}$. A temperature controller is used in-line in conjunction with a heat exchanger to maintain the perfusion temperature in this targeted range.

\section{Perfusion: Pressure, Pulse Rate, Vascular Flow Rate and Oxygen Tension}

The perfusion parameters required to maintain the vascular integrity have been carefully elucidated for the canine transplant model. A systolic perfusion pressure of $>70 \mathrm{mmHg}$ was found to result in substantial mechanically induced endothelial cell damage. Likewise vascular flow rates of $>150 \mathrm{cc} / \mathrm{min}$ have also been found to result in blood vessel damage, while flow rates of $<70 \mathrm{cc} / \mathrm{min}$ were found to provide for inadequate support of oxidative metabolism. Careful evaluations have optimized the perfusion characteristics to target a mean arterial pressure of $35-40 \mathrm{mmHg}$, providing for a vascular flow of approximately $80-120 \mathrm{cc} / \mathrm{min}$ with a pulse rate of 60 beats/min. An in-line manometer controls for the systolic perfusion pressures. An ultrasonic flowmeter is used to monitor the flow rate resulting from the controlled perfusion pressures.

The perfusate, containing the oxygen carrier, is oxygenated prior to contact with the organ via an in-line membrane oxygenator. The solution is gassed with oxygen to maintain adequate oxygen consumption by the organ.

The temperature controlled and oxygenated EMS solution is introduced through the cannulated renal artery. The perfusate leaves the organ as venous effluent and drains by gravity directly into an effluent reservoir situated beneath the compartment of the organ chamber holding the organ. The venous effluent is collected, reheated, reoxygenated and then recirculated, minimizing perfusion contamination due to contact with air. 


\section{CONCLUSION}

The exsanguinous metabolic support system can be used to maintain an organ in a metabolically active state while isolated from the circulatory system of the body. 

CHAPTER 4.1

\section{Deleterious effect of prolonged cold ischemia on renal function}

BM Stubenitsky, L Brasile, MH Booster, CE Haisch, G Kootstra

Transplant International; accepted 


\begin{abstract}
A B STRACT
The detrimental effect of prolonged cold ischemia $(\mathrm{Cl})$ on posttransplant renal function has long been recognized. However, the cellular consequences of $\mathrm{Cl}$ have not been clearly defined. This study describes a model for the identification of $\mathrm{Cl}$ induced injury by evaluating ex vivo renal metabolism and function prior to reperfusion. Small bovine kidneys were cold stored in Viaspan for 24,48 , 72, or 96 hours. Kidneys were then warm perfused $\left(32^{\circ} \mathrm{C}\right)$ using Exsanguinous Metabolic Support (EMS) technology, and evaluated for oxidative metabolism, vascular dynamics and function. Oxygen consumption, vascular resistance, and diuresis were stable in kidneys with $\mathrm{Cl}$ up to 48 hours. After 72 and 96 hours of $\mathrm{Cl}$, all 3 parameters were reduced $(p<0.05)$. Glomerular filtration rate was diminished at $\mathrm{Cl}$ greater than 24 hours $(\mathrm{p}<0.05)$. Results show that function was compromised with $\mathrm{Cl}$ greater than 24 hours and preceded the loss of cell viability following 48 hours of $\mathrm{Cl}$.
\end{abstract}


Cold ischemia (CI) time, defined as the period between the initial cold perfusion of the kidney and reperfusion after reimplantation, is one of the best documented parameters in transplantation studies. The majority of all renal transplantation studies recognize the influence of $\mathrm{CI}$ time on posttransplant outcomes. Based upon these studies, there is general consensus that the longer the CI time the greater the extent of damage to a transplanted organ. In clinical renal transplantation, prolonged cold storage has been recognized to be strongly associated with delayed graft function (DGF) (1-8). Early effects of DGF include prolonged hospitalization, additional imaging studies, biopsies, dialysis, or inappropriate immunosuppression. Increases in costs and patient dissatisfaction are frequent consequences $(9,10)$. In addition, an emerging body of evidence suggests that DGF may have detrimental effects on graft function and survival $(11,12)$. But despite this large amount of information, the impact of CI as an independent marker on graft outcome is much less clear. It often has been difficult to separate injury produced by CI per se from that occurring during reperfusion. Reperfusion initiates a complex interplay between the endothelium, different types of blood cells, and resident leukocytes, adding to the injury obtained during CI.

The present study was designed to analyze $\mathrm{CI}$ induced injury prior to actual reperfusion. We identified the effect of prolonged CI alone on renal metabolism and function using Exsanguinous Metabolic Support (EMS) technology, an acellular ex vivo warm perfusion technology, thereby eliminating the deleterious effects of actual reperfusion. Following CI times varying from 24 to 96 hours, oxidative metabolism, vascular dynamics and organ function were evaluated during EMS perfusion.

\section{MATERIALS AND METHODS}

\section{Animal model}

Bovine kidneys were harvested from 7 day old calves scheduled for slaughter. The kidneys, weighing 70-100 grams, were excised immediately after the animals were killed via a captive bolt from a humane stunner to the cerebrum. The initial postmortem warm ischemic period was less than $15 \mathrm{~min}$. Following harvesting, a cannula was placed in the renal artery after which the kidneys were flushed (200 $\mathrm{ml}$ ) and statically stored in UW preservation solution at $4^{\circ} \mathrm{C}$. CI times were 24,48 , 72 , or 96 hours respectively ( $\mathrm{n}=8$ in each group). 


\section{EMS technology}

After the designated CI periods, the kidneys were re-flushed $(200 \mathrm{ml})$ and transitioned to a pressure controlled warm temperature perfusion $\left(32^{\circ} \mathrm{C}\right)$ system including an oxygenator and a pulsatile pump, retrofitted with controllers to maintain $\mathrm{PaO}_{2}, \mathrm{PaCO}_{2}, \mathrm{pH}$, and temperature (Breonics, Inc.). Both flush solution and perfusate consisted of a highly enriched tissue culture-like solution comprising more than 70 ingredients including amino acids, lipids, carbohydrates, ions, proteins, trophic factors, vasodilators, radical scavengers, and adenine compound substrates, adjusted to a $\mathrm{pH}$ of 7.4 (Breonics, Inc.). The perfusate was supplemented with an oxygen carrier (perfluorocarbon emulsion) to provide adequate oxygen to support ongoing renal metabolism.

\section{Evaluation of renal metabolism, function and vascular dynamics}

Metabolism was assessed by measuring the renal oxygen consumption during EMS perfusion. $\mathrm{PaO}_{2}$ analysis of pre-renal and post-renal samples were performed on a Radiometer ABL5 blood gas analyzer. Oxygen consumption $(\mathrm{ml} / \mathrm{min} / 100 \mathrm{~g})$ was calculated using the following formula:

$$
\text { Oxygen consumption }=\frac{\left(\mathrm{PaO}_{2} \text { art }-\mathrm{PaO}_{2} \text { ven }\right) \times \text { flow rate }}{\text { weight }} \times 100
$$

Function was assessed by urine production $(\mathrm{ml} / \mathrm{min} / 100 \mathrm{~g})$ during EMS perfusion. Furthermore creatinine was added to the re-circulated perfusate as a tracer molecule at a starting concentration of $6 \mathrm{mg} / \mathrm{dL}$. This allowed for urinalysis of tracer creatinine using an Ames Seralyzer III. GFR $(\mathrm{ml} / \mathrm{min} / 100 \mathrm{~g})$ was then calculated by:

$$
\mathrm{GFR}=\frac{\text { creatinine concentration urine } \times \text { diuresis }}{\text { creatinine concentration perfusate }}
$$

Flow and pressure where monitored during warm perfusion and used to calculate vascular resistance:

Vascular resistance $=\frac{\text { mean arterial pressure }}{\text { mean flow rate }}$ 


\section{Histologic evaluation}

Following the 4 hour perfusion period, wedge-shaped biopsies were taken and fixed in $4 \%$ neutral-buffered formalin, dehydrated and paraffin embedded. Four micron sections from each kidney made and stained using haematoxylin and eosin for light macroscopic evaluation. The morphological characteristics of the kidneys were determined by blinded histologic evaluation.

\section{Data analysis}

All values reported are the means along with the calculated standard error. For statistical analysis of differences in obtained data between the experimental groups the Student T-test was used. The level of significance was set at $5 \%$.

\section{RESULTS}

\section{Oxidative metabolism (figure 1)}

During the first 60 minutes of perfusion the oxygen consumption of all kidneys stabilized and stayed constant during the remaining perfusion period. Following 4 hours of EMS perfusion, oxygen consumption was found to be equal in kidneys cold stored for 24 and 48 hours (respectively $18 \pm 5$ and $19 \pm 5 \mathrm{ml} / \mathrm{min} / 100 \mathrm{~g}$ ). When the CI time was increased to 72 hours, the oxygen consumption was markedly reduced $(5.4 \pm 1 \mathrm{ml} / \mathrm{min} / 100 \mathrm{~g})$ and was further reduced at 96 hours of $\mathrm{CI}(3.4 \pm 2$ $\mathrm{ml} / \mathrm{min} / 100 \mathrm{~g}$ ). The differences between kidneys cold stored up to 48 hours and kidneys stored for a longer period reached statistical significance $(\mathrm{p}<0.05)$.

\section{Vascular dynamics (figure 2)}

During EMS perfusion the vascular resistance was equivalent in test groups exposed to CI up to 48 hours (respectively $0.46 \pm 0.05$ and $0.5 \pm 0.03$ ). With CI exposure of 72 hours the vascular resistance doubled and again doubled when CI was increased to 96 hours ( $1.1 \pm 0.3$ and $3.9 \pm 3$ respectively). However, none of these differences between groups reached statistical significance.

\section{Organ function (figures 3 \& 4)}

The pattern of urine flow during EMS perfusion was very similar to that observed with oxygen consumption and vascular resistance. Again, urine flow was only compromised with CI times exceeding 48 hours. The rate of urine production at 24 and 48 hours of CI measured both $0.8 \pm 0.3 \mathrm{ml} / \mathrm{min} / 100 \mathrm{~g}$. Much lower urine flow was seen at 72 hours of $\mathrm{CI}(0.4 \pm 0.06 \mathrm{ml} / \mathrm{min} / 100 \mathrm{~g})$ and at 96 hours of CI 


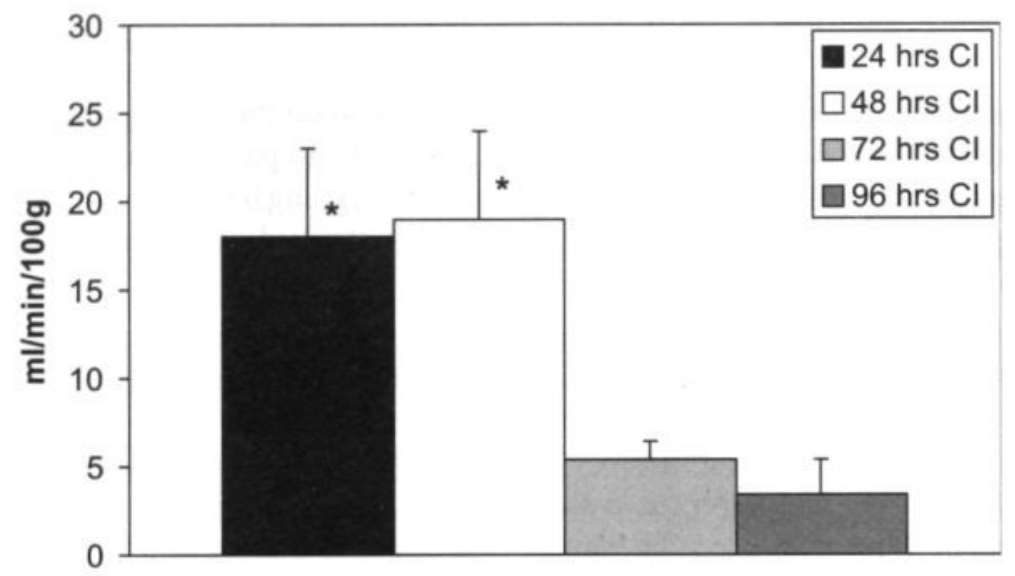

FIGURE 1. Oxidative metabolism during EMS perfusion.

$*=p<0.05$ with respect to 72 and 96 hours of $\mathrm{Cl}$.
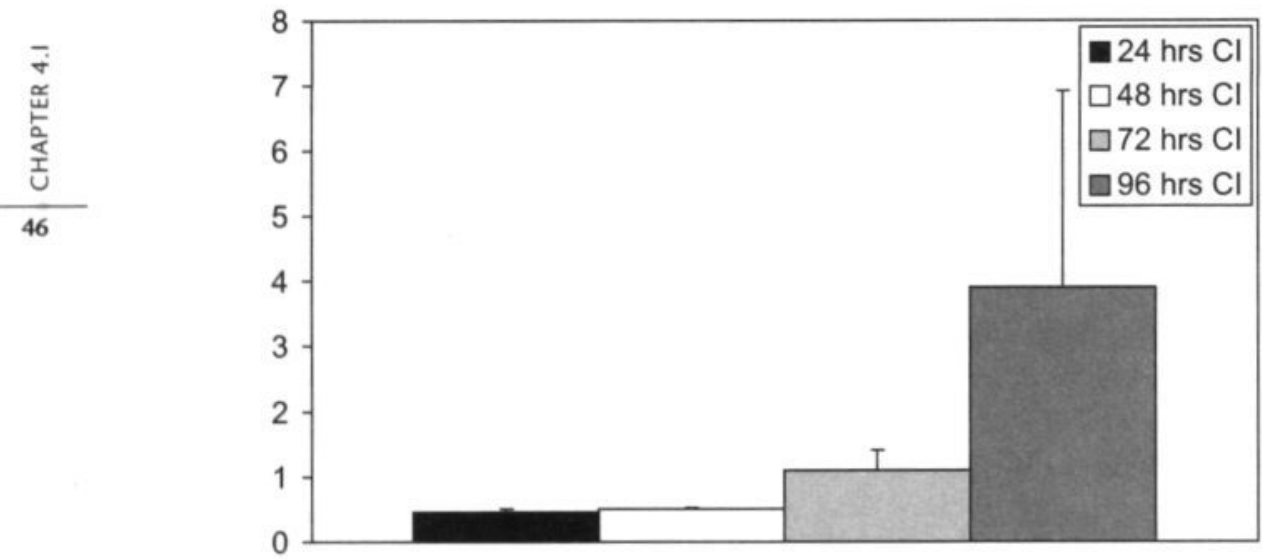

FIGURE 2. Vascular resistance during EMS perfusion. 


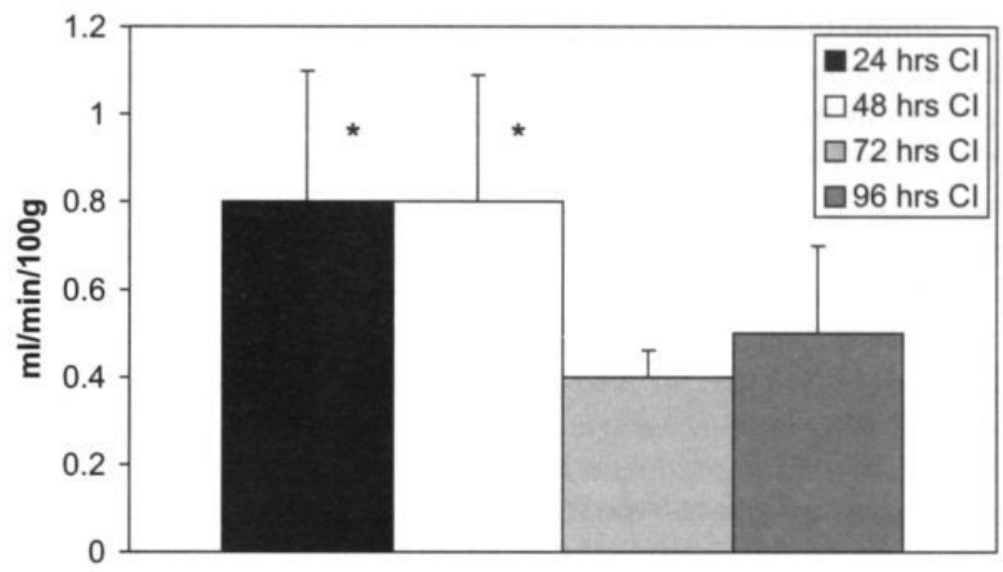

FIGURE 3. Urine production during EMS perfusion.

${ }^{*}=\mathrm{p}<0.05$ with respect to 72 and 96 hours of $\mathrm{Cl}$.

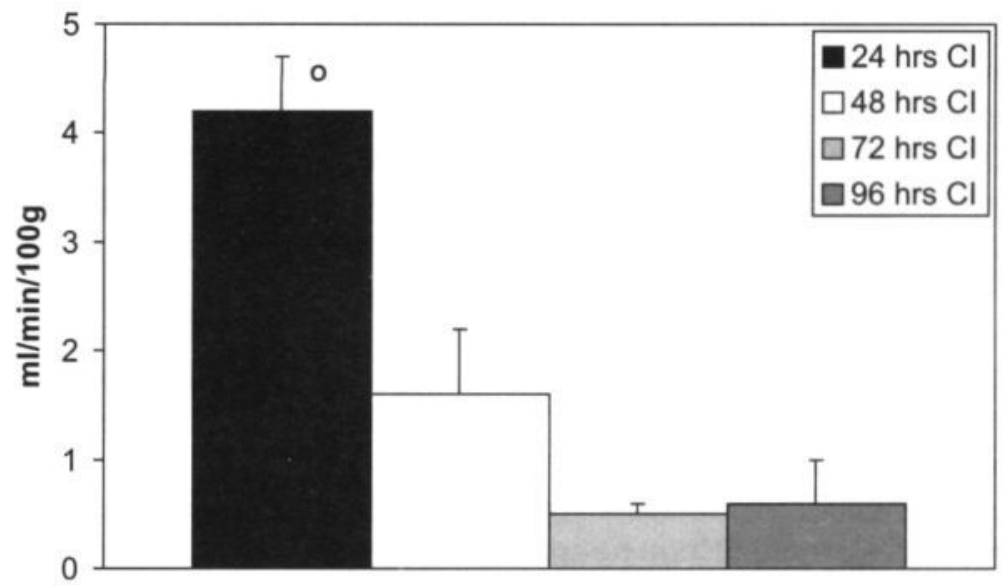

FIGURE 4. Glomerular Filtration Rate during EMS perfusion.

${ }^{\circ}=\mathrm{p}<0.05$ with respect to 48,72 and 96 hours of $\mathrm{Cl}$. 
$(0.5 \pm 0.2 \mathrm{ml} / \mathrm{min} / 100 \mathrm{~g})$. Urine flow after 72 and 96 hours of CI was significantly diminished as compared to kidney stored up to 48 hours ( $<<0.05$ ).

GFR was the only measured parameter capable of differentiating the effect of CI during the first 48 hours of hypothermic preservation. CI exposure of 24 hours provided a GFR of $4.2 \pm 0.5 \mathrm{ml} / \mathrm{min} / 100 \mathrm{~g}$. This dropped by $60 \%$ at 48 hours of exposure to $\mathrm{CI}(1.6 \pm 0.6 \mathrm{ml} / \mathrm{min} / 100 \mathrm{~g})$ and by $85 \%$ at both 72 and 96 hours of CI $(0.5 \pm 0.1$ and $0.6 \pm 0.4$ respectively). Therefore, in contrast to the metabolic parameters, a significant reduction of GFR was seen after 24 hours of $\mathrm{CI}(\mathrm{p}<0.05)$.

\section{Histologic evaluation}

Light microscopic analysis revealed no signs of vascular or glomerular damage in all kidneys. However the occurrence of extensive tubular necrosis was observed at time points of $\mathrm{CI}$ exceeding 48 hours, with the severity dependant upon the duration of the CI period.

\section{DISCUSSION}

There are two areas in transplantation where improvements must be made. One is an understanding of the changes that take place during the period of $\mathrm{CI}$; the other is an understanding of the injurious events that are the result of reperfusion injury. CI causes damage through a gradual process in which biochemical alterations lead to functional impairment, followed by structural changes and ultimately cell death (13). Reperfusion injury is an additional hazard contributing to organ damage upon revascularazation after $\mathrm{CI}$. When blood flow is restored oxygen influx leads to the formation of active free radicals that, by modulating leukocyte-endothelial cells interactions, produce further cellular, membrane and microvascular injury (14-16).

The aim of this study was to determine the effects of $\mathrm{CI}$ on restored ex vivo kidney metabolism and function prior to reperfusion. Restoration of renal metabolism and function was achieved by ex vivo warm perfusion, using EMS technology. The perfusate used during ex vivo warm perfusion was designed to support the nutritional and metabolic needs of the vascular endothelium within a graft, thereby maintaining the integrity of the vasculature and subsequently the normal permeability of the organ. Inhibition of radical oxygen species formation by addition of scavengers, together with the absence of inflammatory cells in the EMS perfusate was thought to eliminate much of the compounding damage seen during actual reperfusion with blood 


\section{Effect of CI on oxidative metabolism}

Renal cell viability was compromised after CI times exceeding 48 hours. The reduced capability to restore metabolism observed after prolonged CI has its origin in the negative effects of ischemia. During ischemia cell metabolism continues, resulting in decreasing adenosine triphosphate (ATP) levels. The loss of ATP may be a critical event in initiating the cascade of events leading to cell death. Cells can certainly tolerate very low concentrations of ATP for a long period, however loss of ATP causes loss of control over metabolism with inhibition of ATP-dependent reactions while catabolic reactions continue. ATP is also necessary for the maintenance of the integrity of membranes. One of the most ATP sensitive cell functions is the sodium and water homeostasis via the sodium-potassium pump. As this pump fails due to lack of ATP, cellular swelling and eventually rupture can occur $(17,18)$. Therefore, although hypothermia reduces the kidneys metabolic demands for nutrients and oxygen, thereby extending the period during which anoxic tissue stays viable, the result is merely a rate change in the processes leading to cell death (13).

\section{Effect of CI on organ function}

Loss of renal function occurred sooner as compared to cell viability, with a marked deterioration of GFR by 48 hours of $\mathrm{CI}(\mathrm{p}<0.05)$. An explanation for the more rapid loss of function might be the increased susceptibility of the proximal tubule cells to ischemic injury. In the literature these cells have been described as the primary cause for the pathophysiologic and clinical aspects of ischemic acute renal failure $(19,20)$. The ischemia leads to a loss of surface membrane polarity and the integrity of the tight junction. Integins are redistributed towards the apical surface (21), and dead and live cells slough into the tubular lumen, thereby contributing to cast formation (22). The cast cause increased intratubular pressure and a reduced GFR. Loss of the epithelial cell barrier and of the tight junctions between viable cells can result in back leakage of the GFR, further reducing effective GFR.

Based upon the results, static cold storage seems to be a method of limited utility for high quality long-term organ preservation. This seems to be due to an exhaustion of nutrients and an accumulation of waste products during the period of preservation (23). Improved preservation could be obtained if catabolism where suppressed and anabolic metabolism stimulated. This has been accomplished by both hypothermic machine perfusion (24) and intermittent normothermic perfusion (25-27). During machine perfusion a cold perfusate is pumped through the organ at low pressure in order to simulating metabolism by supplying oxygen and nutrients and removing metabolic end products. This method appears to give a good quality of long preservation for kidneys (28-30). Kootstra's group demonstrated that intermittent perfusion with normothermic 
blood in the course of cold preservation extended the preservation times significantly. It was postulated that the beneficial effect of this intermittent perfusion could be attributed to a washout of metabolic waste products, and a restoration of exhausted enzyme systems and energy sources. Nevertheless, none of the two described preservation methods has been able to play a dominant role in clinical organ preservation.

Another approach to stimulate anabolic metabolism during preservation in order to prolong adequate preservation time, could be the perfusion of organs at warmer temperatures (31). In an environment where renal metabolism is continuously supported instead of inhibited and waste products are removed, the limitations of static storage may be avoided. In this study we used a limited period of warm perfusion with EMS technology as a tool to identify the deleterious effects of CI on renal metabolism and function. Our next goal is to apply EMS technology to successfully perfuse organs over a longer period of time thereby eliminating cold preservation as a whole. Obviously obstacles will need to be overcome before warm perfusion preservation can become a reality. Issues concerning contamination, long term metabolic support, are just a few of the areas which will need to be addressed. Nevertheless there is growing evidence postulating the feasibility of warm temperature organ preservation (32-35).

The present study focused on the impact of CI on the kidney prior to reperfusion. A better understanding of this injury may facilitate in the development more effective preservation technologies designed to minimize the ischemic damage. Using EMS perfusion we were able to observe a loss of function after 24 hours of $\mathrm{CI}$ and a reduction of cell viability after 48 hours. With the clinically available cold storage techniques, the currently held view in clinical transplantation of attempting to routinely limit $\mathrm{CI}$ to 24 hours appears to be justified. 


\section{REFERENCES}

1. Chertow GM, Milford EL, Mackenzie HS, Brenner BM. Antigen-independent determinants of cadaveric kidney transplant failure. JAMA 1996; 276 (21): 1732.

2. Najarian JS, Gillingham KJ, Sutherland DE, Reinsmoen NL, Payne WD, Matas AJ. The impact of the quality of initial graft function on cadaver kidney transplants. Transplantation 1994; 57 (6): 812.

3. Nicholson ML, Wheatley T], Horsburgh T, Edwards CM, Veitch PS, Bell PR. The relative influence of delayed graft function and acute rejection on renal transplant survival. Transpl Int 1996; 9 (4): 415.

4. Ojo AO, Wolfe RA, Held PJ, Port FK, Schmouder RL. Delayed graft function: risk factors and implications for renal allograft survival [see comments]. Transplantation 1997; 63 (7): 968.

5. Peters TG, Shaver TR, Ames JEt, Santiago Delpin EA, Jones KW, Blanton JW. Cold ischemia and outcome in 17,937 cadaveric kidney transplants. Transplantation 1995; 59 (2): 191.

6. Shoskes DA, Halloran PF. Delayed graft function in renal transplantation: etiology, management and long-term significance. J Urol 1996; 155 (6): 1831.

7. Troppmann C, Gillingham KJ, Benedetti E, et al. Delayed graft function, acute rejection, and outcome after cadaver renal transplantation. The multivariate Nalysis. Transplantation 1995; 59 (7): 962.

8. Troppmann C, Gillingham KJ, Gruessner RW, et al. Delayed graft function in the absence of rejection has no long-term impact. A study of cadaver kidney recipients with good graft function at 1 year after transplantation. Transplantation 1996; 61 (9): 1331.

9. Jacobson HR. Ischemic renal disease: An overlooked clinical entity? Kidney Int 1988; 34: 729.

10. Molitoris BA, Nelson W]. Alterations in the establishment and maintenance of epithelial cell polarity as a basis for disease processes. J Clin Invest 1990; 85: 3.

11. Rosenthal JT, Danovitch GM, Wilkinson A, Ettenger RB. The high cost of delayed graft function in cadaveric renal transplantation. Transplantation 1991; 51 (5): 1115.

12. Yokoyama I, Uchida K, Kobayashi T, Tominaga Y, Orihara A, Takagi H. Effect of prolonged delayed graft function on long-term graft outcome in cadaveric kidney transplantation. Clin Transplant 1994; 8 (2 Pt 1): 101.

13. Southard $\mathrm{JH}$. Biochemistry and cell physiology of organ preservation. In: Collins GM, Dubernard JM, Land W and Persijn GG (eds) Procurement, Preservation and Allocation of Vascularized Organs. Kluwer, Dordrecht 1997: 103.

14. Granger DN, Korthuis RJ. Physiologic mechanisms of postischemic tissue injury. Annu Rev Physiol 1995; 57: 311.

15. Grisham MB, Granger DN, Lefer DJ. Modulation of leukocyte-endothelial interactions by reactive metabolites of oxygen and nitrogen: relevance to ischemic heart disease. Free Radic Biol Med 1998; 25 (4-5): 404.

16. Kurose I, Wolf R, Grisham MB, Granger DN. Modulation of ischemia/reperfusion-induced microvascular dysfunction by nitric oxide. Circ Res 1994; 74 (3): 376.

17. Gute DC, Ishida T, Yarimizu K, Korthuis RJ. Inflammatory responses to ischemia and reperfusion in skeletal muscle. Mol Cell Biochem 1998; 179 (1-2): 169.

18. Massberg S, Messmer K. The nature of ischemia/reperfusion injury. Transplant Proc 1998; 30 (8): 4217.

19. Sutton TA, Molitoris BA. Mechanisms of cellular injury in ischemic ARF. Semin Nephrol 1998; 18: 490 .

20. Thadhani R, Pascual M, Bonventre JV. Acute renal failure. NEJM 1996; 334: 148.

21. Goligorsky MS, DiBona GF. Pathogenetic role of Arg-Gly-Asp-recognizing integrins in acute renal failure. off. Proc Natl Acad Sci U S A 1993; 90 (12): 5700. 
22. Racusen LC, Fivush BA, Li YL, Slatnik I, Solez K. Dissociation of tubular cell detachment and tubular cell death in clinical and experimental "acute tubular necrosis". Lab Invest 1991; 64 (4): 546.

23. Marshall V. Preservation by simple hypothermia. In: Collins GM, Dubernard JM, Land W and Persijn GG (eds) Procurement, Preservation and Allocation of Vascularized Organs. Kluwer, Dordrecht 1997: 115.

24. Belzer FO, Ashby BS, Dunphy JE. 24-hour and 72-hour preservation of canine kidneys. Lancet 1967; 2 (7515): 536.

25. Maessen JG, van der Vusse GJ, Vork M, Kootstra G. Intermediate normothermic perfusion during cold storage of ischemically injured kidneys. Transplant Proc 1989; 21 (1 Pt 2): 1252.

26. Wijk van der J, Slooff MJ, Rijkmans BG, Kootstra G. Successful 96- and 144-hour experimental kidney preservation: a combination of standard machine preservation and newly developed normothermic ex vivo perfusion. Cryobiology 1980; 17 (5): 473.

27. Wijk van der J, Rijkmans BG, Kootstra G. Six day kidney preservation in a canine model. Influence of a one to four hour ex-vivo perfusion interval. Transplantation 1982; 35 (5): 408.

28. Henry ML, Sommer BG, Tesi RJ, Ferguson RM. Improved immediate renal allograft function after initial simple cold storage. Transplant Proc 1990; 22 (2): 388.

29. Mc Anulty JK, Ploeg RJ, Southard JH, Belzer FO. Successful five-day perfusion preservation of the canine kidney. Transplantation 1989; 47 (1): 37.

30. McAnulty JF, Vreugdenhil PK, Southard JH, Belzer FO. Improved survival of kidneys preserved for seven days with a phospholipase inhibitor. Transpl Proc 1991; 23 (1): 691.

31. Stubenitsky BM, Booster MH, Nederstigt AP, Kievit JK, Jacobs RW, Kootstra G. Kidney preservation in the next millenium. Transpl Int 1999; 12 (2): 83.

32. Brasile L, Green E, Haisch C. Ex vivo resuscitation of kidneys following postmortem warm ischemia. Transplant Proc 1997; 29: 3518.

33. Brasile L, Green E, Haisch C. Warm ex vivo perfusion prevents reperfusion injury in warm ischemically damaged kidneys. Transplant Proc 1997; 29: 3422.

34. Haisch C, Thomas F, Green E, Brasile L. Evaluating renal allograft function prospectively. Transplant Proc 1996; 28 (1): 363.

35. Haisch C, Green E, Brasile L. Predictors of graft outcome in warm ischemically damaged organs. Transplant Proc 1997; 29: 3424. 
CHAPTER 4.II

Negative effect of cold ischemia on initial renal function

BM Stubenitsky, MH Booster, L Brasile, EM Green, FHW Hermens, OB Stroosma, G Kootstra

ASAIO Journal 2000; 46(1): 60 


\section{A B STRACT}

Correlation between posttransplant function and the exposure to cold ischemia (Cl) during preservation has been reported. We attempted to identify the effect of $\mathrm{Cl}$ on renal function using Exsanguinous Metabolic Support (EMS) technology, to eliminating the effects of reperfusion complications. Small bovine kidneys were used to evaluate 4 vs. $24 \mathrm{hrs}$ of $\mathrm{Cl}$, after warm ischemic (WI) exposure of $<15,30$ or $60 \mathrm{~min}$. After $\mathrm{Cl}$, kidneys were ex vivo warm perfused $\left(30-32^{\circ} \mathrm{C}\right)$ ex vivo using EMS technology. Restored renal metabolism and function were quantified by oxygen consumption, urine production, glomerular filtration rate (GFR), and hemodynamic characteristics. The results demonstrate a $\mathrm{Cl}$ associated lag-phase in the restoration of metabolism, in which the longer cold preserved kidneys exhibit a lower initial rate of oxygen consumption. However, after 3 hours of EMS perfusion there was no significant difference in the $\mathrm{O}_{2}$ consumed, urine flow, GFR, perfusion flow, and pressure between the kidneys stored for 4 or $24 \mathrm{hrs}$. An initial reduction in metabolism after longer $\mathrm{Cl}$ may influence the severity of the actual reperfusion injury during transplantation. Therefore, these results provide preliminary evidence suggesting that an acellular warm temperature reperfusion ex vivo may enhance restoration of cellular metabolism and minimize damage from the cold seen upon actual reperfusion from the cold. 


\section{INTRODUCTION}

The negative effect of hypothermic preservation on posttransplant function has been long recognized $(1,2)$. This negative effect of cold ischemia $(\mathrm{CI})$ is even more dramatic in kidneys harvested from non-heartbeating (NHB) donors. It is difficult to separate injury produced by $\mathrm{CI}$ per se from injury occurring during reperfusion. Reperfusion initiates a complex interplay between the endothelium, different types of blood cells, and resident leukocytes, adding to the injury obtained during CI.

We attempted to identify the effect of $\mathrm{CI}$ alone on renal metabolism and function using Exsanguinous Metabolic Support (EMS) technology, an acellular ex vivo warm perfusion technology, to eliminating the deleterious effects of actual reperfusion.

\section{MATERIALS AND METHODS}

\section{Animal model}

Bovine kidneys were harvested from 7 day old calves scheduled for slaughter. The kidneys, weighing 70-100 grams, were excised immediately after the animals were killed via a captive bolt from a humane stunner to the cerebrum. . Post mortem warm ischemic (WI) exposure was induced for either $<15$ minutes, 30 minutes, or 60 minutes. Following the warm ischemic insults, a cannula was placed in the renal artery after which the kidneys were flushed $(200 \mathrm{ml})$ and statically stored in storage solution (ViaSpan) at $4^{\circ} \mathrm{C}$. Cold ischemia (CI) times were either 4 or 24 hours ( $\mathrm{n}=4$ in all 6 groups).

\section{EMS technology}

After the designated CI periods, the kidneys were re-flushed $(200 \mathrm{ml})$ and transitioned to a warm temperature perfusion $\left(32^{\circ} \mathrm{C}-34^{\circ} \mathrm{C}\right)$ system including an oxygenator and a pulsatile pump, retrofitted with controllers to maintain $\mathrm{PaO}_{2}$, $\mathrm{PaCO}_{2}, \mathrm{pH}$, and temperature (Breonics, Inc.). Both flush solution and perfusate consisted of a highly enriched tissue culture-like solution comprising more than 70 ingredients including amino acids, lipids, carbohydrates, ions, proteins, trophic factors, vasodilators, and adenine compound substrates, adjusted to a $\mathrm{pH}$ of 7.4 (Breonics, Inc.). The perfusate was supplemented with an oxygen carrier (perfluorocarbon emulsion) to provide adequate oxygen to support ongoing renal metabolism. 
Metabolism was assessed by measuring the renal oxygen consumption during EMS perfusion. $\mathrm{PaO}_{2}$ analysis of pre-renal and post-renal samples were performed on a Radiometer ABL5 blood gas analyzer. Oxygen consumption $(\mathrm{ml} / \mathrm{min} / 100 \mathrm{~g})$ was calculated using the following formula:

$$
\text { Oxygen consumption }=\frac{\left(\mathrm{PaO}_{2} \text { art }-\mathrm{PaO}_{2} \text { ven }\right) \times \text { flow rate }}{\text { weight }} \times 100
$$

Function was assessed by urine production $(\mathrm{ml} / \mathrm{min} / 100 \mathrm{~g})$ during EMS perfusion. Furthermore, creatinine was added to the re-circulated perfusate as a tracer molecule at a starting concentration of $6 \mathrm{mg} / \mathrm{dL}$. This allowed for urinalysis of tracer creatinine using an Ames Seralyzer III. Glomerular filtration rate (GFR) $(\mathrm{ml} / \mathrm{min} /$ $100 \mathrm{~g}$ ) was then calculated by:

$$
\mathrm{GFR}=\frac{\text { creatinine concentration urine } \times \text { diuresis }}{\text { creatinine concentration perfusate }}
$$

Flow and pressure where monitored during warm perfusion and used to calculate vascular resistance:

$$
\text { Vascular resistance }=\frac{\text { mean arterial pressure }}{\text { mean flow rate }}
$$

All values reported are means with their standard error of the mean (SEM). The Mann-Whitney U-Test was used for statistical analysis with the level of significance set at $5 \%$.

\section{RESULTS}

\section{Oxidative metabolism}

Within 60 minutes of starting perfusion, the oxygen consumption of all kidneys stabilized and remained constant during the perfusion period. The initial phase of warm perfusion revealed a clear difference between 4 and 24 hours of CI, indicating a negative effect of longer CI on initial renal metabolism (figure 1). However, following the 3 hours of EMS perfusion, there were no significant differences in the oxygen consumed between the 4 and the 24 hours stored kidneys 


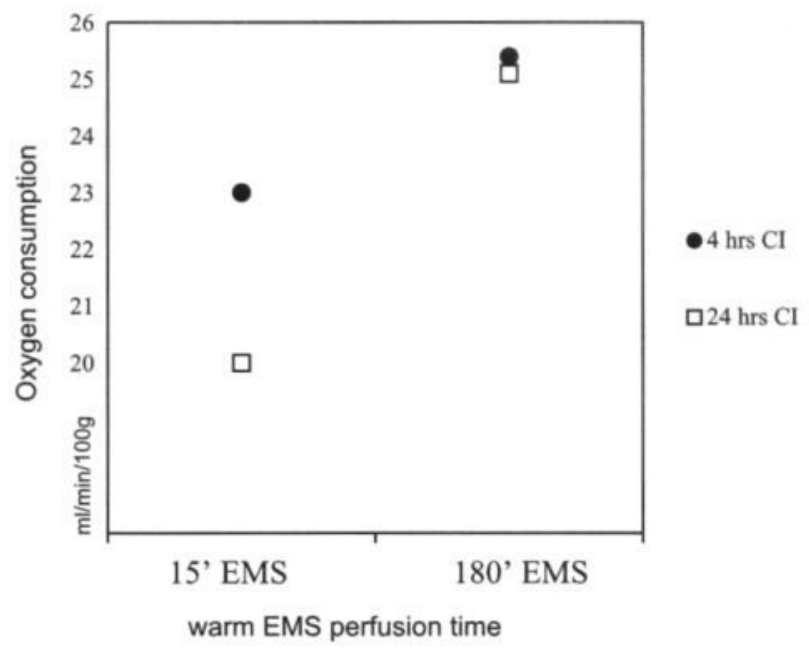

FIGURE 1. Mean Oxygen Consumption ( $\mathrm{ml} / \mathrm{min} / 100 \mathrm{~g}$ ) vs. EMS perfusion time.

(table 1). In contrast, differences in oxygen consumption were observed to correlate with the degree of WI exposure (table 1).

\section{Vascular dynamics}

Pulsatile EMS perfusion resulted in mean arterial pressures of 38 to $45 \mathrm{mmHg}$ with flow rates of 95 to $130 \mathrm{ml}$ per minute. During EMS perfusion, perfusate flow and mean arterial pressure calculated as the vascular resistance were not different in test groups exposed to 4 or 24 hours of CI. There was a tendency towards a slight decrease in vascular resistance as the WI insult increased; however, none of these differences reached statistical significance

\section{Organ function}

Following 3 hours of warm perfusion, urine flow and GFR proved to be similar between 4 and 24 hours of $\mathrm{CI}$ (table 1 ). As seen with renal metabolism, differences in function correlated with the degree of WI exposure (table 1). 
TABLE 1. Metabolism \& Function after 3 hours of EMS perfusion.

\begin{tabular}{|c|c|c|c|c|c|c|}
\hline \multirow[b]{2}{*}{ WI } & \multicolumn{2}{|c|}{$\mathrm{O}_{2}$ cons. $(\mathrm{ml} / \mathrm{min} / 100 \mathrm{~g})$} & \multicolumn{2}{|c|}{ diuresis $(\mathrm{ml} / \mathrm{min} / 100 \mathrm{~g})$} & \multicolumn{2}{|c|}{ GFR $(\mathrm{ml} / \mathrm{min} / 100 \mathrm{~g})$} \\
\hline & $4 \mathrm{hrs} \mathrm{Cl}$ & 24 hrs Cl & $4 \mathrm{hrs} \mathrm{Cl}$ & 24 hrs Cl & $4 \mathrm{hrs} \mathrm{Cl}$ & $24 \mathrm{hrs} \mathrm{Cl}$ \\
\hline$<15^{\prime}$ & $27 \pm 4$ & $29 \pm 3$ & $0.13 \pm 0.03$ & $0.16 \pm 0.07$ & $0.16 \pm 0.07$ & $0.18 \pm 0.10$ \\
\hline $30^{\prime}$ & $28 \pm 2$ & $26 \pm 2$ & $0.03 \pm 0.008$ & $0.03 \pm 0.008$ & $0.05 \pm 0.01$ & $0.05 \pm 0.01$ \\
\hline $60^{\prime}$ & $20 \pm 3$ & $20 \pm 2$ & $0.02 \pm 0.003$ & $0.02 \pm 0.007$ & $0.02 \pm 0.005$ & $0.02 \pm 0.007$ \\
\hline
\end{tabular}

data expressed as means \pm SEM. $0_{2}$ cons. = oxygen consumption; $G F R=$ glomerular filtration rate.

\section{DISCUSSION}

These results suggest that EMS perfusion with an acellular perfusate is suitable for determining the effects of renal preservation on kidney metabolism and function prior to reperfusion. Furthermore, this study demonstrates a CI associated lag-phase in the restoration of metabolism, in which the longer cold preserved kidneys exhibit a lower initial rate of oxygen consumption.

This initially reduction in renal metabolism following longer CI may influence the severity of the actual reperfusion injury during transplantation. If energy-rich phosphates are depleted and active transmembrane ion transport systems are severely inhibited, reperfusion with blood will lead to the accumulation of ions accompanied by an influx of water, resulting in cell swelling of especially the endothelial cells $(3,4)$. This swelling, together with the loss of fluid from the intravascular space and stiffening of blood cells (mainly leukocytes) caused by acidosis, can cumulatively hinder restoration of microvascular blood flow during reperfusion and lead to capillary obstruction ('no reflow' phenomenon) (5).

A significant post-ischemic reperfusion injury negatively affects outcome, and strategies to ameliorate this injury would be important. Re-establishing renal metabolism prior to actual reperfusion could potentially enhance the detrimental injury cascade seen after ischemia-reperfusion.

These results provide preliminary evidence suggesting that an acellular ex vivo warm temperature reperfusion ex vivo may enhance restoration of cellular metabolism and minimize damage seen upon actual reperfusion from the cold. 


\section{REFERENCES}

1. Shoskes DA, Cecka JM. Deleterious effects of delayed graft function in cadaveric renal transplant recipients independent of acute rejection. Transplantation 1998; 66 (12): 1697.

2. Abendroth D. Decreasing the cold ischemia time. Transplant Proc 1998; 30 (8): 4288.

3. Massberg S, Messmer K. The nature of ischemia/reperfusion injury. Transplant Proc 1998; 30 (8): 4217.

4. Gute DC, Ishida T, Yarimizu K, Korthuis RJ. Inflammatory responses to ischemia and reperfusion in skeletal muscle. Mol Cell Biochem 1998; 179 (1-2): 169.

5. Ames Ad, Wright RL, Kowada M, Thurston JM, Majno G. Cerebral ischemia. II. The no-reflow phenomenon. Am J Pathol 1968; 52 (2): 437. 

CHAPTER 5

\section{Ex vivo vability testing of kidneys after postmortem warm ischemia}

BM Stubenitsky, MH Booster, L Brasile, EM Green, CE Haisch, HK Singh, RWA Jacobs, G Kootstra

ASAIO Journal 2000; 46(1): 62 


\section{A B STRACT}

Future approaches to expand the organ donor pool with marginal and non-heartbeating donors, will be dependent upon prospective organ evaluation. Restoration of metabolism by preservation at warmer temperatures could potentially provide the window for such evaluation. Using a small bovine model, kidneys were subjected to either $<15,30$ or 60 minutes of warm ischemia (WI) followed by cold storage $(\mathrm{Cl})$ in ViaSpan. After $\mathrm{Wl}$ and $\mathrm{Cl}$, kidneys were transitioned to a warm temperature perfusion $\left(30^{\circ} \mathrm{C}-32^{\circ} \mathrm{C}\right)$ using Exsanguinous Metabolic Support (EMS) technology. Restored renal metabolism and function was assessed by oxygen consumption, glucose consumption, urine production, glomerular filtration rate, and hemodynamic characteristics. The results of this study suggest that it is feasible to distinguish viable from non-viable organs ex vivo by assessing renal metabolism and function during warm preservation using EMS technology. 


\section{INTRODUCTION}

The growing shortage of transplantable organs has renewed the interest in kidneys obtained from marginal and non-heartbeating (NHB) donors. Effective use of these kidneys is hampered due to a higher incidence of delayed- and never function after transplantation. Successful expansion of the existing donor pool with these marginal and non-heartbeating donors will be dependent upon the development of prospective organ evaluation. Historically this evaluation of the viability status has focussed on the vascular resistance, enzyme release, energy charge, electrolyte concentration, and functional studies during preservation at $4^{\circ} \mathrm{C}(1)$. But despite these numerous efforts there is currently no objective method or assay to evaluate the potential function of an organ, making transplantation the only definitive test of graft viability (2). This seems to be, at least in part, due to the hypothermia used in organ preservation which inhibits renal metabolism by $95 \%$ and decreases oxygen consumption exponentially $(3,4)$, making evaluation of renal function virtually impossible.

Restoration of metabolism by preservation at warmer temperatures could potentially provide the setting for such evaluation. Combining existing knowledge, Breonics Inc. has successfully developed an integrated technology that supports aerobic metabolism during preservation at a warmer temperature (5). This Exsanguinous Metabolic Support (EMS) technology was employed to determine the efficacy of prospective evaluation of renal function following post mortem warm ischemia (WI) and hypothermic preservation using small bovine kidneys. Restored renal metabolism and function were quantified by assessing the oxidative metabolism, the vascular dynamics, the urine production, and the glomerular filtration rate (GFR); calculated by the clearance of a creatinine.

\section{MATERIALS AND METHODS}

\section{Animal Model}

Bovine kidneys, weighing 70-100 grams, were harvested from 7 day old calves scheduled for slaughter. The small bovine model was selected because it provided a large and inexpensive source of kidneys of the same approximate size as canine kidneys. It was anticipated that if feasibility was demonstrated in bovine studies, canine transplantation studies could proceed without the need to re-standardize for a different organ size. Previous studies have demonstrated the similarity in results between the two models (6). The small bovine kidneys were excised immediately after the animals were killed via a captive bolt from a humane stunner to the cerebrum. Control kidneys (group 1) had a warm ischemic period of $<15 \mathrm{~min}$. Post mortem WI was induced by keeping the kidneys in a water bath at $37^{\circ} \mathrm{C}$ for either 30 minutes (group 2); or 60 minutes (group 3). Following the warm 
ischemic insults, a cannula was placed in the renal artery after which the kidneys were flushed and stored with $4^{\circ} \mathrm{C}$ ViaSpan for 24 hours.

\section{EMS Technology}

After the CI period, the kidneys were re-flushed and transitioned to a warm temperature perfusion $\left(30^{\circ} \mathrm{C}-32^{\circ} \mathrm{C}\right)$ system including an oxygenator and a pulsatile pump, retrofitted with controllers to maintain $\mathrm{PaO}_{2}, \mathrm{pH}, \mathrm{PaCO}_{2}$, and temperature (Breonics, Inc.). The perfusate consisted of a highly enriched tissue culture-like solution comprising of more than 70 ingredients including amino acids, lipids, carbohydrates, ions, proteins, trophic factors, vasodilators, and adenine compound substrates, adjusted to a $\mathrm{pH}$ of 7.4 (Breonics, Inc.). The perfusate was supplemented with an oxygen carrier to provide adequate oxygen to support ongoing renal metabolism. Pulsatile perfusion resulted in mean arterial pressures of 40 to $47 \mathrm{mmHg}$ with flow rates of 90 to $130 \mathrm{ml}$ per minute.

\section{Evaluation of Renal Metabolism and Function}

Metabolism was assessed by oxygen $(\mathrm{ml} / \mathrm{min} / 100 \mathrm{~g})$ and glucose consumption $(\mathrm{mg} / \mathrm{min} / 100 \mathrm{~g})$ using the following formulas:

$$
\text { Oxygen consumption }=\frac{\left(\mathrm{PaO}_{2} \text { art }-\mathrm{PaO}_{2} \text { ven }\right) \times \text { flow rate }}{\text { weight }} \times 100
$$

$$
\text { Glucose consumption }=\frac{(\text { glucose } t=0 \mathrm{~min})-(\text { glucose } t=60 \mathrm{~min})}{\text { weight } \times 60} \times 100
$$

$\mathrm{PaO}_{2}$ analysis of pre-renal and post-renal perfusate samples were performed on a Radiometer ABL5 blood gas analyzer.

Function was assessed by urine production $(\mathrm{ml} / \mathrm{min} / 100 \mathrm{~g})$ and GFR $(\mathrm{ml} / \mathrm{min} / 100 \mathrm{~g})$. Creatinine was added to the re-circulated perfusate as a tracer molecule at a starting concentration of $6 \mathrm{mg} / \mathrm{dL}$. The ureter was cannulated tie and all urine produced after the 1 st hour of warm perfusion was collected. The urine was tested for urinary concentrations of tracer creatinine using an Ames Seralyzer III. GFR was calculated by:

$$
\mathrm{GFR}=\frac{\text { creatinine concentration urine } \times \text { diuresis }}{\text { creatinine concentration perfusate }}
$$


Flow and pressure where monitored during warm perfusion and used to calculate vascular resistance. Following the 3 hour perfusion period, wedge-shaped biopsies were taken and fixed in $4 \%$ neutral-buffered formalin, dehydrated and paraffin embedded. Section of 4 um were cut and stained using haematoxylin and eosin for light macroscopic evaluation. Morphological characteristics of the kidneys were evaluated by blinded histologic evaluation.

\section{Data Analysis}

All values reported are means with their standard error of the mean. For statistical analysis of differences in obtained data between the experimental groups at set time points the Mann-Whitney U-Test was used. The level of significance was set at $5 \%$.

\section{RESULTS}

\section{Metabolism}

Oxygen consumption was found to diminish as the WI insult increased (figure 1). In group 1, the mean oxygen consumption during the EMS perfusion was 27 $\mathrm{ml} / \mathrm{min} / 100 \mathrm{~g}$. As the WI period increased to 30 minutes (group 2), the oxygen consumption decreased to $23 \mathrm{ml} / \mathrm{min} / 100 \mathrm{~g}$, and was further reduced in group 3 $(21 \mathrm{ml} / \mathrm{min} / 100 \mathrm{~g})$. The differences in oxygen consumption between group 1 and group 3 reached statistical significance $(\mathrm{p}<0.05)$.

Likewise, glucose consumption slightly decreased with the increasing WI. Although there was no difference between groups 1 and 2 (mean of 0.80 and 0.79 $\mathrm{ml} / \mathrm{min} / 100 \mathrm{~g}$ respectively), glucose consumption was reduced to $0.70 \mathrm{mg} / \mathrm{min} /$ $100 \mathrm{~g}$ in group 3 (no significance).

\section{Function}

The loss of renal function expressed by a marked reduction in both urine flow and GFR (figure 2) was observed as the duration of the post mortem WI increased. In the minimally damaged kidneys (group 1 ) mean urine production was 0.2 $\mathrm{ml} / \mathrm{min} / 100 \mathrm{~g}$ and mean GFR was $0.27 \mathrm{ml} / \mathrm{min} / 100 \mathrm{~g}$. The urine production dropped by approximately $98 \%$ when WI was increased $(0.033 \mathrm{ml} / \mathrm{min} / 100 \mathrm{~g}$ in group 2 and to $0.017 \mathrm{ml} / \mathrm{min} / 100 \mathrm{~g}$ in group 3 ). GFR was reduced to respectively $0.05 \mathrm{ml} / \mathrm{min} / 100 \mathrm{~g}$ and $0.017 \mathrm{ml} / \mathrm{min} / 100 \mathrm{~g}$ in groups 2 and 3, respectively, indicating severe loss of renal function. The differences between the three group all reached statistical significance $(\mathrm{p}<0.05)$. 


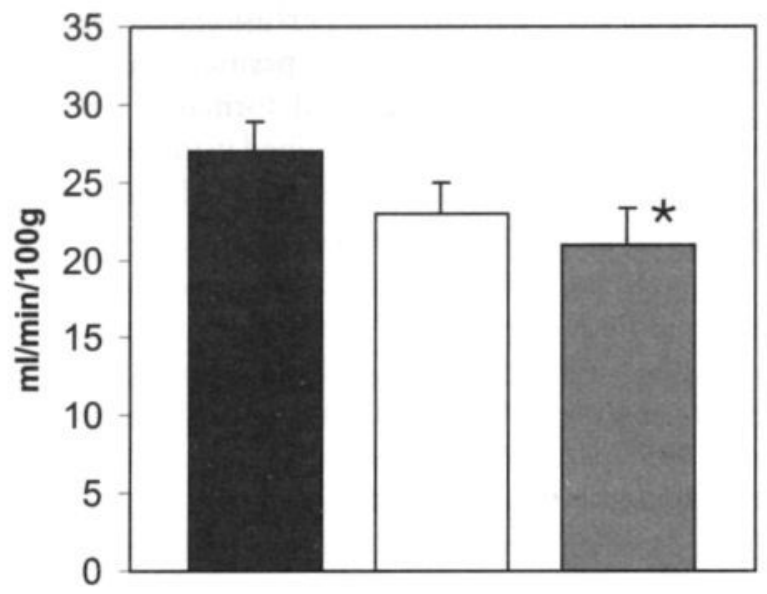

\begin{tabular}{|l|}
$\square$ group 1 \\
$\square$ group 2 \\
$\square$ group 3 \\
\hline
\end{tabular}

FIGURE 1. Oxygen Consumption during EMS perfusion ( $\mathrm{ml} / \mathrm{min} / 100 \mathrm{~g})$.

Data expressed as means with their standard error of mean. group $1 \quad(n=13)$ $<15^{\prime} \mathrm{Wl}$ followed by $\mathrm{Cl}$; group $2(n=10) 30^{\prime} \mathrm{Wl}$ followed by $\mathrm{Cl}$; group $3(n=14)$ $60^{\prime} \mathrm{WI}$ followed by $\mathrm{Cl}^{*}{ }^{*}=\mathrm{p}<0.05$ between group 1 and 3 .
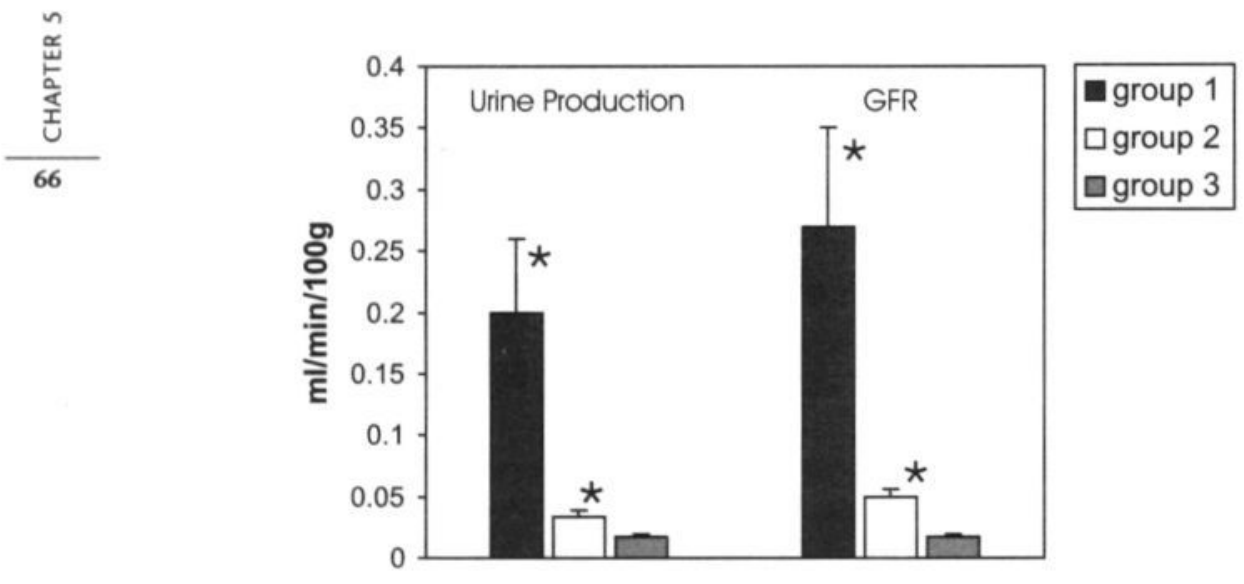

FIGURE 2. Urine Production \& Glomerular Filtration Rate $(\mathrm{ml} / \mathrm{min} / 100 \mathrm{~g})$.

Data expressed as means with their standard error of mean. group $1 \quad(n=13)$ $<15^{\prime} \mathrm{Wl}$ followed by $\mathrm{Cl}$; group $2(n=10) 30^{\prime} \mathrm{Wl}$ followed by $\mathrm{Cl}$; group $3(n=14)$ $60^{\prime} \mathrm{Wl}$ followed by $\mathrm{Cl}^{*}{ }^{*}=\mathrm{p}<0.05$ between all groups. 


\section{Hemodynamic characteristics}

Perfusion flow during EMS perfusion was stable and not significantly different between the three groups (means of respectively $104.5 ; 109.8 ;$ and $115.7 \mathrm{ml} / \mathrm{min}$ ), although there was a tendency towards a slightly higher flow as the WI insult increased. Related to the observed flow, there was a decrease in vascular resistance as the WI insult was extended (means of respectively $0.43 ; 0.40$; and 0.37 ). However none of these differences between the groups reached statistical significance.

\section{Histologic evaluation}

Light microscopic analysis revealed no signs of vascular or glomerular damage in all three groups. However the severity and occurrence of tubular degeneration augmented as the warm ischemic insult increased from $<15$ to 60 minutes of WI $(16 \%, 25 \%, 80 \%$, respectively). Patchy lesions with swollen tubular cell cytoplasm indicative for early stage ischemic damage were observed in group 1 . This same phenomena was seen in group 2, although the occurrence of the lesions was more frequent, not only including the proximal tubule, but also the distal tubule. group 3, the most severely affected, demonstrated loss of tubular epithelium, necrosis of epithelial cells, and the presence of shed cells in lumen, causing tubular obstruction.

\section{DISCUSSION}

We have demonstrated the restoration of renal metabolism (oxygen- and glucose consumption) and function (urine production and GFR) after WI and CI using EMS technology.

The reduction of metabolism with increasing WI damage, expressed by the oxygen and glucose consumption during EMS perfusion, can be interpreted as the loss of cellular viability due to ischemia. The results suggest that WI periods exceeding 30 minutes, compromise renal metabolism. However, loss of renal function occurred sooner, with a marked deterioration of urine flow and GFR by 30 minutes of WI, indicating the existence of acute tubular necrosis (ATN). Blinded histologic evaluation furthermore exhibited a high degree of correlation between the diminished urine flow and GFR and the development of ATN.

With the ever growing shortage of kidneys for transplantation, the marginal and NHB donors represent a valuable source for additional organs. Daemen et al. estimated a 2 to 4.5 fold increase in the number of kidneys available for transplantation with effective use of the pool of potential NHB kidneys (7). Effective evaluation of renal function before transplantation appears to be a necessity within these donor sources. Based upon the metabolic and functional results, we believe 
this study indicates the potential of ex vivo warm perfusion as a tool for prospective organ evaluation.

\section{REFERENCES}

1. Daemen JHC, Wit de R], Heineman E, Kootstra G. Viability testing during organ preservation. Transplant Reviews 1995; 9: 159.

2. Kootstra G. The asystolic, or non-heartbeating, donor. Transplantation 1997; 63 (7): 917.

3. Bickford RJ, Winton FR. The influence of temperature on the isolated dog kidney. J Physiol, Lond 1937; 89: 198.

4. Levy MN. Oxygen consumption and blood flow in the hypothermic, perfused kidney. Am I Physiol 1959; 197: 11.

5. Brasile L, Clarke J, Green E, Haisch C. The feasibility of organ preservation at warmer temperatures. Transplant Proc 1996; 28 (1): 349.

6. Brasile L, Green E, Haisch C. Ex vivo resuscitation of kidneys following postmortem warm ischemia. Transplant Proc 1997; 29: 3518.

7. Daemen JW, Oomen AP, Kelders WP, Kootstra G. The potential pool of non-heart-beating kidney donors. Clin Transplant 1997; 11 (2): 149. 
CHAPTER 6

Exsanguinous Metabolic Support perfusion - a new strategy to improve graft function after kidney transplantation

BM Stubenitsky, MH Booster, L Brasile,

D Araneda, CE Haisch, G Kootstra

Transplantation; accepted 


\section{A B STRACT}

Background. The compounding damage of warm ischemia (WI) followed by cold preservation is a major barrier in renal transplantation. Although the relative effect of $\mathrm{Wl}$ is not yet well understood, therapeutic strategies have mostly focused on minimizing the pathology seen upon reperfusion from the cold.

The present study was designed to examine the effect of restoration of renal metabolism by warm perfusion on graft survival and to investigate the compounding damage of Wl.

Methods. Using a known critical canine autotransplantation model (1), kidneys were exposed to 30 minutes WI followed by 24 hours cold storage in Viaspan. They were then either reimplanted directly or first transitioned to 3 hours of warm perfusion with an acellular perfusate prior to reimplantation. Contralateral kidneys were subjected to 0,30 , or 60 minutes Wl; 24 hours cold storage, and 3 hours warm perfusion.

Results. Transplanted kidneys that were warm perfused prior to reimplantation had both lower 24 hours posttransplant serum creatinine (median of 3.2 vs 4.1 $\mathrm{mg} / \mathrm{dL}$ ) and lower peak serum creatinine (median of $4.95 \mathrm{vs} 7.1 \mathrm{mg} / \mathrm{dL}$ ). Survival rate for warm perfused kidneys was $90 \%(9 / 10)$ vs $73 \%(8 / 11)$.

In the contralateral kidneys, metabolism was affected by the compounding damage of WI. Renal oxygen and glucose consumption diminished significantly, whereas vascular resistance and LDH-release rose significantly with increasing WI. Conclusions. The results demonstrate a reduction of reperfusion damage by an acellular ex vivo restoration of renal metabolism. Furthermore, data from the contralateral kidneys substantiates the relative role of WI on metabolism in renal transplantation. 


\section{INTRODUCTION}

Since the availability of organs is limited, the use of ischemically damaged kidneys for transplantation is increasing. Unfortunately the posttransplant outcome with these kidneys is characterized by a high incidence of delayed function and primary non-function (PNF). Major contributing factors of the organ injury are the detrimental effects WI followed by cold preservation and reperfusion $(2,3)$. Warm ischemia causes damage through a gradual process in which biochemical alterations lead to functional impairment, followed by structural changes (4). Although warm ischemic damage has been shown to reduce the duration of effective cold preservation in renal transplantation, the influence of WI on reperfusion following cold preservation is not clear.

Cold ischemia reduces the tissue's metabolic demands for nutrients and oxygen, thereby lengthening the period during which an anoxic organ retains viability, however this inhibition of metabolism has been known to influence the severity of the reperfusion injury (5). The organ injury caused by reperfusion arises from the acute generation of radical oxygen species subsequent to reoxygenation, which inflict direct tissue damage and initiate a cascade of deleterious cellular responses leading to inflammation, cell death and organ failure. Any attempt to lower the high incidence of delayed function and PNF seen in ischemically damaged kidneys should focus on reduction of the reperfusion injury, and on an understanding of the relative role of WI that compounds the damage seen after reperfusion from the cold.

Since reperfusion injury in renal transplantation occurs following a period of inhibited metabolism, it is logical to reestablish the metabolism prior to the actual reperfusion. It seems very unlikely that the hypothermic preservation methods currently used could sustain this active process, since hypothermia inhibits metabolism by $95 \%(6,7)$. The development of a warm perfusion technology with an acellular perfusate designed to reduce the injury could present an opportunity for ex vivo restoration of metabolism prior to reimplantation. To test this hypothesis a critical canine autotransplantation model consisting of an initial insult of 30 minutes of WI followed by cold storage in Viaspan was employed. In previous studies using this model approximately $70 \%$ of the transplanted kidneys eventually regained function, while $30 \%$ succumbed to PNF.

The contralateral kidneys excised at the time of reimplantation of the test kidneys, were used in a separate study to investigate the impact of varying WI insults followed by a constant period of cold preservation on renal metabolism during ex vivo warm perfusion. A better understanding of the injury mechanism, could potentially lead to successful expansion of the donor pool with ischemically damaged kidneys. 


\section{MATERIALS AND METHODS}

\section{Transplantation}

Experiments were performed on 21 mixed foxhounds weighing 35 - 40 kilograms and approximately two years old. The animals received standard kennel food, routine lighting cycle and room temperature, and demonstrated normal renal function prior to the start of the study. All experiments were performed following the principles of laboratory animal care according to the NIH standards. Kidneys were exposed through a midline incision and the left renal artery, vein, and ureter were mobilized. If two renal arteries were present, the right kidney was used. Ten minutes prior to excision, $1,000 \mathrm{U}$ of heparin and $200 \mathrm{mg} / \mathrm{kg}$ of mannitol were administered intravenously. The excised kidney was exposed to 30 minutes of warm ischemia while remaining in the abdominal cavity $\left(37^{\circ} \mathrm{C}\right)$. Following the warm ischemic period the kidney was flushed and statically stored for 24 hours in ViaSpan $\left(4^{\circ} \mathrm{C}\right)$.

The kidneys were then either reimplanted after the period of hypothermic preservation; or transitioned to warm perfusion $\left(32^{\circ} \mathrm{C}\right)$ with an acellular perfusate for 3 hours prior to reimplantation. Fifteen minutes prior to reperfusion, mannitol $(200 \mathrm{mg} / \mathrm{kg})$ and verapamil $(0.1 \mathrm{mg} / \mathrm{kg})$ were administered. The bladder was mobilized and the ureter was anastomosed with the bladder mucosa.

\section{Posttransplant management}

Each day renal function was evaluated by the serum creatinine and BUN values to determine the clinical course. Animals deemed to be in poor condition, with unlikely chance of recovery from the acute tubular necrosis (ATN) were classified as PNF. Canines with PNF were euthanized; animals that survived the experimental period were sacrificed and the transplanted kidney was excised and fixed for histologic evaluation.

\section{Contralateral kidneys}

Contralateral kidneys were subjected to either 0 minutes of WI ( 0 'WI), 30 minutes of WI ( $\left.30^{\prime} \mathrm{WI}\right)$, or 60 minutes of WI (60'WI) by cross clamping the renal artery and vein. Subsequently they were flushed and stored in $4^{\circ} \mathrm{C}$ Viaspan. After 24 hours of cold storage the kidneys were transitioned to ex vivo warm perfusion for 3 hours. Differences in metabolism, vascular resistance, lactate dehydrogenase (LDH) release, aminotransferase (AST \& ALT) release, and gamma-glutamyltranspeptidase (GGT) release during warm perfusion were recorded. 
Exsanguinous Metabolic Support (EMS) technology (Breonics Inc.) was used for ex vivo warm perfusion. Following the period of cold ischemia, the kidneys were temperature transitioned to $32^{\circ} \mathrm{C}$ by flushing and then placed on a pressure controlled perfusion system including an oxygenator and a pulsatile pump, retrofitted with controllers to maintain $\mathrm{PaO}_{2}, \mathrm{PaCO}_{2}, \mathrm{pH}$ and temperature. The renal artery was connected to the perfusion circuit and perfusion begun. The mean arterial pressure (MAP) was kept at approximately 35 , aiming for a pulsatile perfusion pressure of $50 / 30 \mathrm{mmHg}$. The volume of the circulating perfusate was $0,5 \mathrm{~L}$. Both flush solution and perfusate consisted of a highly enriched tissue culture-like solution with contains essential and non-essential amino acids, lipids, carbohydrates, metabolites, inorganic ions, serum proteins, lipids, hormones, nitrogen bases, vitamins, reducing agents, a buffering system, trophic factors, vasodilators, radical scavengers, and adenine compound substrates adjusted to a $\mathrm{pH}$ of 7.4.

This acellular perfusate was supplemented with an oxygen carrier to provide adequate oxygen to support ongoing renal metabolism (i.e. pyridoxylated hemoglobin). Flow and pressure were continuously monitored and used to calculate the vascular resistance. Metabolism was monitored by oxygen $(\mathrm{ml} / \mathrm{min} / 100 \mathrm{~g})$ and glucose consumption $(\mathrm{mg} / \mathrm{min} / 100 \mathrm{~g}$ ) during EMS perfusion using the following formulas:

$$
\begin{aligned}
& \text { Oxygen consumption }=\frac{\left(\mathrm{PaO}_{2} \text { art }-\mathrm{PaO}_{2} \text { ven }\right) \times \text { flow rate }}{\text { weight }} \times 100 \\
& \text { Glucose consumption }=\frac{(\text { glucose } \mathrm{t}=0 \mathrm{~min})-(\text { glucose } \mathrm{t}=60 \mathrm{~min})}{\text { weight } \times 60} \times 100
\end{aligned}
$$

Furthermore perfusate samples for LDH, AST, ALT, and GGT evaluation were taken after 3 hours of EMS perfusion. All values reported are means with their standard error of the mean. For statistical analysis of differences in obtained data between the experimental groups the Student T-test was used. The level of significance was set at $5 \%$.

\section{Histologic evaluation}

At autopsy the implanted kidneys were bisected for gross macroscopic examination. Wedge-shaped biopsies were taken and fixed in $4 \%$ neutral-buffered formalin, dehydrated and paraffin embedded. Four micron sections from each kidney made and stained using haematoxylin and eosin for light macroscopic evaluation. The morphological characteristics of the kidneys were determined by blinded histologic evaluation. 


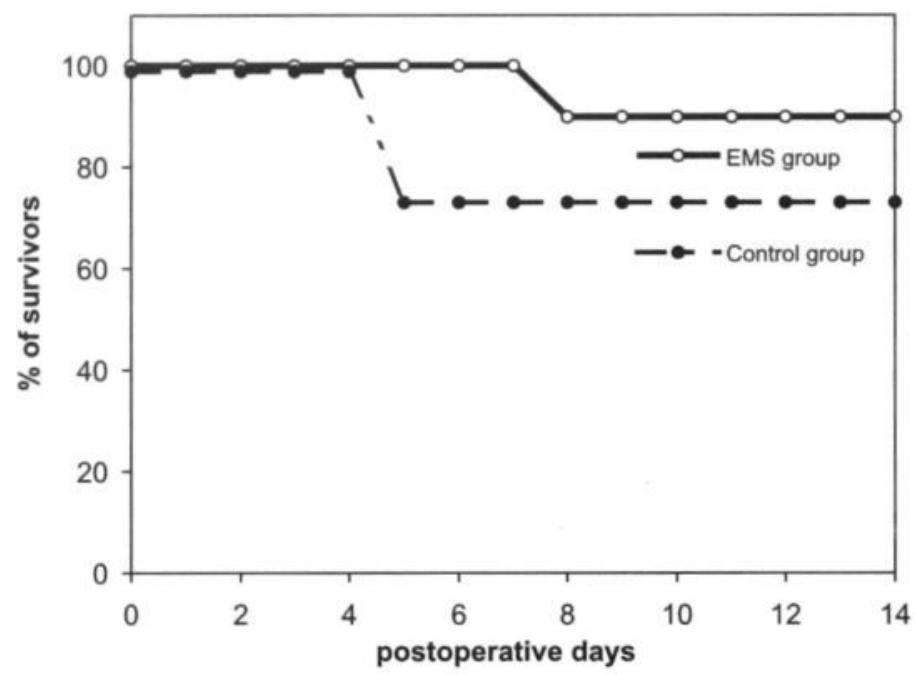

FIGURE 1. Percentage of survival following transplantation.

RESULTS

Effects of EMS perfusion on graft survival (figure 1)

Following 30 minutes of WI and 24 hours of cold storage in Viaspan, grafts were either transplanted directly (control group) or transitioned to 3 hours of EMS perfusion prior to implantation (EMS group). In the control group, $73 \%(8 / 11)$ survived 14 days postoperatively. In the EMS group, reestablishment of metabolism prior to implantation improved survival to $90 \%(9 / 10)$. EMS perfusion also had an effect on duration of graft survival. On day five postoperatively, only $73 \%$ in the control group survived, whereas survival was still $100 \%$ in the EMS group $(\mathrm{p}=0.08)$.

\section{Effect of EMS perfusion on renal damage (figure 2)}

Following transplantation the first urine and daily serum creatinine were posted to determine the clinical course. None of the control kidneys produced urine either on the table or during the first hours postoperatively. The next day the median serum creatinine value was $4.1 \mathrm{mg} / \mathrm{dL}(2.1-6.1 \mathrm{mg} / \mathrm{dL})$. The median peak serum creatinine in the control group was $7.1 \mathrm{mg} / \mathrm{dL}$. In contrast, nine kidneys in the EMS group produced urine within the first four hours of reimplantation. A lower 24 hour median serum creatinine value of $3.2 \mathrm{mg} / \mathrm{dL}(2.0-4.6 \mathrm{mg} / \mathrm{dL})$ was observed; with a lower median peak serum creatinine of $5.0 \mathrm{mg} / \mathrm{dL}$. 


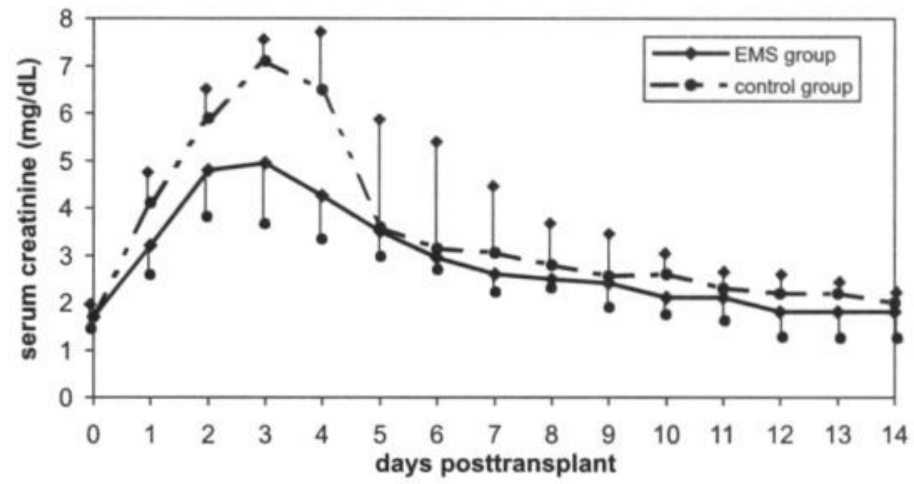

FIGURE 2. Serum creatinine posttransplant.

Median values and interquartile ranges; $25^{\text {th }}$ and $75^{\text {th }}$ percentiles.

\section{Effect of EMS perfusion on histology}

In the nine EMS perfused kidneys exhibiting a reversible ATN with normalization of the serum chemistries, the histologic evaluation of the kidney sections provided evidence of widespread, intermittent cystic dilation of tubules with flattened or regenerating tubular epithelium. There was mild, multifocal mineralization of the cortical tubules. Mild inflammatory infiltrates were found to be associated with areas of regeneration, repair and mineralization. The blood vessels appeared to be normal. The kidney sections from control dogs that eventually recovered, displayed histology similar to that of the nine dogs in the EMS group. The histologic evaluation revealed regenerating tubules, normal blood vessels and the occasional occurrence of proliferative glomerulonephritis.

\section{Effect of WI on renal metabolism (figure 3)}

The contralateral kidneys were subjected to either 0,30 , or 60 minutes of WI followed by 24 hours of cold storage. Kidneys were then transitioned to EMS perfusion for 3 hours. Within 60 minutes of starting EMS perfusion, the oxygen consumption of all kidneys stabilized and remained constant during the perfusion period. However, oxygen consumption was found to diminish as the WI insult increased. In kidneys without WI exposure, the mean oxygen consumption during the EMS perfusion was $18.3 \mathrm{ml} / \mathrm{min} / 100 \mathrm{~g}$. As the WI period increased to 30 minutes, the oxygen consumption decreased to $16 \mathrm{ml} / \mathrm{min} / 100 \mathrm{~g}$, and was observed to be further reduced after 60 'WI to $10.1 \mathrm{ml} / \mathrm{min} / 100 \mathrm{~g}$. The differences in oxygen consumption between 0 'WI \& 60'WI, and 30'WI \& 60'WI reached statistical significance. 


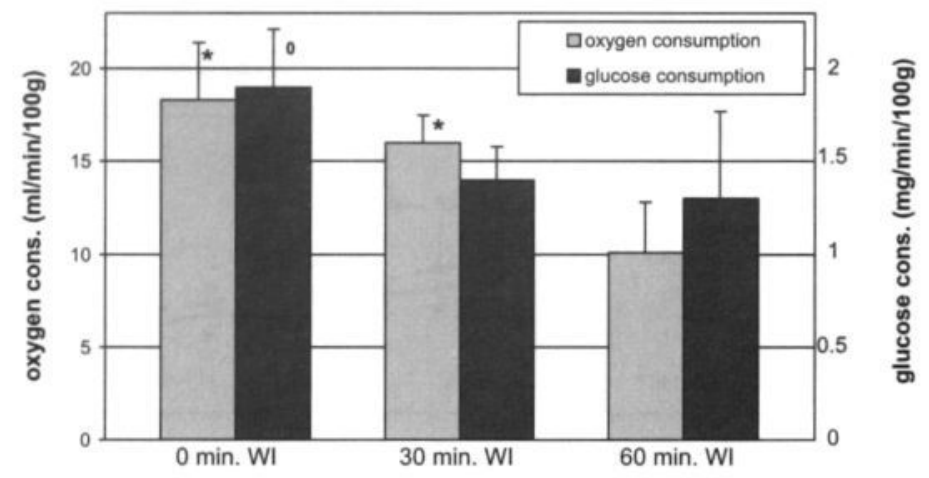

FIGURE 3. Renal metabolism during EMS perfusion.

${ }^{\star}=$ statistically significant with respect to $60^{\prime} \mathrm{WI}(p<0.05)$.

${ }^{\circ}=$ statistically significant with respect to $30^{\prime} \mathrm{WI}$ and $60^{\prime} \mathrm{WI}(\mathrm{p}<0.05)$.

Likewise glucose consumption decreased with the increasing WI. Although there was no significant difference between $30^{\prime} \mathrm{WI}$ and $60^{\prime} \mathrm{WI}$ (mean of 1.4 and 1.3 $\mathrm{mg} / \mathrm{min} / 100 \mathrm{~g}$ respectively), mean glucose consumption was significantly higher $(1.9 \mathrm{mg} / \mathrm{min} / 100 \mathrm{~g})$ in 0 'WI kidneys.

\section{Effects of WI on hemodynamic characteristics (figure 4)}

During the EMS perfusion of the contralaterals, the mean arterial pressure was $33.1 ; 34.9$ and 35.1 in respectively the.0, 30, 60'WI kidneys. Perfusion flow during EMS perfusion remained stable in all three groups during the course of EMS perfusion. Significant differences were observed between 60 'WI and the other two groups, with a tendency towards a lower flow as the WI insult increased (means in 0,30 , and 60 'WI of respectively $111.3 ; 99.1$; and $62.2 \mathrm{ml} / \mathrm{min}$ ). Related to the observed decrease in flow, there was an increase in vascular resistance as the WI insult was extended (means of respectively $0.3 ; 0.4$; and 0.6 ). The differences between 0 'WI \& 30'WI and 0'WI \& 60'WI reached statistical significance.

Effect of WI on LDH, AST, ALT, and GGT release (figure 5)

Only LDH-release was found to increase as the WI insult increased. In 0 'WI kidneys, the mean $\mathrm{LDH}$ release after the EMS perfusion was $450 \mathrm{U} / \mathrm{L} / 100 \mathrm{~g}$. As the WI period increased to 30 minutes, the mean LDH release increased to 510 $\mathrm{U} / \mathrm{L} / 100 \mathrm{~g}$, and was further increased in 60'WI $(675 \mathrm{U} / \mathrm{L} / 100 \mathrm{~g})$. Only the difference between 0 'WI and 60'WI displayed statistical significance. 


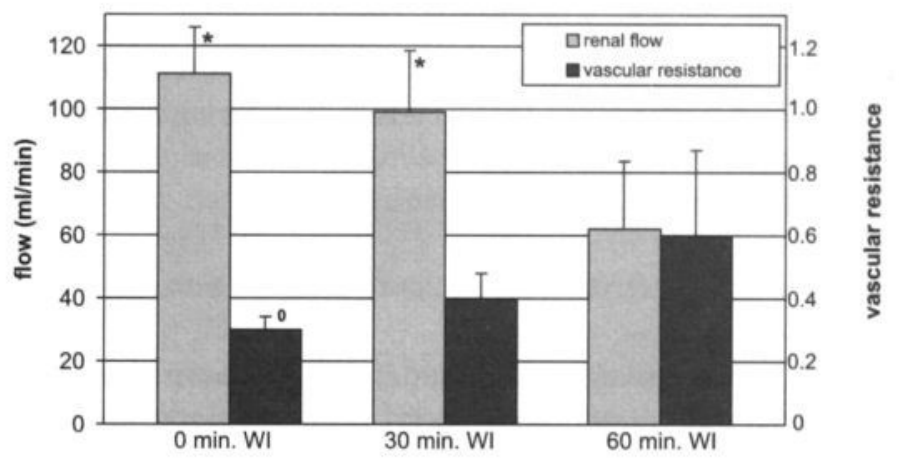

FIGURE 4. Hemodynamic characteristics during EMS perfusion.

${ }^{*}=$ statistically significant with respect to $60^{\prime} \mathrm{WI}(p<0.05)$.

${ }^{\circ}=$ statistically significant with respect to $30^{\prime} \mathrm{WI}$ and $60^{\prime} \mathrm{WI}(\mathrm{p}<0.05)$.

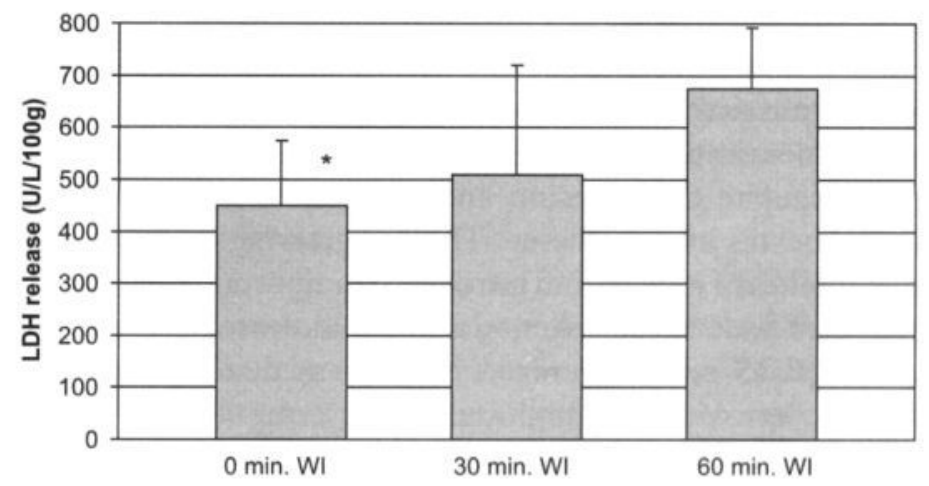

FIGURE S. LDH release during EMS perfusion.

${ }^{\star}=$ statistically significant with respect to $60^{\prime} \mathrm{WI}(\mathrm{p}<0.05)$.

\section{Effect of WI on histology}

Following the 3 hours of EMS perfusion, the contralateral kidneys were bisected for gross macroscopic examination. Wedge-shaped biopsies were taken and fixed in $4 \%$ neutral-buffered formalin, dehydrated and paraffin embedded. Light microscopic analysis revealed no signs of vascular or glomerular damage in all three groups. However the severity and occurrence of tubular degeneration was augmented as the warm ischemic insult increased from 0 to 60 minutes of WI. Patchy lesions with swollen tubular cell cytoplasm indicative of early stage ischemic damage were observed in 0 'WI. This same phenomenon was seen in 30 'WI, although the occurrence of the lesions was more frequent, involving both 
the proximal and the distal tubules. The 60 'WI kidneys were observed to be the most severely affected, demonstrating the loss of tubular epithelium, necrosis of epithelial cells and the presence of shed cells in lumens causing tubular obstruction.

\section{DISCUSSION}

In renal transplantation, warm ischemic damage has been shown to reduce the duration of effective cold preservation and is often associated with the occurrence of delayed function or PNF. Tolerable WI times are therefore reduced when preservation and transplantation follow $(2,3)$.

In order to facilitate the use of ischemically damaged kidneys for transplantation, the detrimental effects of reperfusion and the compounding damage of WI on the graft must be understood. It is well appreciated that reperfusion from a metabolically inactive state results in a microvascular response that exhibits many of the same characteristics as acute inflammation, including endothelial cell injury, fluid accumulation and inflammatory cell infiltration (8). The vasculature occupies one of the most important positions in this inflammatory cascade because of its ability to regulate the adhesion and subsequent infiltration of potentially damaging leukocytes into the tissue. There is growing evidence to suggest that reactive metabolites of oxygen and nitrogen are important physiological modulators of leukocyte-endothelial cell interactions. Increased production of reactive oxygen species (ROS) seen upon reperfusion can mediate responses via induction of endothelial cytotoxicity through oxidation, promotion of the formation of inflammatory mediators, increased synthesis of adhesion molecules in endothelial cells, and inactivation of endothelial cell-derived nitric oxide (9). The diminished availability of nitric oxide is postulated to contribute to diminished endothelium-dependent processes in arterioles (vasodilatation), leukocyte capillary plugging, leukocyte endothelial cell adhesion, platelet-leukocyte aggregation, and albumin extravagation (10).

The available data supports the view that the function of endothelial cells is compromised in all regions of the microvasculature after reperfusion. The accelerated production of ROS and diminished production of nitric oxide in the immediate reperfusion period appear to represent key initiating events in the deterioration of the endothelial function. Thus although it is accepted that hypothermia is the basic principle on which existing kidney preservation methods depend, this inhibition of metabolism appears to cause much of the reperfusion injury. It therefore seems straightforward that the severity of the reperfusion injury could be reduced by restoration of renal metabolism prior to actual reperfusion with blood. Restoration of renal metabolism was achieved by ex vivo warm perfusion, using EMS technology. The perfusate used during ex vivo warm perfusion was designed to support the nutritional and metabolic needs of the 
vascular endothelium within a graft, thereby maintaining the integrity of the vasculature and subsequently the normal permeability of the organ. We postulated that the inhibition of ROS formation by addition of scavengers, together with the absence of inflammatory cells in the EMS perfusate, could potentially eliminate much of the damage seen during actual reperfusion with blood.

\section{Effects of EMS perfusion on renal function and survival}

The results show a clear reduction in the posttransplant serum creatinine when comparing the control group to the EMS group. On the first day posttransplant the control kidneys (group I) have a median serum creatinine that was $28 \%$ higher than the EMS perfused kidneys. This observed difference in posttransplant renal function continued, where on day four posttransplant this difference increased to $52 \%$. Assuming that the serum creatinine values observed were a correlating marker for the degree of injury following reperfusion, one can conclude that EMS perfusion substantially reduced damage seen due to reperfusion. Expressed in actual survival, the rate of PNF, when a graft was not capable of providing life-sustaining function due to irreversible damage, dropped from $27 \%(3 / 11)$ in the control group to $10 \%(1 / 10)$ in the EMS perfused group.

\section{Changes due to warm ischemia}

EMS perfusion appears to reduce both the severity of ATN and the occurrence of PNF seen upon reperfusion from the cold. However little is know about the relative role of WI. Therefore, the contralateral kidneys were used to evaluate the compounding effect of WI and cold storage on renal metabolism. A better understanding of these mechanisms could support the interpretation that sufficient restoration of renal metabolism is needed to substantially reduce the injury seen upon reperfusion from the cold. We aimed at crude parameters of aerobic activity, which could be measured easily and directly (oxygen and glucose consumption). Compared to no WI exposure, WI insults of 30 and 60 minutes reduced oxygen consumption by $13 \% \& 45 \%$; and glucose consumption by $26 \% \& 31 \%$ respectively. The reduction of metabolism observed with increasing WI damage can be interpreted as the loss of cellular viability. In a previous study we investigated the relative role of cold preservation on renal metabolism by varying the cold ischemia times (11). A CI associated lag-phase in the restoration of metabolism was observed, where the longer cold preserved kidneys exhibit a lower initial rate of oxygen consumption. However, following 3 hours of EMS perfusion, oxygen consumption was found to be equal in kidneys cold stored for up to 24 hours. In the present experiments aimed at investigating the relative role of WI, we also observed a lower initial rate of oxygen consumption with increasing WI. In contrast to the effect of cold preservation however, oxygen consumption never equalized between the three WI groups. This observed phenomenon may indicate 
irreversible compounding damage with increasing WI that was not observed with cold storage times up to 24 hours alone. Interestingly, restored renal metabolism was observed with all kidneys after as much as 60 minutes of WI, indicating partial viability of the kidney. This observation was consistent with the current belief that a kidney can tolerate as much as two hours of warm ischemia before the damage becomes so severe that it is irreversible and will not provide a life-sustaining function. However, transplanting an allograft with warm ischemic exposure of this magnitude is never considered clinically.

During EMS perfusion hemodynamic characteristics were measured by renal flow and vascular resistance. One of the known effects of ischemia on a kidney is an increase in vascular resistance (12). This was confirmed in our experiments. In comparison to kidneys without WI insults, renal flow was reduced by $11 \% \&$ $44 \%$; and vascular resistance increased by $33 \% \& 100 \%$ respectively, in the 30 'WI \& 60'WI kidneys. The pathogenesis of this phenomenon is complex. The vascular resistance reflects the constrictive response of the renal vascular bed to the ischemic insult. Local release of vasocontrictive agents, the loss of ability to release endothelium derived relaxing factor (13-15), and swelling of damaged endothelial and perivascular cells $(16,17)$ have been postulated to contribute to the process.

We chose to use the release of intracellular enzymes as an index of cellular damage, since the amount of enzyme release from damaged cells has been correlated with the degree of warm ischemic insult (2). In the ischemic state, plasma membrane integrity is altered, and its permeability is lost through different pathophysiological pathways $(18,19)$. Although the subsequent release of enzymes suggests severe membrane damage, it does not necessarily indicate the death of these cells (20). Nevertheless, the release of the intracellular enzymes ALT, AST, and GGT was not responsive to the varying WI times. In our study only $\mathrm{LDH}$ revealed an increase that correlated with an increasing WI time. Kidneys with 60 'WI had $50 \% \& 32 \%$ more release of $\mathrm{LDH}$ than the 0 'WI \& 30 'WI kidneys. In the literature the $\mathrm{LDH}$ release has often also been reported to correlate with the postischemic function (21-24). Still it remains unclear which renal cells are specifically damaged as LDH is present in almost all living cells.

This study demonstrates convincingly that EMS perfusion minimizes graft injury following transplantation. Ex vivo restoration of sufficient metabolism appears to be a key factor in reducing the injury seen upon reperfusion. The data shows that WI plays a rate-limiting role in the restoration of metabolism after cold preservation. We postulate that if, following severe WI, actual resuscitation of metabolism to a sufficient level were possible, we might one day be able to transplant an allograft with a warm ischemic exposure of a magnitude that is currently never considered. The results form a solid basis for further mechanistic and transplantation experiments. 


\section{REFERENCES}

1. Booster $\mathrm{MH}$, van der Vusse GJ, Wijnen RMH, et al. University of Wisconsin solution is superior to Histidine Tryptophan Ketoglutarate for the preservation of ischemically damaged kidneys. Transplantation 1994; 58: 1.

2. Grundmann R, Bischoff A, Albrod A, Pichlimaier H. Canine kidney perfusion after after various warm ischemia periods. In: Pegg DE, Jacobseen IA (eds). Organ preservation II. New York: Churchill Livingstone. In: Morris PJ, Tilney NL: (eds). Progress in transplantation (vol. 2). New York: Churchill Livingstone 1979: 33.

3. Hardie IR, Balderson GA. Early and long-term function of cadaveric kidneys preserved by ice storagec after flushing with Collins' solution. In: Pegg DE, Jacobsen IA, Halasz NA (eds). Organ preservation: basic and applied aspects. Lancester: MTP. 1982: 313.

4. Schön MR, Hunt CJ, Pegg DE, Wight DG. The possibility of resuscitating livers after warm ischemic injury. Transplantation 1993; 56: 24.

5. Gao W, Takei Y, Marzi I, et al. Carolina rinse solution-anew strategy to increase survival time after orthotopic liver transplantation in the rat. Transplantation 1991; 52: 417.

6. Bickford RJ, Winton FR. The influence of temperature on the isolated dog kidney. JPhysiol, Lond 1937; 89: 198.

7. Levy MN. Oxygen consumption and blood flow in the hypothermic, perfused kidney. Am J Physiol 1959; 197: 11.

8. Granger DN, Korthuis RJ. Physiologic mechanisms of postischemic tissue injury. Annu Rev Physiol 1995; 57: 311.

9. Grisham MB, Granger DN, Lefer DJ. Modulation of leukocyte-endothelial interactions by reactive metabolites of oxygen and nitrogen: relevance to ischemic heart disease. Free Radic Biol Med 1998; 25 (4-5): 404.

10. Kurose I, Wolf R, Grisham MB, Granger DN. Modulation of ischemia/reperfusion-induced microvascular dysfunction by nitric oxide. Circ Res 1994; 74 (3): 376.

11. Stubenitsky BM, Booster MH, Brasile $L$, et al. Negative effect of cold ischemia on initial renal function. ASAIO journal 2000; 46 (1): 60.

12. Booster $\mathrm{MH}$, Wijnen RM, Yin $\mathrm{M}$, et al. Enhanced resistance to the effects of normothermic ischemia in kidneys using pulsatile machine perfusion. Transplant Proc 1993; 25 (6): 3006.

13. Satoh S, Stowe NT, Inman SR, Sankari BR, Magnusson MO, Novick AC. Renal vascular response to vasodilators following warm ischemia and cold storage preservation in dog kidneys. J Urol 1993; 149 (1): 186.

14. Lieberthal W, Rennke HG, Sandock KM, Valeri CR, Levinsky NG. Ischemia in the isolated erythrocyte-perfused rat kidney. Protective effect of hypothermia. Ren Physiol Biochem 1988; $11(1-2): 60$.

15. Moncada S, Palmer RM, Higgs EA. The discovery of nitric oxide as the endogenous nitrovasodilator. Hypertension 1988; 12 (4): 365.

16. Gute DC, Ishida T, Yarimizu K, Korthuis RJ. Inflammatory responses to ischemia and reperfusion in skeletal muscle. Mol Cell Biochem 1998; 179 (1-2): 169.

17. Massberg S, Messmer K. The nature of ischemia/reperfusion injury. Transplant Proc $1998 ; 30$ (8): 4217.

18. Weinberg JM. The cell biology of ischemic renal injury. Kidney Int 1991; 39 (3): 476.

19. Siegel NJ, Devarajan P, Van Why S. Renal cell injury: metabolic and structural alterations. Pediatr Res 1994; 36 (2): 129.

20. Leaf A, Macknight ADC, Cheung JY, Bonventre JV. The cellular basis of ischemic acute renal failure. In: Andreoli TE, Hoffman JF, Fanestil DD, Schultz SG, eds. Physiology of membrane disorders. New York: Plenum Publishing Corp. 1986; 769. 
21. Daemen JW, Oomen AP, Janssen MA, et al. Glutathione S-transferase as predictor of functional outcome in transplantation of machine-preserved non-heart-beating donor kidneys. Transplantation 1997; 63 (1): 89.

22. Kohn M, Ross H. Lactate dehydrogenase output of the excised kidney as an index of acute ischaemic renal damage. Transplantation 1971; 11 (5): 461.

23. Belzer FO, Ashby BS, Downes GL. Lactic acid dehydrogenase as an index of future function of cadaver kidneys during isolated perfusion. Surg Forum 1968; 19: 205.

24. Codd JE, Garvin PJ, Morgan R, Jellinek M, Newton WT. Allograft viability determined by enzyme analysis. Transplantation 1979; 28 (6): 447. 
CHAPTER 7

\section{Pretransplant prognostic testing of damaged kidneys during ex vivo warm perfusion}

BM Stubenitsky, MH Booster, L Brasile,

D Araneda, CE Haisch, G Kootstra

Transplantation; accepted 


\section{A B STRACT}

Background. Further expansion of the donor pool with ischemically damaged kidneys will be predicated on the ability to develop prognostic testing. Using a well established canine autotransplant injury model, we assessed if actual restoration of renal metabolism by ex vivo warm perfusion could be used to predict the status of an organ before transplantation.

Methods. Kidneys were subjected to 30 minutes of warm ischemia (WI) followed by 24 hours of static storage in ViaSpan at $4^{\circ} \mathrm{C}$. Following WI and static storage the kidneys were transitioned to three hours of warm perfusion using Exsanguinous Metabolic Support technology. During this period, parameters indicative of renal metabolism and vascular function were employed to predict outcomes prospectively. Parameters included measures of oxidative metabolism, perfusion characteristics, and vascular condition. A Viability Score (VS) was calculated as the sum of the three parameters mentioned above. Results were grouped by a VS $>2$ and a VS $<2$.

Results. A clear association between the severity and duration of graft dysfunction and the VS was observed. Organs with a VS $>2$ had a significantly milder period of ATN, with both a less severe rise in serum creatinine (mean of $4.4 \mathrm{vs} 11 \mathrm{mg} / \mathrm{dL}$ ) and a shorter recovery period (mean of 8 vs 18 days) than those with a VS $<2$. Conclusions. Results indicate the possibility of utilizing warm perfusion to evaluate kidneys prior to transplantation. The VS developed demonstrated efficacy in classifying the severity of the acute tubular necrosis and the occurrence of primary non-function, offering a sensitive assay for prospective organ testing. 


\section{INTRODUCTION}

The success in renal transplantation has resulted in an increased demand for transplantable organs. Procurement of kidneys from heartbeating or living related donors has not kept pace with demand. Although a more liberal legislation together with a more positive attitude towards organ donation might increase the effectiveness of these conventional procurement programs, the number of suitable donor organs is unlikely to ever meet the demand. This growing shortage of transplantable organs has renewed the interest in kidneys obtained from non-heartbeating (NHB) donors, thereby offering an untapped source of renal grafts.

Unfortunately the extent of ischemic damage suffered, resulting in a higher incidence of delayed- and primary non-function (PNF) after transplantation, hampers effective use of these kidneys. It is known that, due to variation in the resistance to ischemia, the duration of the insult does not always correlate with graft function posttransplantation. Successful expansion of the existing donor pool with NHB donors will, therefore, be dependent upon the development of prospective organ evaluation during preservation.

From the beginning of kidney transplantation, attempts have been made to prospectively determine organ viability. Viability is determined by the integrated metabolism of all cells in an organ (1). However metabolism is severely inhibited during the hypothermia used in organ preservation $(2,3)$, making transplantation the only way to determine the status of a kidney (4).

It seems logical to consider that a measurement in an environment that mirrors physiological metabolism would provide the best means of distinguishing between viable and non-viable kidneys prior to reimplantation. The development of a warm perfusion technology could provide the opportunity for ex vivo restoration of metabolism, thereby creating a window for prognostic testing (5).

The aim of this study was to develop a sensitive Viability Score (VS) using and combining parameters measured during ex vivo warm perfusion, that could be used to predict the severity of acute tubular necrosis (ATN) within an experimental group subjected to the same ischemic injury.

\section{MATERIALS AND METHODS}

\section{Animals and surgical protocol}

The autotransplantation experiments were performed on mixed foxhounds weighing 35 - 40 kilograms and approximately two years old $(n=10)$. The animals received standard kennel food, routine lighting cycle and room temperature, and demonstrated normal renal function prior to the start of the study. All experiments were performed following the principles of laboratory animal care 
according to the NIH standards. Kidneys were exposed through a midline incision and the left renal artery, vein, and ureter were mobilized. If two renal arteries were present, the right kidney was used. Ten minutes prior to excision, 1,000 U of heparin and $200 \mathrm{mg} / \mathrm{kg}$ of mannitol were administered intravenously. The excised kidney was exposed to 30 minutes of warm ischemia (WI) while remaining in the abdominal cavity $\left(37^{\circ} \mathrm{C}\right)$. Following the warm ischemic period the kidney was flushed and statically stored for 24 hours in ViaSpan $\left(4^{\circ} \mathrm{C}\right)$. The kidneys were then transitioned to warm perfusion $\left(32^{\circ} \mathrm{C}\right)$ with an acellular perfusate for 3 hours prior to reimplantation. Fifteen minutes before to reperfusion, mannitol $(200 \mathrm{mg} / \mathrm{kg})$ and verapamil $(0.1 \mathrm{mg} / \mathrm{kg})$ were administered. Contralateral nephrectomy was performed prior to reperfusion of the preserved kidney.

\section{Posttransplant graft function}

Blood samples for BUN and serum creatinine were taken each morning and analyzed using an ACE analyzer (Schiapparelli Biosystems, Inc., Fairfield, NJ, USA). Animals deemed to be in poor condition, with unlikely chance of recovery from the ATN were classified as PNF. Canines with PNF were euthanized. For the purpose of grading the severity of the ATN the area under the curve (AUC) of the post transplant serum creatinine was determined (6). AUC was calculated as the area under the curve above a normal value of $2.0 \mathrm{mg} / \mathrm{dL}$. Additional to the AUC, the peak serum creatinine (Peak-Scr) and the day serum creatinine normalized (D-norm) were measured. Serum creatinine was considered normal once the curve fell below $2.0 \mathrm{mg} / \mathrm{dL}$.

\section{Ex vivo warm perfusion}

Exsanguinous Metabolic Support (EMS) technology (Breonics, Inc., Schenectady, NY, USA), was used for ex vivo warm perfusion. Following the period of cold ischemia, the kidneys were temperature transitioned to $32^{\circ} \mathrm{C}$ by flushing and then placed on a pressure controlled perfusion system including an oxygenator and a pulsatile pump, retrofitted with controllers to maintain $\mathrm{PaO}_{2}$, $\mathrm{PaCO}_{2}, \mathrm{pH}$ and temperature. The renal artery was connected to the perfusion circuit and perfusion begun. The mean arterial pressure was kept at approximately 35 , aiming for a pulsatile perfusion pressure of $50 / 30 \mathrm{mmHg}$. The volume of the circulating perfusate was $0,5 \mathrm{~L}$. Both flush solution and perfusate consisted of a highly enriched tissue culture-like solution that contained amino acids, carbohydrates, metabolites, inorganic ions, serum proteins, lipids, hormones, nitrogen bases, vitamins, reducing agents, a buffering system, trophic factors, vasodilators, radical scavengers, and adenine compound substrates adjusted to a $\mathrm{pH}$ of 7.4. The warm flush/perfusion solution is a proprietary of Breonics, Inc. (Schenectady, NY, USA). 
The acellular perfusate was supplemented with pyridoxylated bovine hemoglobin $(6 \mathrm{~g} \%)$ (Ezon, Inc., Piscataway, NJ, USA) to provide adequate oxygen $\left(\mathrm{PaO}_{2}\right.$ of $200 \mathrm{mmHg}$ ) to support ongoing renal metabolism (5).

\section{Testing during EMS perfusion}

Oxidative Index. The initial oxygen consumption during actual EMS perfusion was determined after 15 minutes of perfusion. Within 60 minutes of starting EMS perfusion, the oxygen consumption of all kidneys stabilized and remained constant during the perfusion period. This stabilized oxygen consumption was calculated as the average oxygen consumption during subsequent hours of EMS perfusion. The blood gas analyzer used was an ABL5 (Radiometer Medical A/S, Copenhagen, Denmark). Both initial and average oxygen consumption $(\mathrm{ml} / \mathrm{min} /$ $100 \mathrm{~g}$ ) were calculated using the following formula:

$$
\frac{\left(\mathrm{PaO}_{2} \text { art }-\mathrm{PaO}_{2} \text { ven }\right) \times \text { flow }}{\text { weight }} \times 100
$$

The initial oxygen consumption was then divided by the average oxygen consumption to yield an index indicative of the initial impairment in the ability to restore oxidative metabolism after injury. The range of the index was between 0 and 1 ; since initial $\mathrm{O}_{2}$ consumption could at best be as good as the average $\mathrm{O}_{2}$ consumption and at worst be zero. Threshold value for the average $\mathrm{O}_{2}$ consumption for this calculation was $10 \mathrm{ml} / \mathrm{min} / 100 \mathrm{~g}$; if the $\mathrm{O}_{2}$ consumption of a kidney was not able of reaching $10 \mathrm{ml} / \mathrm{min} / 100 \mathrm{~g}$ a score of zero was given.

Perfusion Index. The ability to regain normal perfusion pressures of approximately $50 / 30 \mathrm{mmHg}$ and flow rates of $80-120 \mathrm{ml} / \mathrm{min}(1-2 \mathrm{ml} / \mathrm{min} / \mathrm{g})$, as determined in previous experiments $(7,8)$, was assigned with a score of either 1 or 0 , with 1 if the perfusion characteristics normalized or 0 if the perfusion characteristics remained out of the normal range.

Vascular Index. While many parameters could be used to assess vascular function, for the purpose of this study, we selected a well standardized measurement for evaluation of vascular integrity. By determining the ratio of the platelet concentration in the perfusate after 15 minutes of EMS perfusion in comparison to the platelet concentration after three hours of perfusion, an overall assessment of the vascular condition was approximated. The difference in platelet count was believed to be indicative of the status of the vasculature, in that normal, non-damaged kidneys maintain stable platelet counts during the course of EMS perfusion. Increased platelet counts was thought to be indicative of inadequate vascular flushing due to constricted or clogged microvessels and was assigned a decreasing value as the platelet count incrementally increased (table 1). Platelet 
TABLE 1. Vascular Index.

\begin{tabular}{ll}
\hline Platelet increase (K/uL) during EMS perfusion & Vascular Index scoring \\
\hline $0-<2000$ & 1.0 \\
$2000-<3000$ & 0.75 \\
$3000-<4000$ & 0.50 \\
$4000-<5000$ & 0.25 \\
$>5000$ & 0.0 \\
\hline
\end{tabular}

counts were performed using an ACT Diff analyzer (Beckman, Corp., Miami, Fl, USA) coultercounter.

\section{The Viability Score}

A VS was calculated as the sum of the three parameters listed above; resulting in the formula:

$$
\text { VS }=\text { oxidative index }+ \text { perfusion index }+ \text { vascular index }
$$

The oxidative index, perfusion index, and the vascular index all had a score ranging from 0 of 1 . Therefore the relative weight of each parameter within the VS was $33.3 \%$.

\section{Histologic evaluation}

At autopsy the implanted kidneys were bisected for gross macroscopic examination. Wedge-shaped biopsies were taken and fixed in $4 \%$ neutral-buffered formalin, dehydrated and paraffin embedded. Four micron sections from each kidney made and stained using haematoxylin and eosin for light macroscopic evaluation. A minimum of five sections per kidney were studied. The morphological characteristics of the kidneys were determined by blinded histologic evaluation.

\section{RESULTS}

\section{Posttransplant graft function}

The posttransplant serum creatinine concentrations of all kidneys are illustrated in figure 1. One dog was symptomatic of uremia and was euthanized on day 7 post-transplant with a serum creatinine of $12.5 \mathrm{mg} / \mathrm{dL}$. It was classified as a PNF. 
In one case a double renal artery was missed leading to a prolonged period of ATN. Although the dog survived and the kidney recovered normal renal function on day 18 post-transplant, the viability measurements were excluded from the study. The AUC, the marker for the severity of ATN; together with the Peak-Scr and the D-norm for each dog are listed in table 2.

\section{Testing during EMS perfusion}

Values from each kidney comprised of the oxidative, the perfusion, and the vascular index, were combined to yield the VS and are listed in table 3.

Viability Score. The VS was used as prognostic index to predict of the severity of the ATN, and was expressed as the AUC. There appeared to be a continuous relationship between the VS and the outcome measure AUC, in that the dogs with the least severe ATN were found to have the highest VS. Similarly, the kidneys with the lowest VS had poorer outcomes. The one dog with PNF was found to have the lowest VS. Regression analysis demonstrated a high level of significance between the VS and the AUC as shown in figure 2.

For the purpose of determining statistical significance of the VS in predicting graft outcomes, results were grouped by score, where VS $>2$ represented mild ATN and VS $<2$ severe ATN. Only one case of PNF occurred, and the result of using a VI demarcation of 2.0 grouped this case with the cases of severe ATN. Table 4 gives the statistical comparison between the two groups. Because the standard deviations increased with the mean concentration, the data was transformed by a logarithmic transformation (9). The difference is expressed as the ratio of the geometric means. A clear association between the severity of graft dysfunction and the VS was observed in that a greater peak value and a longer period needed for recovery in organs with a VS $<2$ than in those with a VS $>2(\mathrm{p}<0.05)$.

\section{Histology}

In the eight EMS perfused kidneys exhibiting a reversible ATN, the histologic evaluation of the kidney sections provided evidence of widespread, intermittent cystic dilation of tubules with flattened or regenerating tubular epithelium. There was mild, multifocal mineralization of the cortical tubules. Mild inflammatory infiltrates were found to be associated with areas of regeneration, repair and mineralization. The blood vessels appeared to be normal.

In the dog with PNF, the kidney sections revealed a markedly different histologic evaluation. There was moderate, segmental, acute glomerulonephritis with glomerular thrombosis, neutrophil infiltrates and occasional mesangial proliferation. There was also marked interstitial hemorrhage and tubular necrosis. Several wedge-shaped hemorrhagic infarcts extending from the medulla were observed together with focal arteriolar thrombosis. 


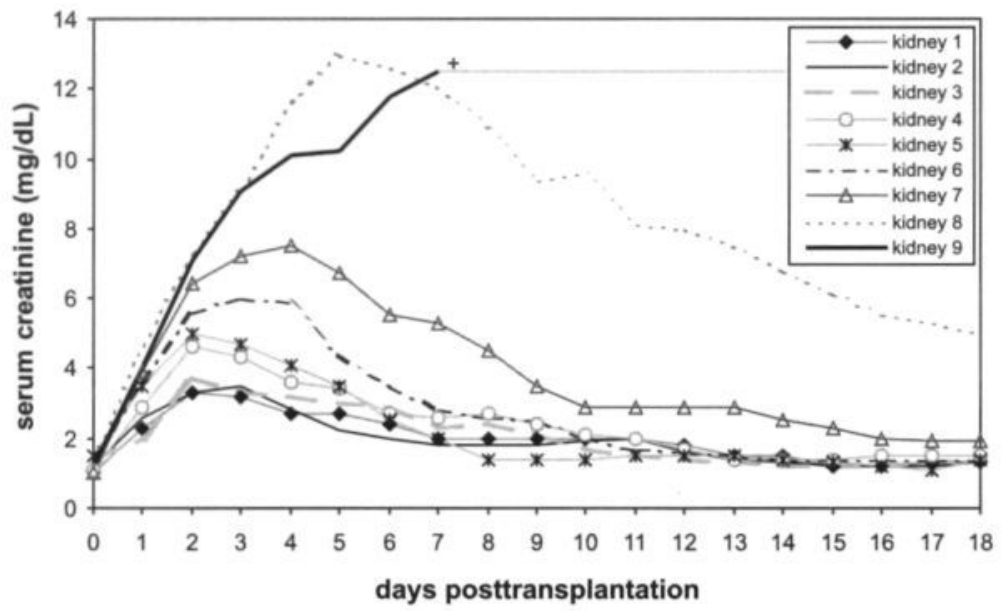

FIGURE 1. Posttranspant survival $+=$ death.

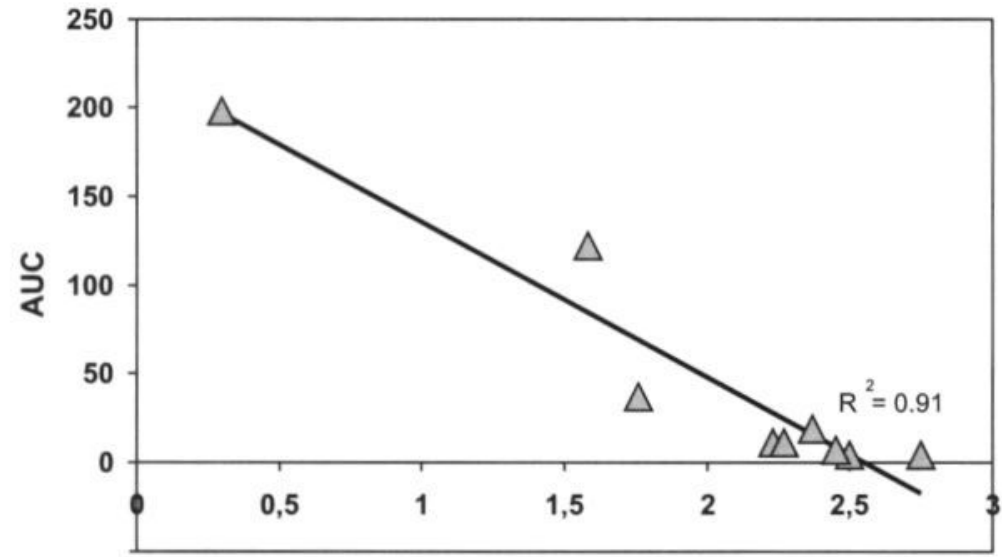

Viability Score

FIGURE 2. Correlation between VS and AUC.

$V S=$ Viability Score; $A U C=$ area under the curve. 
TABLE 2. Posttransplant graft function.

\begin{tabular}{lrcc}
\hline Kidney \# & AUC & Peak-Scr $(\mathrm{mg} / \mathrm{dL})$ & D-norm (days) \\
\hline 1 & 4.6 & 3.3 & 7 \\
2 & 4.4 & 3.5 & 6 \\
3 & 6.9 & 3.7 & 9 \\
4 & 11.3 & 4.6 & 11 \\
5 & 11.3 & 5 & 7 \\
6 & 18.9 & 6 & 10 \\
7 & 36.9 & 7.5 & 16 \\
8 & 121.8 & 13 & $18^{*}$ \\
9 & 197.8 & 12.5 & $18^{*}$ \\
\hline
\end{tabular}

$\mathrm{AUC}=$ area under the curve; Peak-Scr = peak serum creatinine; $\mathrm{D}$-norm = day serum creatinine normalized $(<2.0 \mathrm{mg} / \mathrm{dL}){ }^{*}{ }^{*}=$ surpassed study period of 18 days.

TABLE 3. Measurements during EMS perfusion.

\begin{tabular}{|c|c|c|c|c|c|}
\hline Kindey \# & $\begin{array}{l}\text { Oxidative } \\
\left(I^{\star} / A^{\star \star}\right) \text { and }\end{array}$ & Index & Perfusion Index & Vascular Index & Viability Score \\
\hline 1 & $(16 / 16)$ & 1.00 & 1 & 0.75 & 2.75 \\
\hline 2 & $(16 / 16)$ & 1.00 & 1 & 0.50 & 2.50 \\
\hline 3 & $(14 / 14)$ & 1.00 & 1 & 0.50 & 2.50 \\
\hline 4 & $(12 / 16)$ & 0.75 & 1 & 0.50 & 2.25 \\
\hline 5 & $(13 / 17)$ & 0.76 & 1 & 0.50 & 2.26 \\
\hline 6 & $(13 / 15)$ & 0.87 & 1 & 0.50 & 2.37 \\
\hline 7 & $(11 / 14)$ & 0.76 & 1 & 0.00 & 1.76 \\
\hline 8 & $(5 / 15)$ & 0.33 & 1 & 0.25 & 1.58 \\
\hline 9 & $(5 / 17)$ & 0.30 & 0 & 0.00 & 0.30 \\
\hline
\end{tabular}

- I = Initial $\mathrm{O}_{2}$ consumption $(\mathrm{ml} / \mathrm{min} / 100 \mathrm{~g}) ; * A=$ Average $\mathrm{O}_{2}$ consumption $(\mathrm{ml} / \mathrm{min} / 100 \mathrm{~g}) ; \mathrm{O}_{2}$ consumption calculated by $\left\{\left[\left(\mathrm{PaO}_{2}\right.\right.\right.$ art- $\mathrm{PaO}_{2}$ ven $) \times$ flow $] /$ weight $\} \times 100$. 
TABLE 4. Correlation between the Viability Score and posttransplant outcomes.

\begin{tabular}{l|lll}
\hline & AUC & Peak-Scr $(\mathrm{mg} / \mathrm{dL})$ & D-norm (days) \\
\hline & Mild ATN & Mild ATN & Mild ATN \\
Arithmetic mean (SD) & $9.6(5)$ & $4.4(1)$ & $8.3(2)$ \\
Geometric mean & $8.1(1.7)$ & $4.2(1)$ & $8.0(1.3)$ \\
& & & \\
& Severe ATN & Severe ATN & Severe ATN \\
Arithmetic mean (SD) & $118.8(80)$ & $11(3)$ & $17.3(1)$ \\
Geometric mean & $92.8(2.3)$ & $10.5(1.3)$ & $17.6(1)$ \\
& & & 2.2 \\
\hline \multirow{2}{*}{ Ratio of Geometric mean } & 11.5 & 2.5 & $1.7-2.7$ \\
95\% Confidence Interval & $2-60$ & $1.3-4.5$ & $<0.05$ \\
\hline
\end{tabular}

$\mathrm{AUC}=$ area under the curve; Peak-Scr= peak serum creatinine; $\mathrm{D}$-norm= day serum creatinine normalized $(<2.0 \mathrm{mg} / \mathrm{dL}) ; \mathrm{SD}=$ standard deviation.

\section{DISCUSSION}

Viability testing in clinical transplantation has gained renewed interest with the resurgence of the NHB donor. Historically, evaluation of organ viability has focused on the determination of the energy charge, various enzymes and electrolyte releases, perfusion characteristics, and the functional and morphologic status of the kidney. Despite these efforts there is currently no objective method or assay to evaluate the potential function of a kidney (4). An impediment to developing viability testing is the inhibition of metabolism that occurs during hypothermia. Hypothermia merely slows the ongoing ischemic damage leading to cell death (10) making evaluation of the integrated metabolic capacity, needed for actual determination of the viability, virtually impossible (1).

With the development of a more physiologic preservation technology that supports adequate metabolism at a warm temperature, it seems feasible to develop viability testing that could distinguish between viable and non-viable organs $(5,11-13)$.

Two important issues play a major role in the viability of an organ. First, the ability to support and maintain an adequate and sufficient metabolic state. Second, the maintenance of the integrity and normal barrier function of the vasculature. Ischemia impairs both the cellular metabolic capacity and the vascular functions within a kidney. In view of this, three parameters for the prognostic testing of a kidney during ex vivo warm perfusion were developed: 
- initial and overall oxygen consumption

- ability to normalize the perfusion pressures and flow rate

- estimation of the vascular condition as determined by the release of platelets during warm perfusion.

The three viability parameters were measured during 3 hours of warm perfusion following a known critical autotransplantation model (14). The injury model consisted of an initial insult of 30 minutes of WI followed by 24 hours cold storage in Viaspan, after which the kidney was transitioned to warm perfusion using Exsanguinous Metabolic Support (EMS) technology (Breonics, Inc.). Addition of the 3 hours of warm perfusion to the WI and cold storage prior to transplantation did not adversely affect posttransplant outcomes. In fact EMS technology proved to be beneficial in reducing the injury seen after WI and CS (15).

\section{Oxidative Index}

The oxygen consumption has been described as a marker for renal damage (16, 17). In a previous study we investigated the relative role of cold preservation on initial renal metabolism by varying the cold ischemia times (7). A cold ischemia associated lag-phase in the restoration of metabolism was observed, where the longer cold preserved kidneys exhibit a lower initial rate of oxygen consumption. However, following 3 hours of EMS perfusion, oxygen consumption was found to be equal in kidneys cold stored for up to 24 hours. In the present experiments both the initial oxygen consumption and the average oxygen consumption were incorporated into the oxidative index. A lower initial oxygen consumption, indicative of more extensive damage, resulted in a lower oxidative index. Those kidneys found to have substantially reduced rates of oxygen consumption at the start of warm perfusion experienced longer periods of ATN. In two kidneys the initial oxygen consumption was severely impaired. One kidney represented the upper limit of ATN in this model with a peak serum creatinine of $13.0 \mathrm{mg} / \mathrm{dL}$ on day 5 (kidney \#8). The other kidney with severely impaired initial oxygen consumption proved to be PNF (kidney \#9).

\section{Perfusion Index}

Deterioration in hemodynamic characteristics have frequently been observed to occur during hypothermic perfusion, and have been correlated with poor function posttransplant $(12,13,18-20)$. Initial vasoconstriction or immediate dilation, when placed on EMS perfusion, were not found to correlate with outcomes. Rather, the ability to regain normal perfusion pressures of approximately 50/30 $\mathrm{mmHg}$ and flow rates of $80-120 \mathrm{cc} / \mathrm{min}$ was indicative of a reversible ATN. The only kidney that did not regain normalized perfusion during the period of EMS perfusion was the kidney with PNF. 


\section{Vascular Index}

During the WI period, depletion of energy-rich phosphates and inhibition of active transmembrane ion transport systems, lead to swelling of especially the endothelial cells $(21,22)$ and rigidity of blood cells, resulting in obstruction in the capillaries (23-25).

During the course of EMS perfusion, blood cells trapped in the capillaries are flushed out and circulate in the acellular EMS perfusate. Since the amount of blood cells released is small in regard to the volume of the circulating perfusate, the only measurable and indicative blood cells were the platelets. Platelet release test used in this study, while representing a routine laboratory test, provided an effective means to assess one aspect of the vascular integrity. An increased platelet count during perfusion appeared to reflect areas of the kidney where damage resulting in edema and constriction prevented adequate flushing and preservation of the vasculature.

\section{Viability Score}

Since numerous types of metabolically active cells govern organ viability, organ assessment during warm perfusion most likely would require multiple assays forming a score that could predict posttransplant outcome better than one analysis alone $(1,5)$. The aim of this study was to develop a sensitive VS, composed of the three parameters, which could be used to predict the variability in the innate resistance to ischemia between kidneys subjected to the same ischemic injury.

The three, previously established, parameters measured during the EMS perfusion were all given an equal share in the VS: $33.3 \%$.

The time points used for the viability testing were carefully chosen. In previous attempts to evaluate organs during hypothermic preservation there still was a subsequent injury at reperfusion, confounding any possible correlation between the testing and the posttransplant outcomes. Ex vivo restoration of sufficient metabolism appears to be a key factor in reducing the injury seen upon reperfusion (15). By measuring viability during warm perfusion, just prior to reimplantation, the injury normally seen at reperfusion is reduced substantially, making the viability testing more reliable.

Based on these results, we conclude that prognostic information collected prior to transplant can effectively be linked to transplant outcomes. There appeared to be a direct correlation between a decreasing VS and an increase in the severity of the ATN, both in terms of the peak serum creatinine and time necessary for repair.

The results of this study indicate that it is possible to utilize the ongoing metabolism during the warm temperature EMS perfusion to assess organs before they are transplanted. 


\section{REFERENCES}

1. Southard JH. Viability assays in organ preservation. Cryobiology 1989; 26 (3): 232.

2. Bickford RJ, Winton FR. The influence of temperature on the isolated dog kidney. JPhysiol, Lond 1937; 89: 198.

3. Levy MN. Oxygen consumption and blood flow in the hypothermic, perfused kidney. Am J Physiol 1959; 197: 11.

4. Kootstra G. The asystolic, or non-heartbeating, donor. Transplantation 1997; 63 (7): 917.

5. Stubenitsky BM, Booster MH, Nederstigt AP, Kievit JK, Jacobs RW, Kootstra G. Kidney preservation in the next millenium. Transpl Int 1999; 12 (2): 83.

6. Matthews JN, Altman DG, Campbell MJ, Royston P. Analysis of serial measurements in medical research [see comments]. BMJ 1990; 300 (6719): 230.

7. Stubenitsky BM, Booster MH, Brasile L, et al. Negative effect of cold ischemia on initial renal function. ASAIO journal 2000; 46 (1): 60.

8. Stubenitsky BM, Booster MM, Brasile L, et al. Ex vivo viability testing of kidneys after postmortem warm ischemia. ASAIO J 2000; 46 (1): 62.

9. Armitage P, Berry G. Statistical methods in medical research. Oxford: Blackwell Scientific 1987: 355.

10. Southard JH. Biochemistry and cell physiology of organ preservation. In: Collins GM, Dubernard JM, Land W and Persijn GG (eds) Procurement, Preservation and Allocation of Vascularized Organs. Kluwer, Dordrecht 1997: 103.

11. Brasile L, Clarke J, Green E, Haisch C. The feasibility of organ preservation at warmer temperatures. Transplant Proc 1996; 28 (1): 349.

12. Haisch C, Thomas F, Green E, Brasile L. Evaluating renal allograft function prospectively. Transplant Proc 1996; 28 (1): 363.

13. Haisch C, Green E, Brasile L. Predictors of graft outcome in warm ischemically damaged organs. Transplant Proc 1997; 29: 3424.

14. Booster MH, van der Vusse GJ, Wijnen RMH, et al. University of Wisconsin solution is superior to Histidine Tryptophan Ketoglutarate for the preservation of ischemically damaged kidneys. Transplantation 1994; 58: 1.

15. Stubenitsky BM, Booster MH, Brasile L, Araneda D, Haisch CE, Kootstra G. A melioration of ischemic damage by ex vivo warm perfusion. Transplantation 2000; 69(8): S 205.

16. Kuramochi $\mathrm{G}$, Homma S. Postischemic recovery process of renal oxygen consumption in normal and streptozotocin diabetic rats. Ren Fail; 15 (5): 587.

17. Brasile L, Green E, Haisch C. Oxygen consumption in warm-preserved renal allografts. Transplant Proc 1997; 29 (1-2): 1322.

18. Belzer FO, Ashby BS, Dunphy JE. 24-hour and 72-hour preservation of canine kidneys. Lancet 1967; 2 (7515): 536.

19. Matsuno N, Sakurai E, Tamaki I, et al. Effectiveness of machine perfusion preservation as a viability determination method for kidneys procured from non-heart-beating donors. Transplant Proc 1994; 26 (4): 2421.

20. Tesi RJ, Elkhammas EA, Davies EA, Henry ML, Ferguson RM. Pulsatile kidney perfusion for evaluation of high-risk kidney donors safely expands the donor pool. Clin Transplant 1994; 8 (2 Pt 1): 134.

21. Massberg S, Messmer K. The nature of ischemia/reperfusion injury. Transplant Proc 1998; 30 (8): 4217.

22. Gute DC, Ishida T, Yarimizu K, Korthuis RJ. Inflammatory responses to ischemia and reperfusion in skeletal muscle. Mol Cell Biochem 1998; 179 (1-2): 169.

23. Ames Ad, Wright RL, Kowada M, Thurston JM, Majno G. Cerebral ischemia. II. The no-reflow phenomenon. Am J Pathol 1968; 52 (2): 437. 
24. Weed RI, LaCelle PL, Merrill ET. Erythrocyte metabolism and cellular deformability. Vox Sang 1969; 17 (1): 32.

25. Urbaniak JR, Seaber AV, Chen L. Assessment of ischemia and reperfusion injury. Clin Orth Rel Res 1997; 334: 30. 
CHAPTER 8

Conclusions

Summary

Samenvatting 



\section{Conclusions}

The results of the studies support the concept that a warm temperature ex vivo organ preservation technology is feasible and could play an important role in transplantation. Hypothermic preservation technology is at present the foundation of clinical kidney preservation. The ability to procure kidneys distally and distribute them over wide geographical areas is dependant upon hypothermic preservation techniques. However, the ability to expand the donor organ pool, to asses the functional status of a kidney prospectively, and eventually the future ability to immuno-modify or even repair grafts will be dependent upon facilitating organ metabolism. Since hypothermic preservation has by definition the goal of inhibiting metabolism by more than $95 \%$ at $4^{\circ} \mathrm{C}$, the only way further developments can be made in the field of organ preservation is by raising the temperature at which kidneys are stored. In contrast to hypothermic techniques, the warm preservation technology described in these studies are predicated upon continued organ metabolism during ex vivo preservation. These two approaches of organ preservation are not mutually exclusive. As can be seen from the studies, a period of warm perfusion following hypothermic preservation may in fact combine both of the technologies. Warm preservation may be implemented in the future following harvest from a non-heartbeating donor to assess the degree of damage or likelihood of eventual recovery of function. Once assessed, the kidney could be stored or transported using traditional hypothermic preservation techniques. Alternatively, warm preservation technology could be employed following hypothermic preservation to evaluate or treat organs to avoid subsequent reperfusion injury when implanted. Therefore, the future of organ preservation technology may represent a synergy between the abilities to support ongoing metabolic functions and the ability to inhibit them. This projection is based on the following conclusions:

\section{Impact of cold ischemia on renal function}

Although hypothermic preservation is one of the foundations of clinical transplantation, it is a general consensus that with increasing cold ischemia (CI) times, damage to the kidney seen after reperfusion increases. Nevertheless, uncertainty exists concerning the mechanism by which $\mathrm{CI}$ influences the severity of the reperfusion injury. We studied the negative effect of hypothermia on renal metabolism and function using an ex vivo warm perfusion technology. The results indicated that renal function was compromised with CI greater than 24 hours and preceded the loss of cell viability following 48 hours of CI. 
A CI associated lag-phase in the restoration of metabolism was also seen, where the longer cold stored kidney showed a diminished metabolic rate. We concluded that these observations might provide preliminary evidence suggesting that ex vivo restoration of metabolism could minimize damage from actual reperfusion from the cold.

\section{Reduction of reperfusion injury}

Reperfusion from a metabolically inactive state results in endothelial cell injury, fluid accumulation and inflammatory cell infiltration. The vasculature seems to have one of the most prominent positions in this inflammatory cascade, with reactive metabolites of oxygen as important modulators. Our experiments focused on an inhibition of the formation of radical oxygen and their activation of inflammatory cells. We achieved this by restoring metabolism with a perfusate containing scavengers and lacking inflammatory cells (EMS perfusate). The results indicated that ex vivo restoration of sufficient metabolism appeared to be a key factor in reduction of the reperfusion injury. We furthermore postulated that the initial warm ischemic injury, as seen in non-heartbeating donors, plays an important rate-limiting factor in the actual restoration of a sufficient level of metabolism.

\section{Impact of warm ischemia on renal function}

It is well appreciated that warm ischemic damage reduces the duration of effective cold preservation. This means that tolerable warm ischemia (WI) times are reduced when preservation and transplantation follow. To enhance the use of non-heartbeating donors as a source of kidneys for transplantation, the compounding damage of WI on the graft must be understood. In our experiments, kidneys were transitioned to a warm temperature perfusion following WI and CI. Increasing the WI time, reduced the renal metabolism substantially, and was interpreted as the loss of cellular viability. One of the known effects of ischemia on a kidney is an increase in vascular resistance and LDH release. This was confirmed in our experiments.

The data showed that WI plays a rate-limiting role in the restoration of metabolism after cold preservation. We furthermore believe that these studies indicate the potential of ex vivo warm perfusion as a useful tool in prospective organ evaluation.

\section{Viability testing}

Viability testing in clinical transplantation has gained renewed interest with the resurgence of the non-heartbeating donor. Despite efforts there is currently no objective method to evaluate the potential function of a kidney. This can, in part, be attributed to the severe inhibition of renal metabolism that occurs during 
hypothermic preservation. Warm perfusion seems to create an opportunity for viability testing through the restoration of metabolism prior to actual transplantation.

The degree of metabolism and the integrity of the vasculature both play a major role in the viability of an organ. In view of this, three parameters for the viability testing were developed, forming a score that could predict posttransplant outcome. Our results show that it is possible to use the ongoing metabolism during the warm temperature perfusion to effectively assess the kidney before it is transplanted.

In conclusion, these findings indicate that a period of warm perfusion reduces reperfusion injury upon implantation and provides a means for viability testing, that will allow for use of kidneys with longer warm ischemic times. We postulate that if, following severe WI, actual resuscitation of metabolism to a sufficient level were possible, we might one day be able to transplant an allograft with a warm ischemic exposure of a magnitude that is currently never considered. 



\section{Summary}

The present thesis was designed to examine the effect of restoration of renal metabolism by ex vivo warm perfusion with an acellular perfusate on (1) the reduction of the damage to the kidney seen upon reperfusion from the cold (2) the development of prognostic testing to evaluate the functional status of kidneys prior to implantation.

Chapter 1 is a brief overview of the development of organ preservation and immunosuppression in the field of organ transplantation. It discusses the organ shortage, the major obstacle facing today's clinical transplantation, and formulates the general introduction to this thesis.

In chapter 2 a historical overview of previous attempts at warm preservation, in the context of the current status of kidney preservation, is presented. The principle of preservation at warmer temperatures is not new, but with the present developments and approaches, successful clinical application appears to be within reach. The potential for prospective testing of the function and enhanced resistance to ischemic damage are discussed.

Chapter 3 discusses the original concept underlying the development of warm perfusion using Exsanguinous Metabolic Support (EMS) technology. EMS functions by supporting two major ongoing and critical processes: the support of continued cellular metabolism and the maintenance of the integrity of the vasculature in order to provide continued barrier functions. If these two requirements can be met, it seems feasible to preserve an organ at a near physiologic temperature in conditions that mirrored cells in tissue culture. The warm perfusion solution and perfusion system are reviewed in detail.

In chapter 4 , using a bovine calf slaughterhouse model, the effect of varying cold ischemia times on the metabolism and function of the kidney is described. It is shown that renal function is compromised prior to the loss of cell viability with increasing cold ischemia times. This finding suggests that an acellular warm temperature reperfusion ex vivo may enhance restoration of metabolism and thereby reduce the damage seen upon actual reperfusion from the cold.

The influences of warm ischemia on renal metabolism and function are investigated in chapter 5 . The studies in the bovine calf slaughterhouse model form a basis for the development of a sensitive viability test prior to transplantation.

Using a critical autotransplantation model in the dog, the effect of restoring renal metabolism by warm perfusion on reperfusion injury was investigated in chapter 6 . As compared to reperfusion from the cold, the results showed a clear reduction in the severity of delayed graft function following transplantation. 
Chapter 7 discusses the renewed interest in viability testing with the resurgence of the non-heartbeating donor. With the development of a more physiologic preservation technology that supports adequate metabolism at a warm temperature, it appears feasible to develop viability testing that can distinguish between viable and non-viable organs.

In chapter 8 the general conclusions are discussed and interpreted, indicating the possible synergy between the cold and the warm in the field of organ transplantation. 


\section{Samenvatting}

In dit proefschrift zijn de effecten beschreven van een ex vivo herstel van niermetabolisme op (1) de reductie van nierschade zoals waargenomen bij reperfusie vanuit de koude preservatie, (2) de ontwikkeling van prognostische testen om de functionele status van de nieren nog voor transplantatie te bepalen. Het metabolisme werd hersteld middels warme perfusie met een acellulair perfusaat.

Hoofdstuk 1 vormt de algemene introductie voor dit proefschrift. Het geeft een kort overzicht van de ontwikkeling van nierpreservatie en immunosuppressie op het gebied van de orgaantransplantatie. Tevens wordt het tekort aan nieren, één van de voornaamste obstakels in de hedendaagse klinische transplantatiegeneeskunde, besproken.

In hoofdstuk 2 wordt een historisch overzicht gegeven van eerdere pogingen tot warme perfusie van nieren. Het principe van warme perfusie is niet nieuw, maar met de huidige technieken en ontwikkelingen, lijkt een succesvolle klinische toepasbaarheid binnen handbereik. De potentie van warme perfusie voor het prospectief testen van de nierfunctie en de toegenomen weerbaarheid tegen ischemische schade wordt besproken.

Hoofdstuk 3 bespreekt het oorspronkelijke concept hetgeen ten grondslag ligt aan de ontwikkeling van warme perfusie met 'Exsanguinous Metabolic Support' (EMS) technologie. EMS werkt via het ondersteunen van twee, tijdens preservatie, kritieke processen: het cellulair metabolisme en de vasculaire integriteit teneinde respectievelijk de functionaliteit van de niercellen en de barrière functies van het vaatbed te behouden.

Indien aan deze twee voorwaarden is voldaan, lijkt het haalbaar een orgaan te bewaren bij een bijna fysiologische temperatuur onder omstandigheden die gelijk zijn aan die van cellen in een celkweek. De perfusie vloeistof en het perfusie systeem komen in detail aan de orde.

In hoofdstuk 4 wordt met behulp van een kalver-slachthuismodel het effect beschreven van verschillende periodes van koude preservatie op het metabolisme en de functie van de nier. Er wordt aangetoond dat met toenemende periodes van koude ischemie de nierfunctie wordt gecompromitteerd vóórdat er verlies optreedt van de levensvatbaarheid van de niercellen. De bevindingen van deze studies wijzen op een mogelijk positief effect van ex vivo herstel van het metabolisme. Dit herstel van metabolisme zou kunnen leiden tot een vermindering van de nierschade, welke gezien wordt bij reperfusie na koude preservatie.

De invloeden van warme ischemie op het niermetabolisme en -functie worden onderzocht in hoofdstuk 5 (kalver-slachthuismodel). Deze onderzoeken vormen 
de basis voor de ontwikkeling van prognostische testen om de functionele status van de nieren vóór transplantatie te bepalen.

Middels een kritisch auto-transplantatie model bij honden is in hoofdstuk 6 het effect van het ex vivo herstel van niermetabolisme op reperfusieschade onderzocht. Vergeleken met reperfusie na uitsluitend koude preservatie, tonen de resultaten dat de functie van een tijdelijk warm geperfuseerde nier na transplantatie minder gecompromitteerd wordt.

Hoofdstuk 7 (auto-transplantatie model bij honden) bespreekt het belang van kwaliteitstesten naar de levensvatbaarheid van nieren. Met de toepassing van een meer fysiologische preservatie technologie, welke een adequaat metabolisme ex vivo ondersteunt, lijkt het haalbaar om kwaliteitstesten voor nieren te ontwikkelen die kunnen differentiëren tussen al dan niet levensvatbare nieren vóór transplantatie.

In hoofdstuk 8 worden de algemene conclusies besproken en geïnterpreteerd. Deze wijzen op een mogelijk synergisme tussen koude en warme preservatie op het gebied van orgaantransplantatie in de toekomst. 
CHAPTER 9

Acknowledgements

Curriculum vitae 


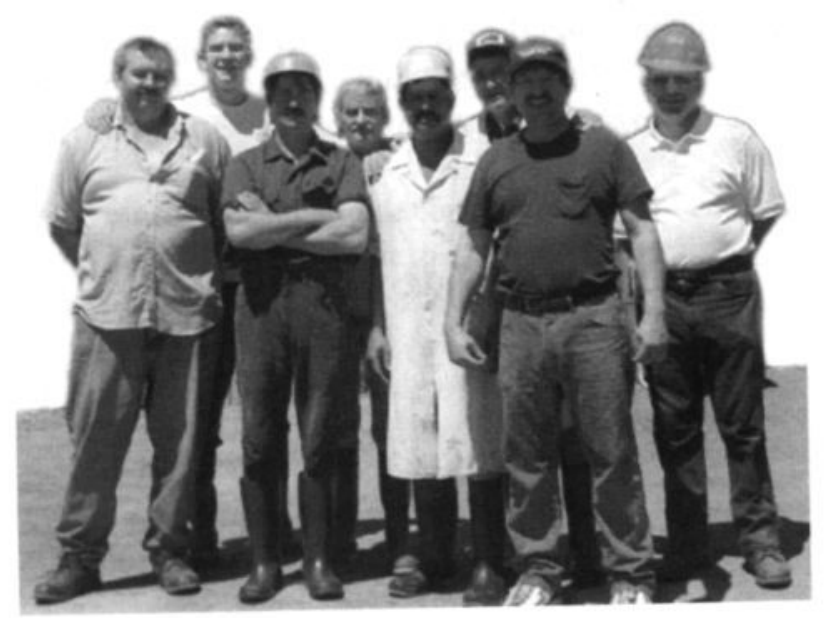

The guys from Greenville Packing 


\section{Acknowledgements}

Great research often starts in strange places. For me, it was Greenville Packing, a small slaughterhouse in rural New York. Without the cooperation of the people there, this thesis would not have been. Thanks guys.

You may ask yourself, how did I get there in the first place? That, I owe to a man with a vision, Prof. dr. Gauke Kootstra. His inspiration and belief in nonheartbeating donors as a source of kidneys for transplantation form the basis for this thesis. I am especially grateful to my co-promotor and friend Dr. Maurits Booster whose insights, expertise and support were immensely important to the project.

A special word of thanks goes to you, Lauren Brasile and Ernie Green, my American family. Lauren, you are one of the most inspiring persons I have met. Your dedication will always be an example to me. Ernie, you have been like a father to me. Thank you for your knowledge and teaching me the things real men do. Both your hospitality during my stays has made me feel at home.

The transplant studies were performed in Maastricht and in North Carolina. I would like to thank all the people involved for their help; in particular May, Joyce, Corinne, Anita, and Peggy for their good care of the dogs.

My friends and colleagues, especially Jurren, Guy, Marijn, Job, Rolf, Ellen, and Eric, have been of great importance these past years. The many meaningful and meaningless discussions with all of you were a source of inspiration. To my $\mathrm{PhD}$-companions Jurren and Guy, who both often alleviated my sufferings with theirs, thanks for being my 'paranimfen'.

My mother and brother have supported me, no matter what. Mom, you have been my most dedicated fan for all these years. Jaap, bro, these past years we have become closer than ever. Dad, thank you for being my example during my formative years. And Jaap Bouma, wise man, thank you.

A loving and special thanks goes to Annemieke, who believed in me and gave me her full support throughout the entire project. 



\section{Curriculum Vitae}

The author was born in Washington DC, USA on March $28^{\text {th }} 1971$. After graduating from the European School in Luxembourg (baccalaureate), he started his medical education at the University of Maastricht, The Netherlands. During his studies he was a student researcher at the Department of Surgery (chairman Prof. dr. Kootstra), and spent a year of research at the University of Wisconsin, Madison, WI, USA, under the guidance of Dr. Southard and the late Prof. dr. Belzer. In February 1998 he graduated from Medical School, and started his $\mathrm{PhD}$ research as a fellow of the Department of Surgery from 1998 to 2000. During this period he spent a year at Breonics, Inc., Schenectady, NY, USA. At present he is a medical consultant for Breonics, Inc. and has been accepted for Surgical residency. 
